FHWA/IN/JTRP-2000/3

Final Report

MONITORING OF LONG-TERM PERFORMANCE OF HIGHWAY BRIDGE COLUMNS RETROFITTED BY ADVANCED COMPOSITE JACKETS IN INDIANA

Ming-Hung Teng

Elisa D. Sotelino

Wai-Fai Chen

July 2000 
Final Report

FHWA/IN/JTRP-2000/3

\title{
MONITORING OF LONG-TERM PERFORMANCE OF HIGHWAY BRIDGE COLUMNS RETROFITTED BY ADVANCED COMPOSITE JACKETS IN INDIANA
}

\author{
By \\ Ming-Hung Teng \\ Graduate Research Assistant \\ and \\ Elisa D. Sotelino \\ Associate Professor \\ School of Civil Engineering \\ Purdue University \\ and \\ Wai-Fai Chen \\ Dean, School of Engineering \\ University of Hawaii \\ (formerly \\ Professor of Civil Engineering \\ Purdue University) \\ Joint Transportation Research Program \\ Project No: C-36-56NN \\ File No: $7-4-40$ \\ SPR-2161 \\ Prepared in Cooperation with the \\ Indiana Department of Transportation and \\ the U.S. Department of Transportation \\ Federal Highway Administration
}

The contents of this report reflect the views of the authors who are responsible for the facts and the accuracy of the data presented herein. The contents do not necessarily reflect the official views or policies of the Federal Highway Administration and the Indiana Department of Transportation. This report does not constitute a standard, specification or regulation.

Purdue University

West Lafayette, Indiana

July 2000 
TECHNICAL REPORT STANDARD TITLE PAGE

\begin{tabular}{|c|c|c|}
\hline $\begin{array}{l}\text { 1. Report No. } \\
\text { FHWA/IN/JTRP-2000/3 }\end{array}$ & 2. Government Accession No. & 3. Recipient's Catalog No. \\
\hline \multirow{2}{*}{\multicolumn{2}{|c|}{$\begin{array}{l}\text { 4. Title and Subtitle } \\
\text { Monitoring of Long-Term Performance of Highway Bridge Columns Retrofitted by } \\
\text { Advanced Composite Jackets in Indiana }\end{array}$}} & $\begin{array}{l}\text { 5. Report Date } \\
\text { July } 2000\end{array}$ \\
\hline & & 6. Performing Organization Code \\
\hline \multicolumn{2}{|c|}{$\begin{array}{l}\text { 7. Author(s) } \\
\text { Ming-Hung Teng, Elisa D. Sotelino, and Wai-Fai Chen }\end{array}$} & $\begin{array}{l}\text { 8. Performing Organization Report No. } \\
\text { FHWA/IN/JTRP-2000/3 }\end{array}$ \\
\hline \multirow{2}{*}{\multicolumn{2}{|c|}{$\begin{array}{l}\text { 9. Performing Organization Name and Address } \\
\text { Joint Transportation Research Program } \\
1284 \text { Civil Engineering Building } \\
\text { Purdue University } \\
\text { West Lafayette, Indiana } 47907-1284\end{array}$}} & 10. Work Unit No. \\
\hline & & $\begin{array}{l}\text { 11. Contract or Grant No. } \\
\text { SPR-2161 }\end{array}$ \\
\hline \multirow{2}{*}{\multicolumn{2}{|c|}{$\begin{array}{l}\text { 12. Sponsoring Agency Name and Address } \\
\text { Indiana Department of Transportation } \\
\text { State Office Building } \\
100 \text { North Senate Avenue } \\
\text { Indianapolis. IN } 46204\end{array}$}} & $\begin{array}{l}\text { 13. Type of Report and Period Covered } \\
\text { Final Report }\end{array}$ \\
\hline & & 14. Sponsoring Agency Code \\
\hline \multicolumn{3}{|l|}{ 15. Supplementary Notes } \\
\hline
\end{tabular}

\section{Abstract}

The service life of highway bridges is limited by the deterioration of their substructure components. In the U.S., it is estimated that more than 240,000 (about $40 \%$ ) of the highway bridges are functionally or structurally deficient. Repairing these deteriorated bridges using traditional methods is usually time-consuming and expensive. Furthermore, these methods are such that they can cause a number of problems, such as being a threat to public safety and severe traffic disruption. Thus, it is important that new safer and more efficient methods be developed. Fiber Reinforced Plastics (FRP) have a great potential to provide such a solution. Due to their superior material properties, such as corrosion-resistance and costeffectiveness, FRP composite materials have been effectively used in a wide variety of applications in a number of industries. In recent years, prototype projects in civil infrastructure have demonstrated the effectiveness and the benefits of the use FRP in this industry. However, the long-term performance of FRP-wrapped columns, under severe environmental conditions has not yet been fully assessed, and thus requires further investigation. This research assesses their performance in terms of corrosion resistance and freeze-thaw effect. This has been accomplished through field monitoring, field inspection, and laboratory tests.

\section{Key Words}

Fiber Reinforced Plastics (FRP), Civil infrastructure rehabilitation, Composites, Reinforced concrete columns, Corrosion resistance, Freeze-thaw effect

\section{Distribution Statement}

No restrictions. This document is available to the public through the National Technical Information Service, Springfield, VA 22161
19. Security Classif. (of this report)

Unclassified
20. Security Classif. (of this page)

Unclassified

21. No. of Pages
155

155 


\section{TECHNICAL Summary}

INDOT Research

Technology Transfer and Project Implementation Information

TRB Subject Code: 25-1 Bridge Design and Performance

July 2000

Publication No.: FHWA/IN/JTRP-2000/3, SPR-2161

Final Report

\section{Monitoring Long-Term Performance of Highway Bridge Columns Retrofitted by Advanced Composite Jackets in Indiana}

\section{Introduction}

In the summer of 1997 , the bridge piers at the junction of Indiana state highway I-69 and U.S.14 were repaired by the GFRP (Glass FiberReinforced Plastics) wrapping system, which is one of the applications of advanced composites. There are several reasons why this bridge was in need of rehabilitation. First, the use of deicing salt caused the bridge piers to deteriorate due to corrosion. Secondly, aging, heavy traffic loads, and severe environmental conditions, such as extremely cold temperatures and large temperature changes magnified this deterioration process.

These types of composite materials have been used extensively in the West Coast, especially in
California, primarily for seismic rehabilitation, and in some eastern states for corrosion protection or strengthening. They have also been used in many other industries, such as aerospace, automotive, chemical, shipbuilding, etc., for decades.

Due to their superior material properties, such as corrosion-resistance and cost-effectiveness, composites have been effectively used in a wide variety of applications in civil engineering construction in recent years. However, the longterm performance of FRP-wrapped columns, under severe environmental conditions, has not yet been fully assessed, and thus requires further investigation.

\section{Findings}

The environmental effects on the long-term performance of the FRP composites wrapped columns in Indiana have been monitored and evaluated. It has been found that these materials provide an excellent protection against aggressive environmental conditions.

It has been found that freeze-thaw cycles have little effect on the overall behavior of columns wrapped with FRP.

\section{Implementation}

Ductility and durability are two main reasons why FRP composite jackets are installed on reinforced concrete structural components. These types of retrofit are used either to

It has been found that FRP wraps provide an excellent corrosion protection even when a single layer is used.

It has been observed that due to accidents one of the columns wrapped with FRP has experienced some damage to the wraps themselves. strengthen the structure or at least restore its initial strength (ductility), or to protect the structure from aggressive environmental conditions. 
Based on the findings of this study, it is recommended that the field performance of bridge columns wrapped with FRP be further monitored and inspected. In the current field application, damage to the FRP wraps themselves due to auto collisions has already been observed. Since the glass fiber is sensitive to water (moisture), once the epoxy cover is damaged, the glass fiber might absorb water causing volume expansion and consequently further damage other fibers.

\section{Contacts}

For more information:

\section{Prof. Elisa Sotelino}

Co-Principal Investigator

School of Civil Engineering

Purdue University

West Lafayette IN 47907

Phone: (765) 494-2228

Fax: (765) 496-1105
FRP wraps perform well in new structures, though its most promising application is for deteriorated structures. It is recommended that two possible avenues to proceed with this work include laboratory testing and field monitoring with damaged RC specimens wrapped with FRP. In addition, to ensure if this type of retrofit prevent further corrosion in deteriorated columns, a methodology to detect damage in columns wrapped with FRP will be developed.

\author{
Indiana Department of Transportation \\ Division of Research \\ 1205 Montgomery Street \\ P.O. Box 2279 \\ West Lafayette, IN 47906 \\ Phone: (765) 463-1521 \\ Fax: (765) 497-1665 \\ Purdue University \\ Joint Transportation Research Program \\ School of Civil Engineering \\ West Lafayette, IN 47907-1284 \\ Phone: (765) 494-9310 \\ Fax: (765) 496-1105
}




\section{TABLE OF CONTENTS}

Page

LIST OF TABLES $\mathrm{V}$

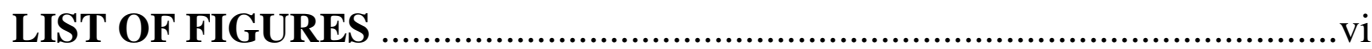

\section{$>$ CHAPTER 1 - Introduction}

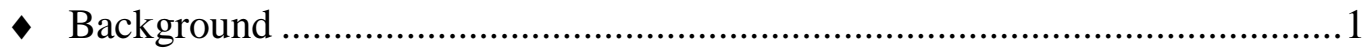

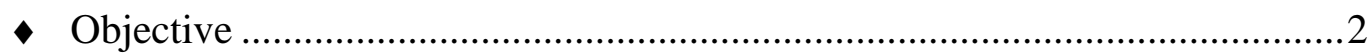

Organization of the Report ...............................................................................4

CHAPTER 2 - Advanced Composite Materials in Structural Engineering

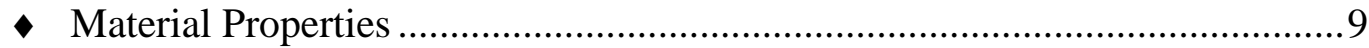

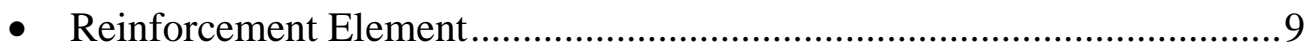

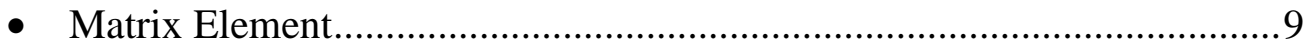

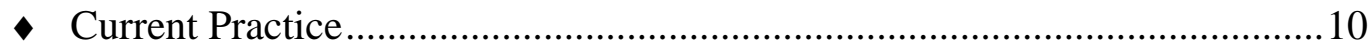

- Some cases in the U.S.A. ................................................................ 11

- The Advantages and Disadvantages of FRP ...............................................11

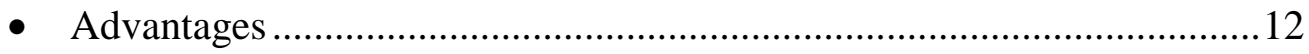

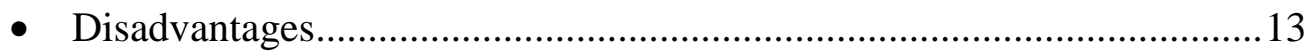

- Materials and Specimen Preparation........................................................... 14

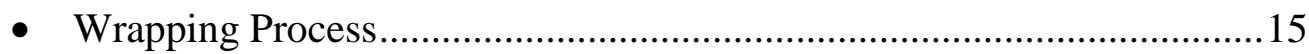

- Surface Preparation .............................................................15

- Application of Adhesive Epoxy .............................................. 15

- Application of FRP............................................................. 15

- Application of Coating System ............................................... 16

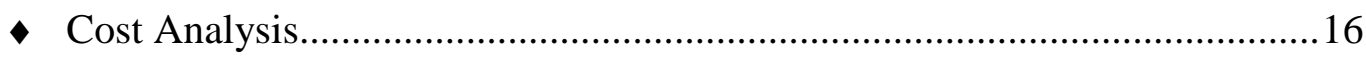

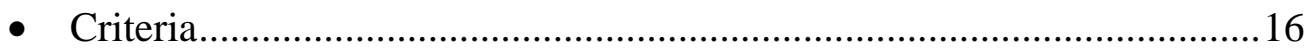

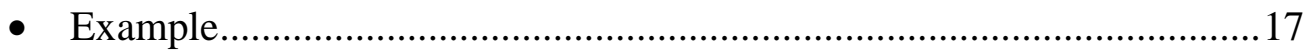

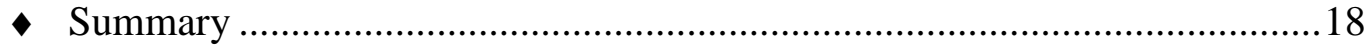

CHAPTER 3 - Field Evaluation

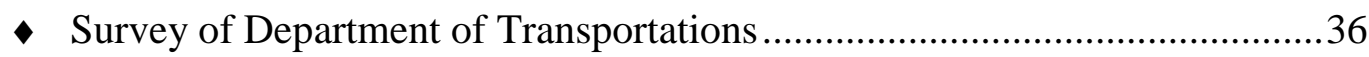

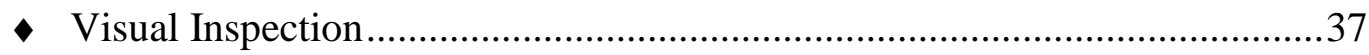




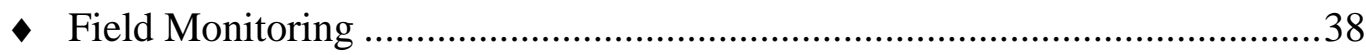

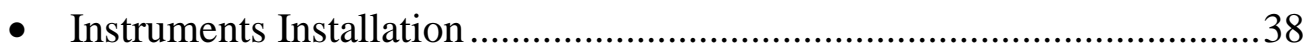

- Data Collection..................................................................................................

> CHAPTER 4 - Laboratory Assessments for Corrosion

- Problem statement and Literature review.....................................................55

- Corrosion of the reinforcing steel in concrete ................................................57

- Acceleration of the corrosion process and simulation .....................................60

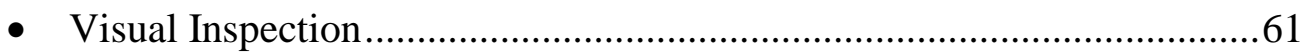

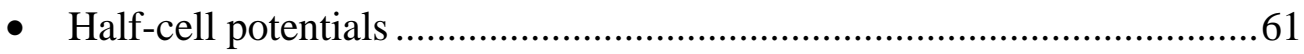

- Measured corrosion current/resistance....................................................62

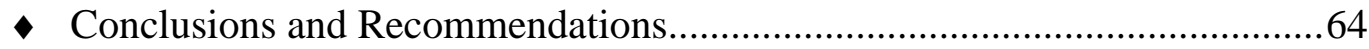

\section{CHAPTER 5 - Laboratory Assessments for Freeze-thaw}

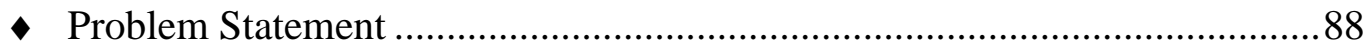

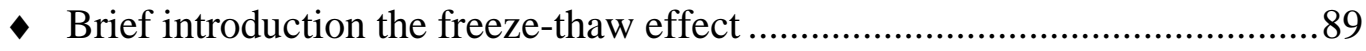

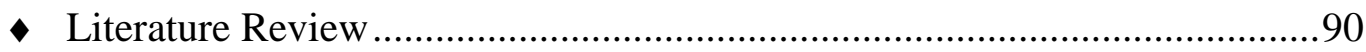

- Experimental procedure ……………………………………………….....91

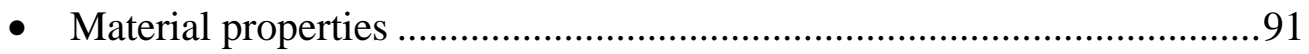

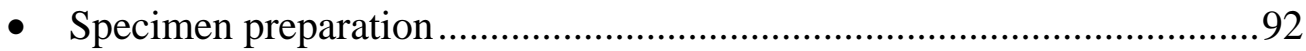

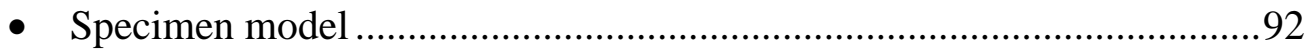

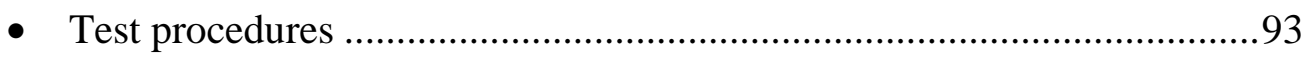

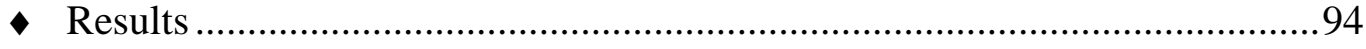

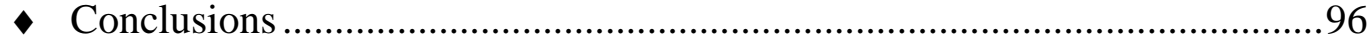

D CHAPTER 6 - Summary, Conclusions and Recommendations

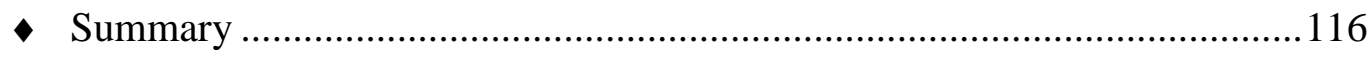

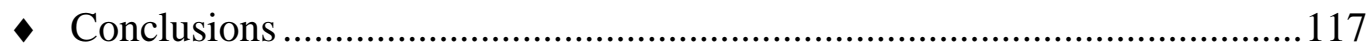




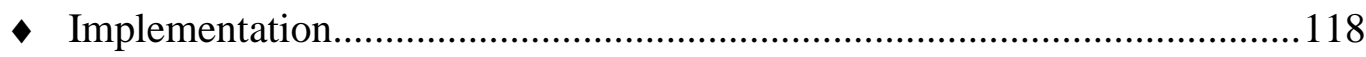

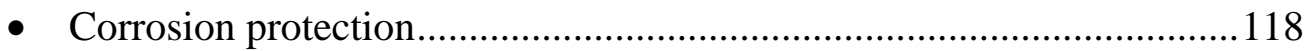

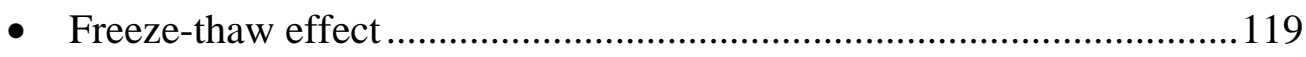

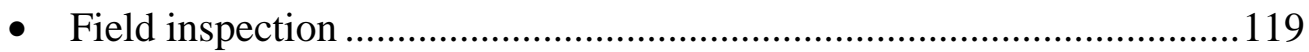

- Laboratory tests for damaged columns .....................................................120

- FRP confined concrete model due to environmental effects...................121

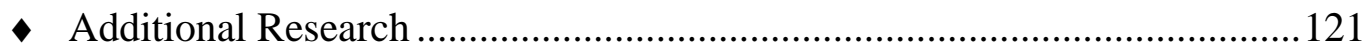

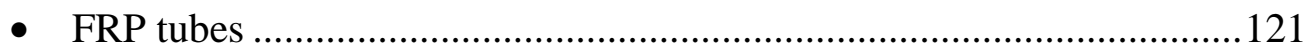

- Extension to other structural components .................................................122

- FRP as a retrofit for seismic applications...............................................122

- A user-friendly software tool for the design of structural components wrapped with FRP............................................................ 122

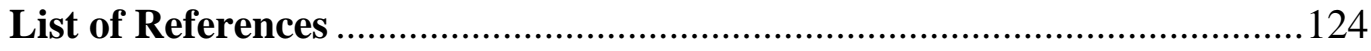

\section{Appendices}

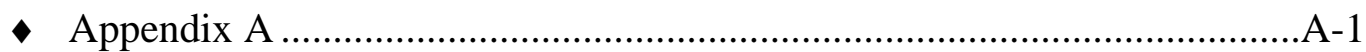

- Using FRP Applications on the Lists of DOTs

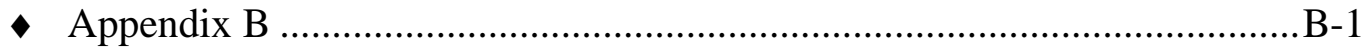

- Database Collections

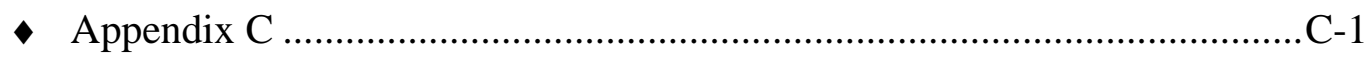

- Survey Form

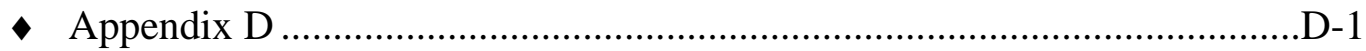

- Field Inspection 


\section{LIST OF TABLES}

Table Page

1-1Comparison between FRP and steel plates (wraps) retrofit ...............................5

2-1 Properties of TYFO-S Composite Fiberwrap System .....................................19

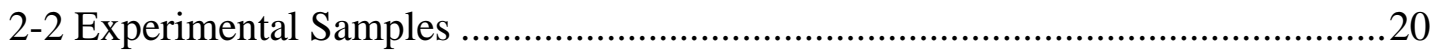

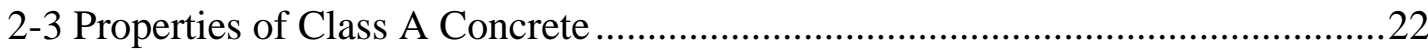

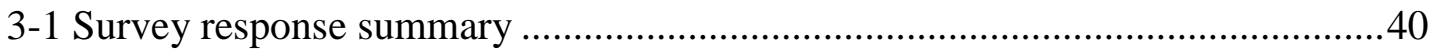

3-2 Temperature variations throughout the columns ............................................44

4-1 Five 20" $\times 10$ " beams using \#5 rebars for the corrosion test.............................66

4-2 ASTM criteria for the corrosion of steel in concrete for the standards Half-Cell \& corrosion current methods. .........................................................67

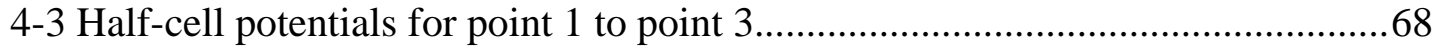

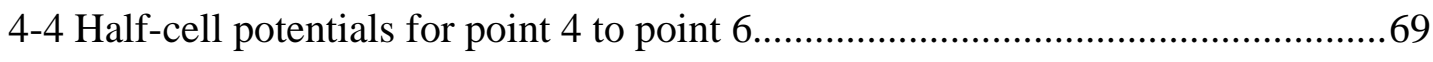

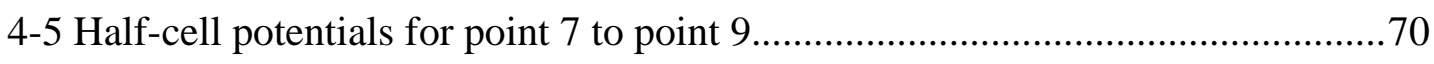

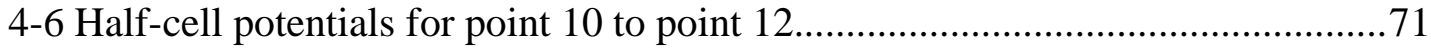

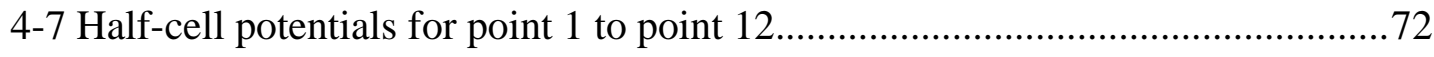

4-8 Half-cell potentials between the first week and $46^{\text {th }}$ week .............................. 73

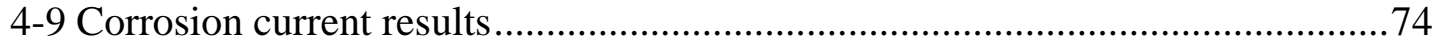

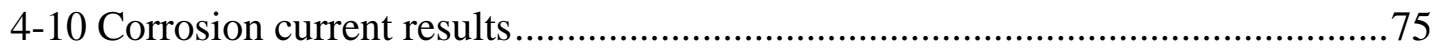

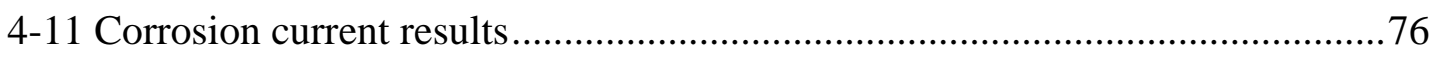

5-1 Results from freeze and thaw cycles on seventeen 3"x4"x15"

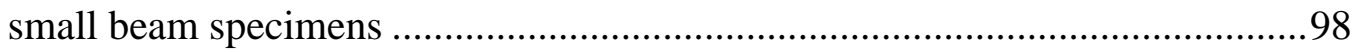




\section{LIST OF FIGURES}

Figure page

1-1 Composite materials used in the aerospace industry .....................................6

1-2 Use of composite materials in the automotive industry ...................................

1-3 Use of composite materials in leisure products ............................................ 8

2-1 Fiberglass composite jackets in an application near Sacramento, Calif. .............23

2-2 Bridge damaged due to vehicular impact, Naples, FL...................................24

2-3 Bridge damaged due to corrosion, Melbourne Beach, FL ................................25

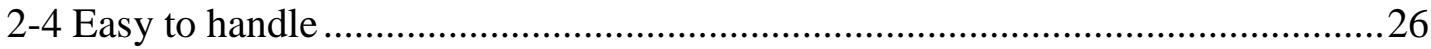

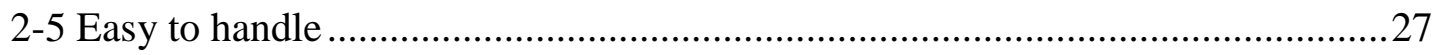

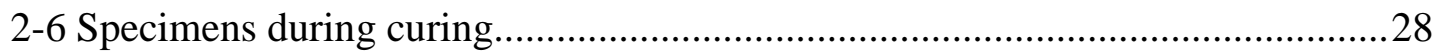

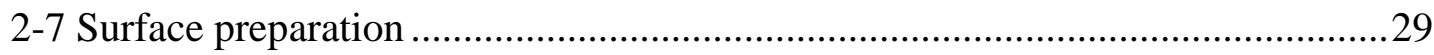

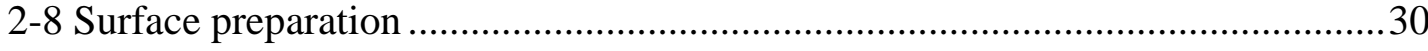

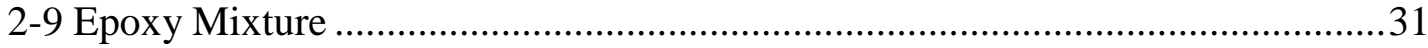

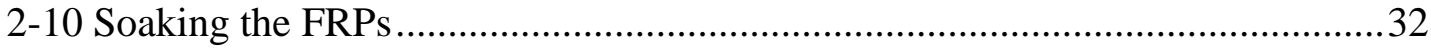

2-11 Release the entrapped air and the finalized application .................................33

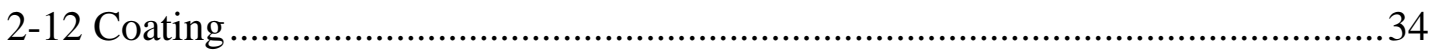

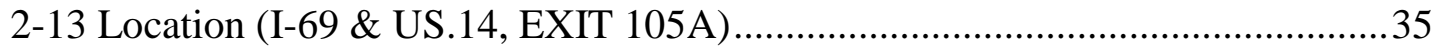

3-1 Damaged FRP on the edge of a column, Bend 2, October 9, 1999 ....................45

3-2 Damaged FRP on the side of the footing, Bend 2, October 9, 1999..................46

3-3 Damaged on the middle side of the footing at bend 4 between

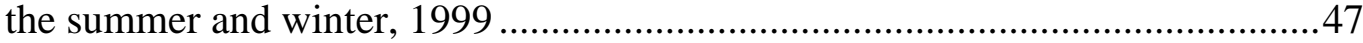

3-4 Damaged FRP on the edge of a column, Bend 4, summer, 1999 ......................48

3-5 Damaged FRP on the edge of a column, Bend 4, October 9, 1999 ...................49

3-6 Installation locations of strain gates and thermal couples ...............................50

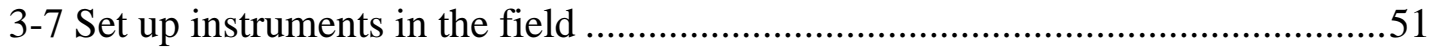


3-8 EGP-5-350 strain gauge and electrical resistance strain gauge .52

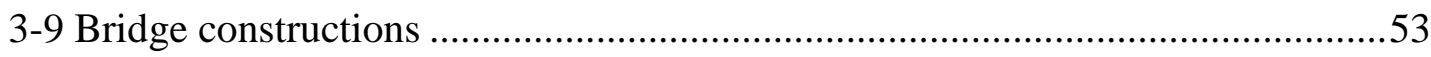

3-10 Accumulate some aggressive materials, Bend 2......................................54

4-1 Basic processes of corrosion of steel in reinforced concrete ........................... 77

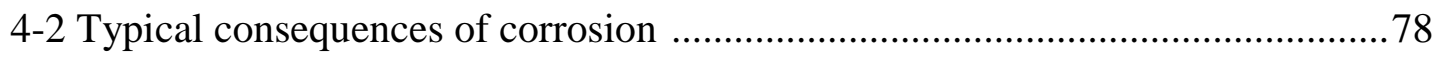

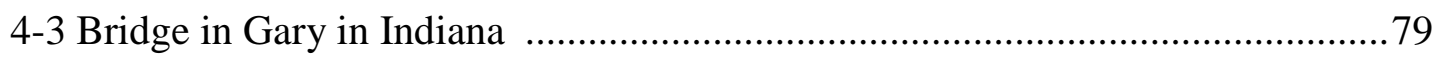

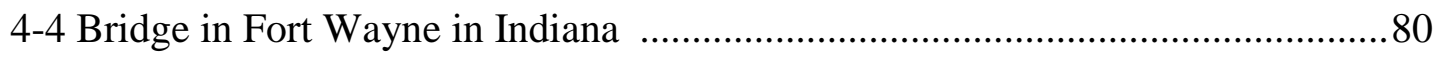

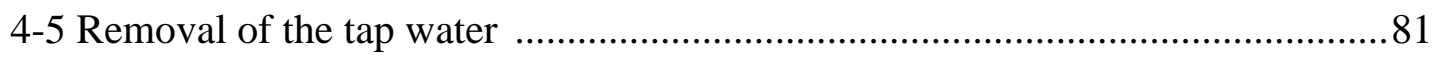

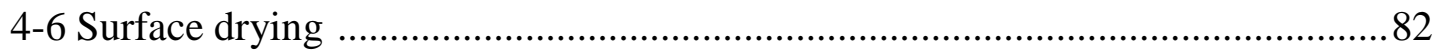

4-7 Acceleration of the corrosion process and sunny condition simulation ..............83

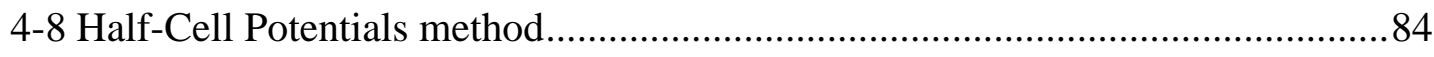

4-9 Point locations for the half-cell potentials method ….................................. 85

4-10 The half-cell potentials measurements................................................... 86

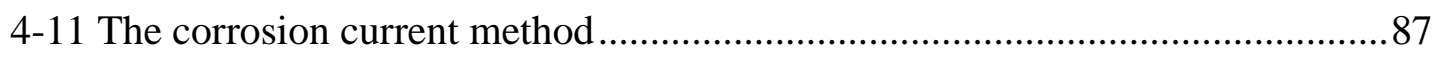

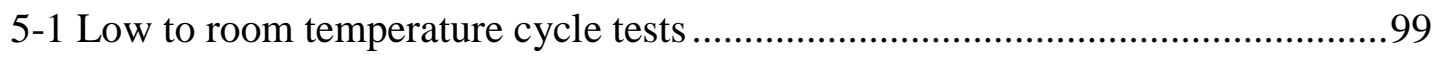

$5-2$ Low to room temperature cycle tests ....................................................... 100

5-3 Freeze-thaw tests at Freeze-Thaw Concrete Laboratory at INDOT .................101

5-4 Stress-strain relationships for plain concrete with low temperature cycles ........102

5-5 Stress-strain relationships for one layer with low temperature cycles............... 103

5-6 Stress-strain relationships for two layers with low temperature cycles ............. 104

5-7 Stress-strain relationships for two layers with low temperature cycles ............. 105

5-8 Stress-strain relationships for epoxy cover specimens with

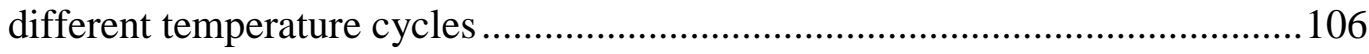

5-9 Stress-strain relationships for one-layer specimens with different temperature cycles ................................................................... 107

5-10 Stress-strain relationships for two-layer specimens with different temperature cycles .............................................................. 108 
5-11 Stress-strain relationships for three-layer specimens with different temperature cycles

5-12 Stress-strain relationships for one-layer specimens wrapped with different conditions

5-13 Stress-strain relationships for two-layer specimens wrapped with different conditions

5-14 Stress-strain relationship for one to three layers

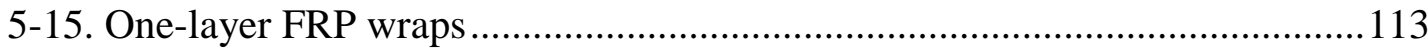

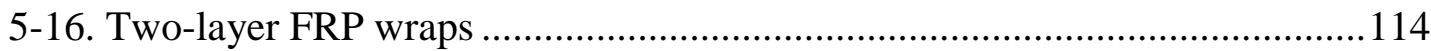

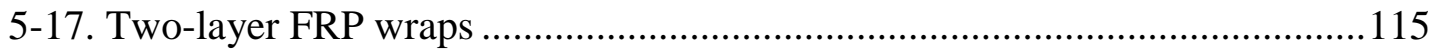

D-1 Location of the bridge and side view of the bridge......................................

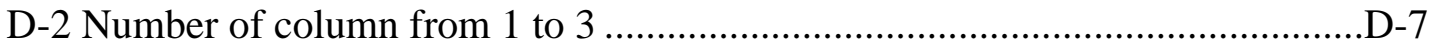

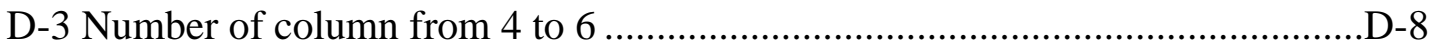

D-4 Number 7 and total view of columns ...........................................................

D-5 Some void spaces between the layers .....................................................

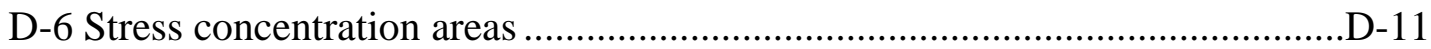

D-7 Corrosion, spalling and cracks on some columns ....................................... 12

D-8 Corrosion, spalling and cracks on some columns .......................................

D-9 Cracks and spalling besides the wrapped column....................................... 


\section{CHAPTER 1 INTRODUCTION}

\section{Background}

The service life of reinforced concrete structures is limited by the deterioration of their substructure components. In highway bridges, columns are the critical structural elements. Insufficient strength due to increase in traffic load conditions and corrosion by chloride contamination is the major cause for the deterioration of civil infrastructure. These are costly problems. In the U.S., it is estimated that more than 240,000 (about $40 \%)$ of the highway bridges are functionally or structurally deficient [1]. It is also estimated that the cost for repairing all deteriorating bridges is $\$ 78$ billion; however, only $\$ 5$ billion a year are available for such repairs [2]. It is, thus, essential that these bridges be repaired in the most efficient manner.

An early method for repairing concrete bridges consisted of removing the unsound and partially sound concrete, then sand blasting the corroded steel, and finally patching the damage with concrete of good quality. However, this only solved minor problems and for a short period of time. Currently steel jackets retrofits have become increasingly popular and are being used extensively in the United States. More recently, Fiber Reinforced Plastics (FRP) wraps have been used as an alternative. A comparison between these two types of retrofits is given in Table 1-1. A major drawback of steel jacket retrofits is their cost and lengthy installation process. Furthermore, to install the steel jackets, heavy clamping tools must be used; there is the potential for major accidents. Also since several travel lanes have to be closed, traffic accidents are more prone. This type of retrofit, thus, poses significant threat to public safety. 
To improve aging bridge structures, research on new materials is needed that have the potential to provide profitable and efficient alternatives to traditional materials for upgrading existing structures. In addition, these new solutions should also provide good performance for new structures. In the present work, new materials and techniques to effectively and economically revive aging or deteriorating infrastructure are studied. Fiber reinforced composite materials offer significant advantages over conventional materials, because of their chemical and corrosion resistance, lightweight, and high strength. These advantages make them attractive for the rehabilitation of civil infrastructure. These types of materials have been used extensively in the West Coast, especially in California, primarily for seismic rehabilitation, and in some mid-western states for corrosion protection or strengthening. A list of FRP applications for Department of Transportations (DOTs) in United States is shown in Appendix A. FRP composite materials have also been used extensively in many other fields such as the aerospace industry (Figure 1-1), transportation industry (Figure 1-2), chemical industry, shipbuilding, and leisure product industry (Figure 1-3). Examples of their use in the development of leisure products include race bicycles, tennis rackets, and golf clubs.

In the early 1980's, the US Federal Highway Administration [3] first studied the feasibility of using composite materials in highway bridges. In this study, it was concluded that composite materials are the most suitable materials for decks and cable components of highway bridges.

\section{Objective}

FRP composite have been considered as an alternative to improve the load-carrying capacity as well as the long-term performance of structural components. In order to 
improve the service life of existing or new bridges, and to assess the feasibility of implementing this technology in a practical manner, it is necessary to study their performance under aggressive environmental conditions. In particular, in the present work, the durability of FRP wrapped highway bridges columns is addressed.

The objective of this study is to gather information and to analyze the long-term performance, in terms of durability of existing (or new) bridges repaired (or constructed) with FRP wraps, when they have been exposed to harsh environmental conditions. Both field monitoring and laboratory experiments have been carried out. The field evaluation has included the inspections of two bridges (one located in Gary, Indiana, and the other in Fort Wayne, Indiana) as well as field monitoring in Fort Wayne. The laboratory evaluations have used exposure testing in order to accelerate the corrosion processes. Accelerated thermal cycles for freeze-thaw testing have also been used in these evaluations. These laboratory tests concentrated in the evaluation of the aspects of the long-term performance of FRP wrapped components that could not be evaluated through field monitoring. In the present work, a FE model will be developed, which will be used to predict the trend of the load-deformation behavior of structured components under freeze-thaw conditions. It will also trace the state of strain in the jacket.

The overall goal of the present study is to better understand the performance of the FRP applications subjected to aggressive environmental effects. The information from this study will help engineers assess the benefits of using FRP wraps when compared to other traditional rehabilitation methods. Another goal of the present study is to develop a FE model, which can be used to estimate ultimate strain of the FRP jacket under freezethaw conditions. 


\section{Organization of the Report}

In the present work, the performance of FRP wrapped highway bridge columns subjected to severe environmental conditions, such as chloride migration and freeze-thaw effects has been evaluated via field monitoring and laboratory testing. The organization of this work is provided next.

In chapter 2, a discussion of the properties of advanced composite materials and their use in other industries is provided. Also the current practice involving the use of these materials by the Civil Engineering industry is described. A cost analysis comparing this type of applications is also given. In particular, an example is provided in which the total cost of the FRP application in Fort Wayne, IN is calculated. The advantages and disadvantages of this type of retrofit when compared to other types of retrofit are also discussed.

In chapter 3, issues related to the field monitoring are provided. The details of the field evaluation are given, as well as of the data collection and data analysis. In particular, the database created using the Microsoft Access is discussed [4]. The survey of other DOTs, who are currently using FRP wraps for rehabilitation or upgrades, is also provided in this chapter.

In chapter 4 and 5, the laboratory experiments developed to study the corrosion and freeze-thaw effects on FRP retrofits are discussed. A literature review on both of these effects is also provided. The laboratory evaluations including test descriptions, results, and analysis are detailed.

Finally, chapter 6 provides a summary of the performed research activities and gives some conclusions, as well as recommendations and future research directions. 
Table 1-1 Comparison between FRP and steel plates (wraps) retrofit [5]

\begin{tabular}{|c|c|c|}
\hline Items & FRP Wraps & Steel Wraps \\
\hline Self-Weight & Very low & High \\
\hline Tensile Strength & Very high & Small \\
\hline Overall Thickness & Very thin & Yes \\
\hline Corrosion & No & Limited \\
\hline Length & Unlimited & Good \\
\hline Fatigue Résistance & Excellent & Low \\
\hline Material Cost & High & High \\
\hline Installation Cost & Low & Increase \\
\hline Durability Factor & 2-4 & $\begin{array}{c}\text { Rigid, difficult and it } \\
\text { requires lifting equipment } \\
\text { and clamping device. }\end{array}$ \\
\hline Stiffness & $\begin{array}{c}\text { Negligible increase } \\
\text { Flexible, easy, and } \\
\text { no special tools are } \\
\text { necessary }\end{array}$ & \\
\hline Installation & & \\
\hline
\end{tabular}




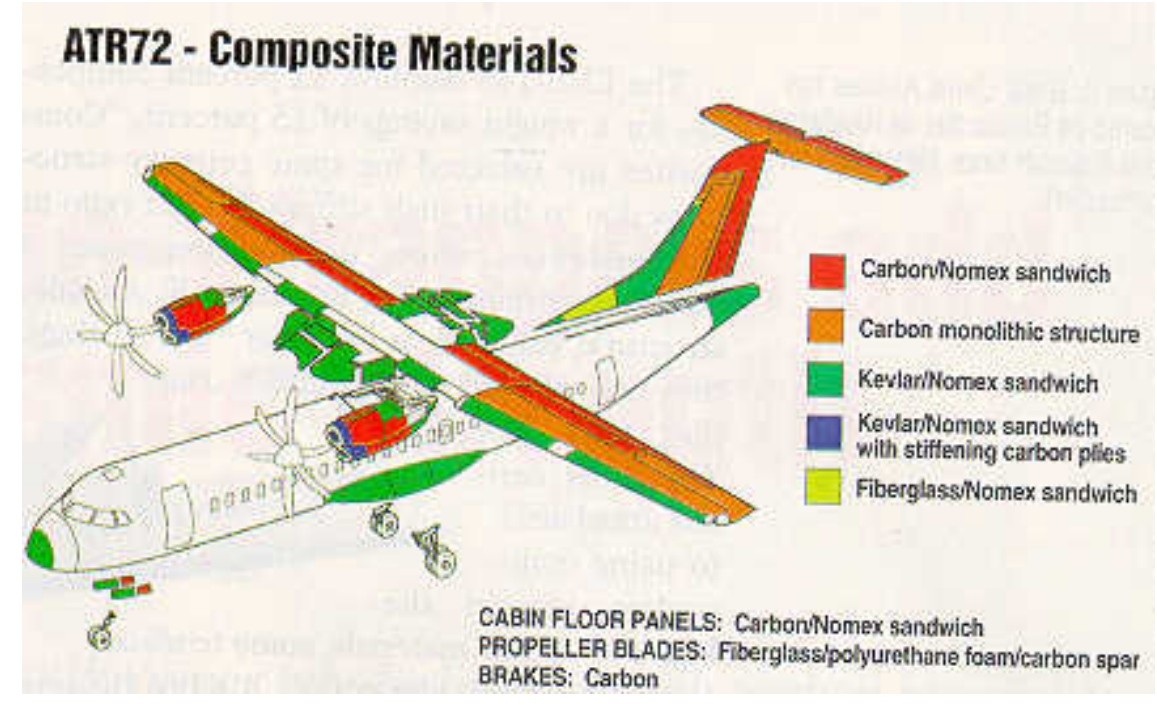

Figure 1-1 Composite materials used in the aerospace industry. 

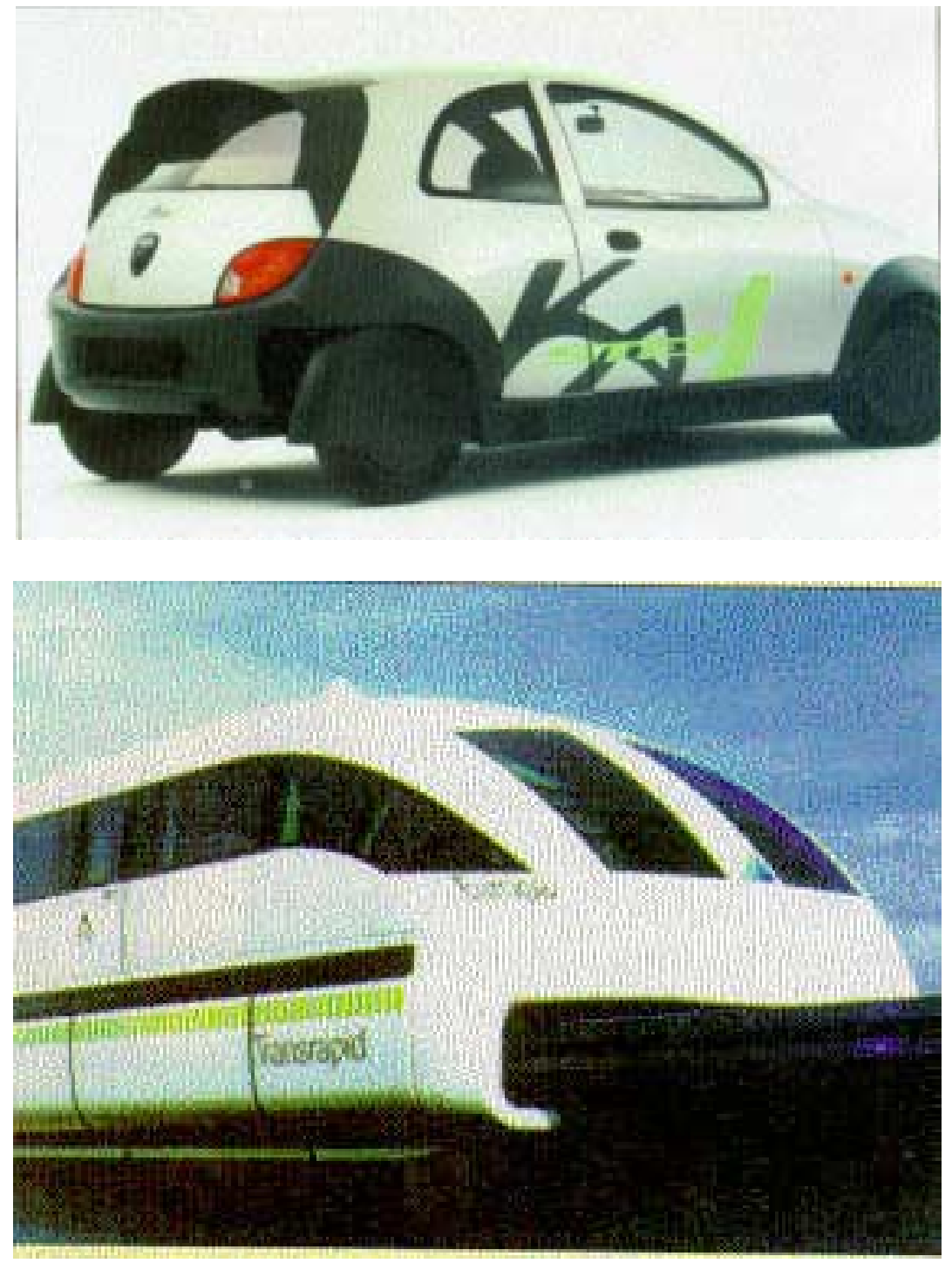

Figure 1-2 Use of composite materials in the automotive industry 

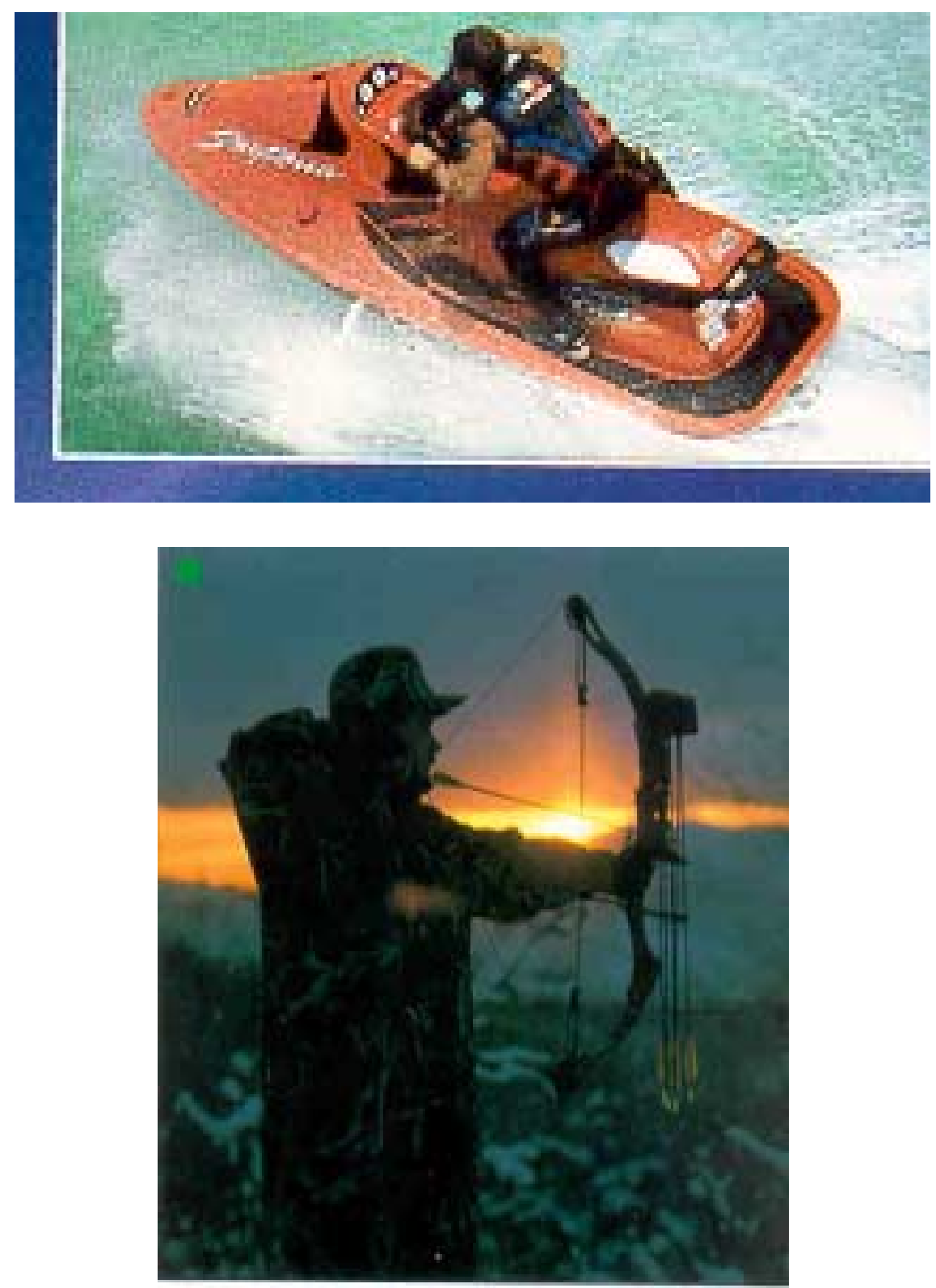

Figure 1-3 Use of composite materials in leisure products. 


\section{CHAPTER2 Advanced Composite Materials in Structural Engineering}

\section{$\underline{\text { Material Properties }}$}

Advanced composite materials usually have two components: a reinforcing element and a supporting matrix. The reinforcing element is, in general, much stiffer and stronger than the matrix and as such it is the load-carrying element. The matrix, on the other hand, provides lateral support for the reinforcing element. Each component is discussed in details next $[6,7]$.

\section{Reinforcement Element}

As the name implies, reinforcements are used to make the structure of the whole composite stronger. High performance fibers are used to provide the reinforcement for the matrix of composite materials. In Fiber Reinforced Plastics (FRPs), which are typically used in civil engineering application, these fibers are usually made of carbon (graphite), glass, and aramid $\left(\operatorname{Kevlar}^{\circledR}\right)$. In FRPs, the reinforcing fibers are imbedded in a resin matrix (e.g. epoxy resins) and they provide most of the tension strength of the composite just like steel does in reinforced concrete. These FRPSs are usually used in the continuous woven form into different lengths or directions in order to provide the best performance for different applications.

\section{Matrix Element}

The matrix element is a binder material. It supports and separates the fibers, and it also protects the fibers in severe environmental conditions. Thermosetting polymer resins are the most common types of matrix element. In particular polyesters, epoxies and phenolics are the most common resins used in civil engineering applications. When 
compared to epoxy, polyester resins are relatively inexpensive; however, epoxy resins have a higher strength, a slightly higher elasticity modulus, low shrinkage, good resistance to chemicals, and good adhesion to other fibers. Phenolic resins are usually employed in high temperature applications.

\section{Current Practice}

For financial reasons, glass fibers have been the most commonly used type of reinforcements. In particular, E-glass and S-glass fibers are the most widely adopted. By far, the most common type of fiber used in civil infrastructure is the TYFO-S Fibrwrap composite.

The TYFO-S Fibrwrap system (Table 2-1) primarily uses electrical (E) glass fibers in the main (column transverse) direction due to their compatible expansion characteristics, impact resistance, long life, and low cost. In the vertical direction, polyaramid is often chosen for civil infrastructure applications because of its maximum vertical strength with minimum interference on the primary glass hoops around the column. The fabric for the composite casing of TYFO-S is a continuous filament woven fabric, and has a thickness of 0.051 inches. The utilization of these systems is cost-effective and it improves the durability of a structure. Furthermore, they are easy to apply and they do not impact the environment negatively. Since their matrix consists of epoxy resin, which provides excellent bond characteristics, good long-term durability and high elasticity. Also the application of the mixed epoxy resin allows approximately a 5-hour working time. 
Some selected applications in the U.S.A. [Appendix C]

In Sacramento, California, it is estimated that there are 3500 concrete columns that currently being retrofitted with fiberglass funded by the California Department of Transportation (CDOT) [8]. The CDOT chose fiberglass wraps instead of steel wraps because they are completely noncorrosive, easy to install and they are more durability than steel jackets. Most of the columns are retrofitted for seismic, and some are for strengthening. Figure 2-1 shows an application near Sacramento, California.

In Florida, several structural components have been retrofitted using FRPs. The major causes for the serious damage in this state are corrosion, over-loading, and vehicular impact. They have been using Carbon Fiber Reinforced Plastics (CFRP) instead of Glass Fiber Reinforced Plastics (GFRP). In their procedure, they first remove the unsound concrete and clean the steel reinforcements using the sandblast. Then they patch the damage with fresh concrete and wrap the structural component with FRP (see Figures 2-2 and 2-3).

\section{The Advantages and Disadvantages of FRP}

Advanced composites have a number of significant advantages when compared to conventional materials such as metals and concrete. In recent years, these advantages have been recognized, and the uses of these materials in civil engineering applications have become more and more popular. FRPs have the potential to provide a viable alternative to traditional concrete reinforcing material. Furthermore, they can meet most of the requirements necessary for the renewal of civil infrastructures. Some selected advantages and disadvantages for highway bridge applications are given next. 


\section{Advantages}

- Higher strength-to-weight ratio.

Not only do they have a high strength to weight ratio, but they are also superior in terms of stiffness and tensile strength (they are much stronger than steel and concrete).

- Superior corrosion and chemical resistance.

Experimental results have showed that advanced composite materials have excellent corrosion resistance behavior under harsh environmental conditions. This corrosion resistance can be further enhanced with the use of better resin, such as epoxy.

- Easy to handle.

Due to their lightweight and easy handling, FRPs have the potential to decrease construction time and result in simpler repairs. Thus, use of these materials both in rehabilitation or retrofit of existing bridges and in the construction of new bridges can decrease the traffic congestion, time delays, and improve safely (Figures 2-4 and 2-5).

- Low life cycle costs.

The excellent corrosion resistance and strength characteristics of FRPs significantly reduce the potential maintenance costs during the life cycle of a structure. Thus, the maintenance costs associated with the use of these material is potentially much lower than other conventional choices of retrofitting materials, such as metals and concrete. 
- Good fatigue behavior.

If the cycle loading is less than one-half of the ultimate strength, the fibers will not fatigue. So the fatigue behavior of the composite fibers is superior to that of A36 steels, when suitable designs are used.

- No joint.

Unlike steel plate jackets, composite materials are fabricated in a continuous form; therefore, no joints are needed.

- Good earthquake-resistance [9].

FRPs have the potential to protect the structures to better resist earthquakes. They can be used for aging structures as well as external confinement.

\section{Disadvantages}

- High initial cost.

The initial cost of this technology is high. Although this cost can be offset because of the potential reduction in construction time, and lower maintenance, this technology is still not widely used. Standardization of commercially used FRP should help reduce this initial cost. Because of the need of a specialized labor force, the costs associated with this technology depend on the geographic location of the job.

- Lack of efficient mechanical connections.

Compared to traditional bolted and welded steel structures, FRP composites use adhesive type joints. However, for the effective design of this kind of joints, a good understanding of the adhesive and of the bond surface are necessary. Furthermore, many engineers tend not to accept this type of connection. 
- Lack of practical codes.

Due to their complexity and current lack of specifications, engineers have avoided utilizing these excellent materials. Even though several researchers have provided design criteria for specific application of FRP, no unified design specification is currently available. However, it is widely recognized that the potential of FRP application is enormous and promising.

\section{Materials and Specimen Preparation:}

To evaluate the durability and strength of bridges columns constructed with FRP wraps; sixty 6"×12" cylinders, seventeen 3"x4"x15" small beams and five 10"x10"x20" rectangular beams were fabricated in the Karl $\mathrm{H}$. Kettelhut structural Laboratory at Purdue University. The 17 small beams were tested in the Freeze-Thaw Concrete laboratory at INDOT (Indiana Department of Transportation) and the other specimen were tested in the structures Laboratory at Purdue University. Figure 2.6 shows specimens and Table 2-2 gives the details of the fabrication issues for each specimen. All of these samples were made using "Class A Concrete" (Table 2-3) in order to stimulate the behavior of actual bridge columns in Indiana.

Following the ASTM C192 [10] standard, concrete test cylinders were cast to the standard size of 6 in diameter and 12 in height using a "Class A Concrete". These specimens were cured for 14 days before further use. The strength for 28-day and 56-day was 6000 psi and $6500 \mathrm{psi}$, respectively, with a secant elasticity modulus of $3500 \mathrm{psi}$. The variation in strength for these specimens was less than 3\% for 28-day and $2 \%$ for 56 -day. After allowing for the 10-day cure period, specimens were classified in two groups. 
Group I: Air-dry for 4 days before wrapping and group II Curing in the curing room before wrapping. The total wrapped specimens included 43 cylinders, small beams and rectangular beams. They were all wrapped using the TYFO-S Fibrwrap system.

\section{Wrapping Process [11,12]}

In addition to the specimens wrapped in the laboratory, as described above, the highway bridge columns (I-69 \& US.14) were also wrapped using TYFO-S Fibrwrap system. The wrapping process is described in detail in the following subsections.

*Surface Preparation:

The surfaces of the columns and specimens were prepared using a grinder to establish a smooth dust-free surface, free of undulations in order to facilitate the full contact between concrete and the column wrap. These surfaces were freed from fins, sharp edges and protrusions that could cause voids behind the casing and damage the fiber (Figures 2-7 and 2-8). The contact surfaces of the column were completely dry at the time of application of the composite.

*Application of Adhesive Epoxy:

The ambient temperature and the temperature of the epoxy resin components were between $55^{\circ} \mathrm{F}$ and $95^{\circ} \mathrm{F}$ at the time of mixing. TYFO-S epoxy $\mathrm{A}$ and $\mathrm{B}$ were mixed together with a mechanical mixer and applied uniformly to the dust-free concrete columns with a brush roller, as shown in Fig. 2-9.

*Application of FRP:

The composite (FRP) was applied when the relative humidity was less than $85 \%$. Before wrapping, the components of epoxy resin were applied uniformly to the fiber at a rate that insured complete saturation of the fabric, as shown in Figure 2- 
10. Then the fabric/epoxy composite was applied to the surface of the column by using wrapping methods that produce a uniform force that is distributed across the entire fabric width. Manually, the entrapped air was released before the epoxy set, as shown in Figure 2-11. Also, Figure 2-11 shows the entire bridge substructure after wrapping. The construction time was one week including the 1-day preparation time for the surface.

*Application of Coating System:

A final coating system is required to protect the fibers from the UV rays and to give the final aesthetic effect. The coated areas were painted a minimum of two finish coats and the total dry film thickness of all applications of the finish coats was not less than 4 millimeters or more than 8 millimeters, as shown in Figure 212.

\section{Cost analysis}

According to the RJ Watson, Inc., the cost of the fibrwrap varies greatly depending on the number of wraps and the size of the job. The cost may depend on the following criteria.

\section{Criteria}

1. Size of the application - The cost will be quite different for 1 column than for 100 columns. The mobilization and de-mobilization for one column can increase the cost dramatically.

2. Obstacles/Traffic - If an installation has several obstacles it will be more difficult to install, which incurs a higher cost than an installation that has free access. 
3. Type of Material - Glass and carbon can differ in price up to 4 times; the materials used can greatly influence the cost.

4. Number of Layers - Usually the cost estimates are given in $\$ / \mathrm{sq} \mathrm{ft} /$ layer. Thus, the larger the number of layers, the higher the cost. This is dependent on design requirements.

5. Type of Application - Beams are more labor intensive than columns. So each application has a different cost per square foot.

6. Method of Installation - There are two ways of installing composite wraps; one is to have a certified contractor do the entire application, and another is to have a certified installer that oversees the installation using DOT's labor. The two methods incur different costs, since the former involves the cost of the full installation, while the latter only involves materials and supervision.

Generally for a medium size job, the installed price, not including any column repairs required before the wrap, for TYFO-S is about $\$ 8$ to $\$ 10$ per square foot per layer.

\section{Example}

For example, the total cost of wrapping the columns and footings for the highway bridge located at I-69 and U.S.14 (Figure 2-13) in Fort Wayne was $\$ 96,860$. Based on the job size, the unit price was $\$ 10$ per square foot per layer. This value has been obtained by calculating the total wrapped area including the columns and footings. This area is approximately 3300 square feet. So the total expense is obtained as: $\left(3300 \mathrm{ft}^{2}\right) *(3$ Layers) $*\left(\$ 10 / \mathrm{ft}^{2} /\right.$ Layer $)=\$ 99,000$. For larger projects (more columns), according to R.J. Watson Inc., the approximate cost can run as low as $\$ 5-\$ 7$ per square foot per layer. 
Also the cost of replacing the Fort Wayne bridge (I-69 \& U.S.14) was \$2,390,669.53;

however, the cost of installing FRP wraps, included labors and materials, was only $\$ 96,860$. It is only about $4 \%$ of total cost.

\section{$\underline{\text { Summary }}$}

The needs to rehabilitate and retrofit civil infrastructures have motivated many DOTs in the US to try to use advanced composite materials. Based on their advantages and fast installation, although the initial cost is high, these materials provide an effective alterative to conventional material. In addition, repairing existing structures is, in general, more cost effective than replacing them.

When compared to traditional materials, advanced composites are more expensive. However, by increasing the size of the job, by scheduling a number of retrofits during the same period, the cost can be reduced. Furthermore, the long-term cost of maintenance during the lifecycle of these structures is much lower when these materials are adopted. 
Table 2-1 Properties of TYFO-S Composite Fiberwrap System

\begin{tabular}{|l|c|c|}
\hline & $\begin{array}{c}\text { Primary Direction } \\
\text { (E-glass) }\end{array}$ & $\begin{array}{c}\text { Transverse Direction } \\
\text { (Aramid) }\end{array}$ \\
\hline Tension Strength $(\mathrm{Fj})$ & $60 \mathrm{ksi}$ & $5.5 \mathrm{ksi}$ \\
\hline Modulus of Elasticity & $3000 \mathrm{ksi}$ & $1200 \mathrm{ksi}$ \\
\hline Elongation Strain $(\varepsilon)$ & 0.02 & 0.005 \\
\hline
\end{tabular}


Table 2-2 Experimental Samples

3" X 4" X 15" small beams

\begin{tabular}{|l|c|c|}
\hline \multicolumn{1}{|c|}{ NAME } & ABBREVIATION & NO. of specimens \\
\hline Air dry without wraps & A & 3 \\
\hline Wet without wraps & W & 2 \\
\hline Air dry only coated by Epoxy & AE & 2 \\
\hline Wet coated by Epoxy & WE & 3 \\
\hline Air dry wrapped by 1 layers FRP & A1L & 2 \\
\hline Wet wrapped by 1 layers FRP & W1L & 2 \\
\hline Air dry wrapped by 2 layers FRP & A2L & 2 \\
\hline Wet wrapped by 2 layers FRP & W2L & 1 \\
\hline & TOTAL & 17 \\
\hline
\end{tabular}

6" X 12" cycles

\begin{tabular}{|l|c|c|}
\hline \multicolumn{1}{|c|}{ NAME } & ABBREVIATION & NO. of specimens \\
\hline Dry control samples & DC & 12 \\
\hline Wet control samples & WC & 12 \\
\hline Air dry only coated by Epoxy & AE & 6 \\
\hline Wet coated by Epoxy & WE & 6 \\
\hline Air dry wrapped by 1 layers FRP & A1L & 4 \\
\hline Wet wrapped by 1 layers FRP & W1L & 6 \\
\hline Air dry wrapped by 2 layers FRP & A2L & 4 \\
\hline Wet wrapped by 2 layers FRP & W2L & 6 \\
\hline Air dry wrapped by 3 layers FRP & A3L & $\mathbf{6 0}$ \\
\hline
\end{tabular}


Table 2-2 Experimental Samples (Cont.)

10 X 10 ” 20 " rectangular specimens

\begin{tabular}{|l|c|c|}
\hline \multicolumn{1}{|c|}{ NAME } & ABBREVIATION & NO. of specimens \\
\hline Plain concrete (control sample) & PC & 1 \\
\hline Concrete with Epoxy on surface & CE & 1 \\
\hline Wrapped by 1 layers FRP & 1L & 1 \\
\hline Wrapped by 2 layers FRP & 2L & 1 \\
\hline $\begin{array}{l}\text { Wrapped by 2 layers FRP then dry } \\
\text { freeze-thaw cycles }\end{array}$ & FT2L & 5 \\
\hline & TOTAL & 5 \\
\hline
\end{tabular}


Table 2-3 Properties of Class A Concrete

Cement

\begin{tabular}{|l|c|}
\hline \multicolumn{1}{|c|}{ Class of Concrete } & A \\
\hline $\begin{array}{l}\text { Cement content in Kilograms of cement per cubic } \\
\text { meter ( lbs./cubic yard) of concrete }\end{array}$ & 564 \\
\hline $\begin{array}{l}\text { Maximum water/cement ratio in kilogram (pounds) } \\
\text { of water per Kilogram (pound) of cement }\end{array}$ & $(335)$ \\
\hline
\end{tabular}

Coarse Aggregates:

For exposed concrete, size No.8

For non-exposed concrete, size No.8

\begin{tabular}{|c|c|}
\hline & Percents Passing \\
\hline Sieve Sizes (No.) & 8 \\
\hline $100 \mathrm{~mm}(4 \mathrm{in})$ & \\
\hline $90 \mathrm{~mm}\left(3 \frac{1}{2} \mathrm{in}\right)$ & \\
\hline $63 \mathrm{~mm}\left(2 \frac{1}{2} \mathrm{in}\right)$ & \\
\hline $50 \mathrm{~mm}(2 \mathrm{in})$ & 100 \\
\hline $37.5 \mathrm{~mm}\left(1 \frac{1 / 2}{\mathrm{in})}\right.$ & $75-95$ \\
\hline $25 \mathrm{~mm}(1 \mathrm{in})$ & $40-70$ \\
\hline $19 \mathrm{~mm}(3 / 4 \mathrm{in})$ & $20-50$ \\
\hline $12.5 \mathrm{~mm}(1 / 2 \mathrm{in})$ & $0-15$ \\
\hline $9.5 \mathrm{~mm}(3 / 8 \mathrm{in})$ & $0-10$ \\
\hline $4.75 \mathrm{~mm}(\mathrm{No} .4)$ & \\
\hline $2.36 \mathrm{~mm}(\mathrm{no} .8)$ & \\
\hline
\end{tabular}




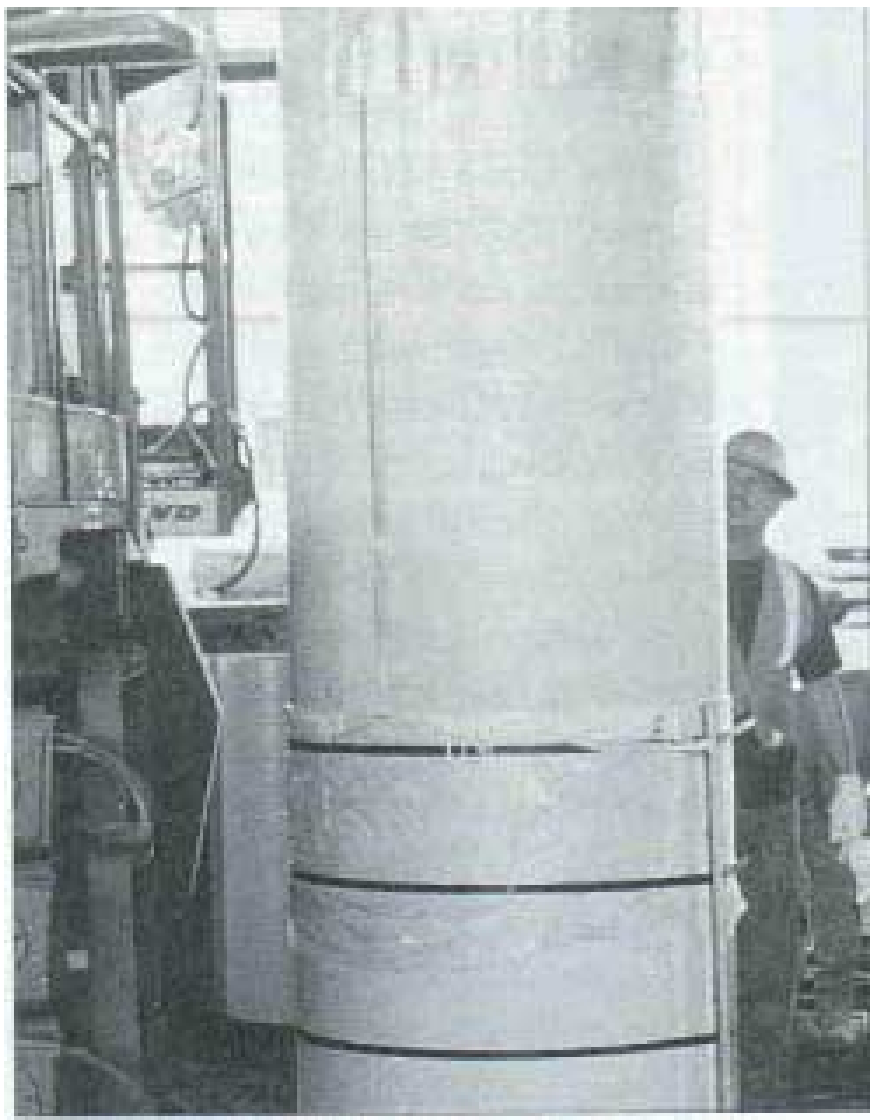

Figure 2-1 Fiberglass composite jackets in an application near Sacramento, Calif. 

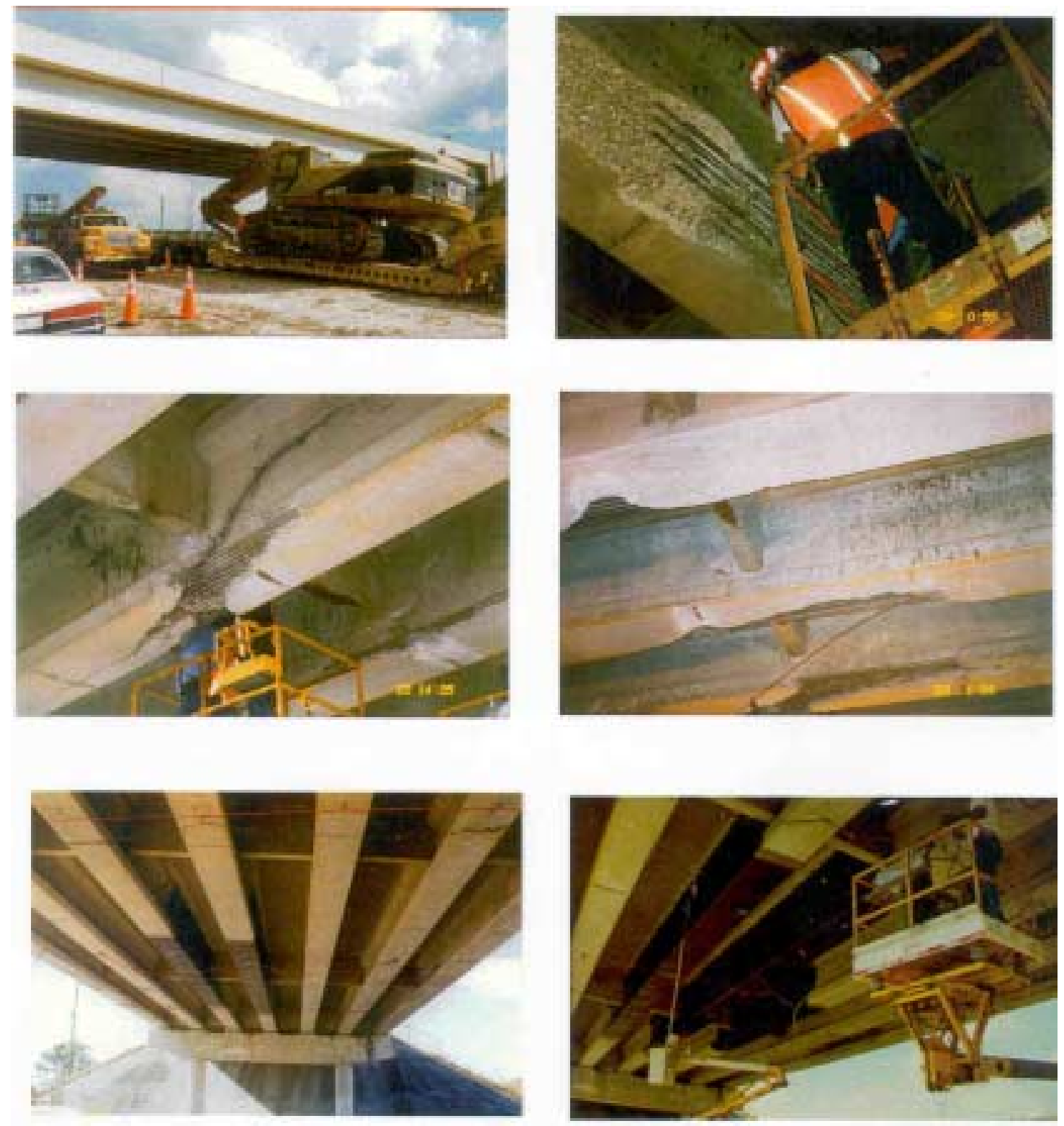

Figure 2-2 Bridge damaged due to vehicular impact, Naples, FL 

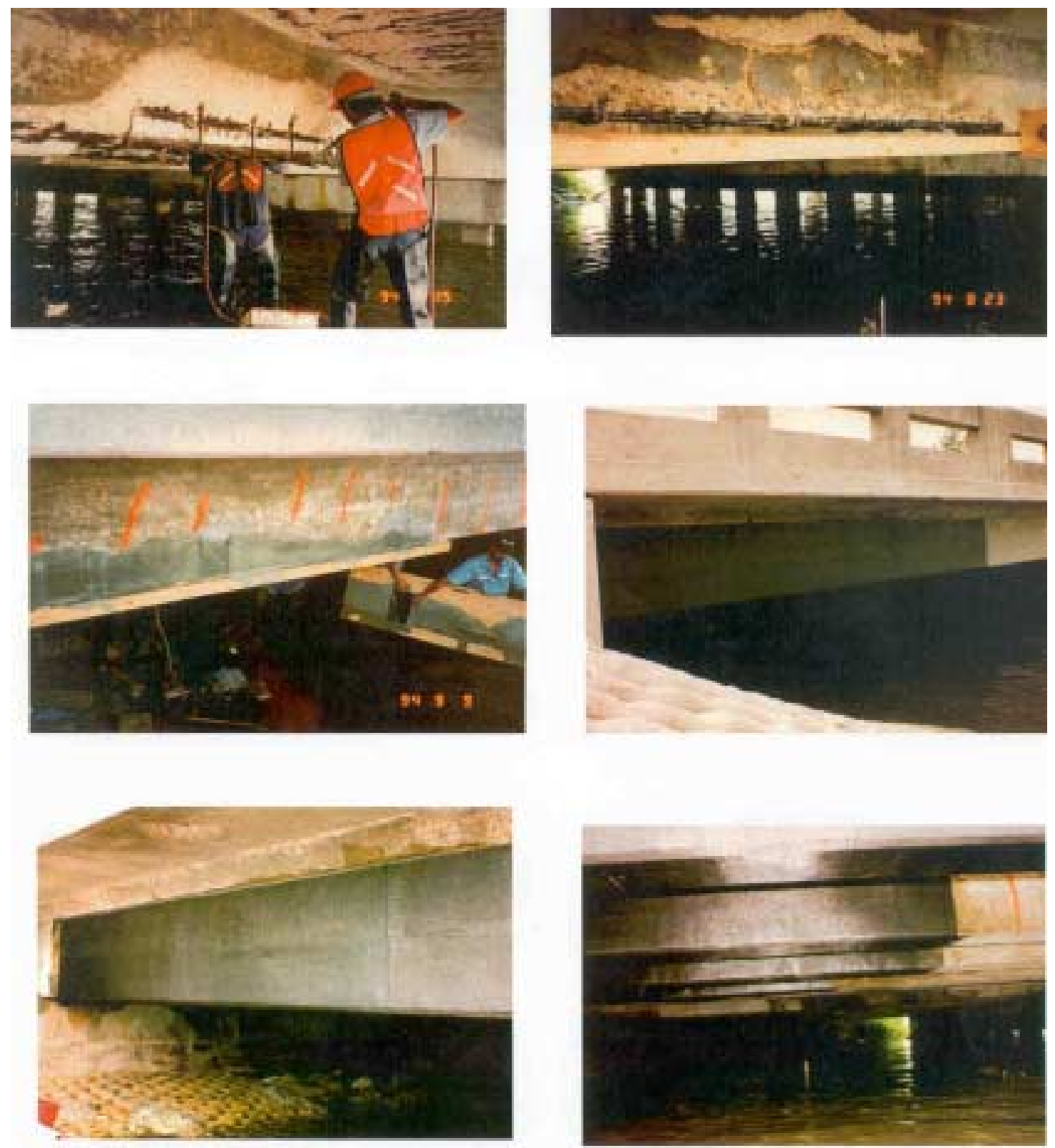

Figure 2-3 Bridge damaged due to corrosion, Melbourne Beach, FL 

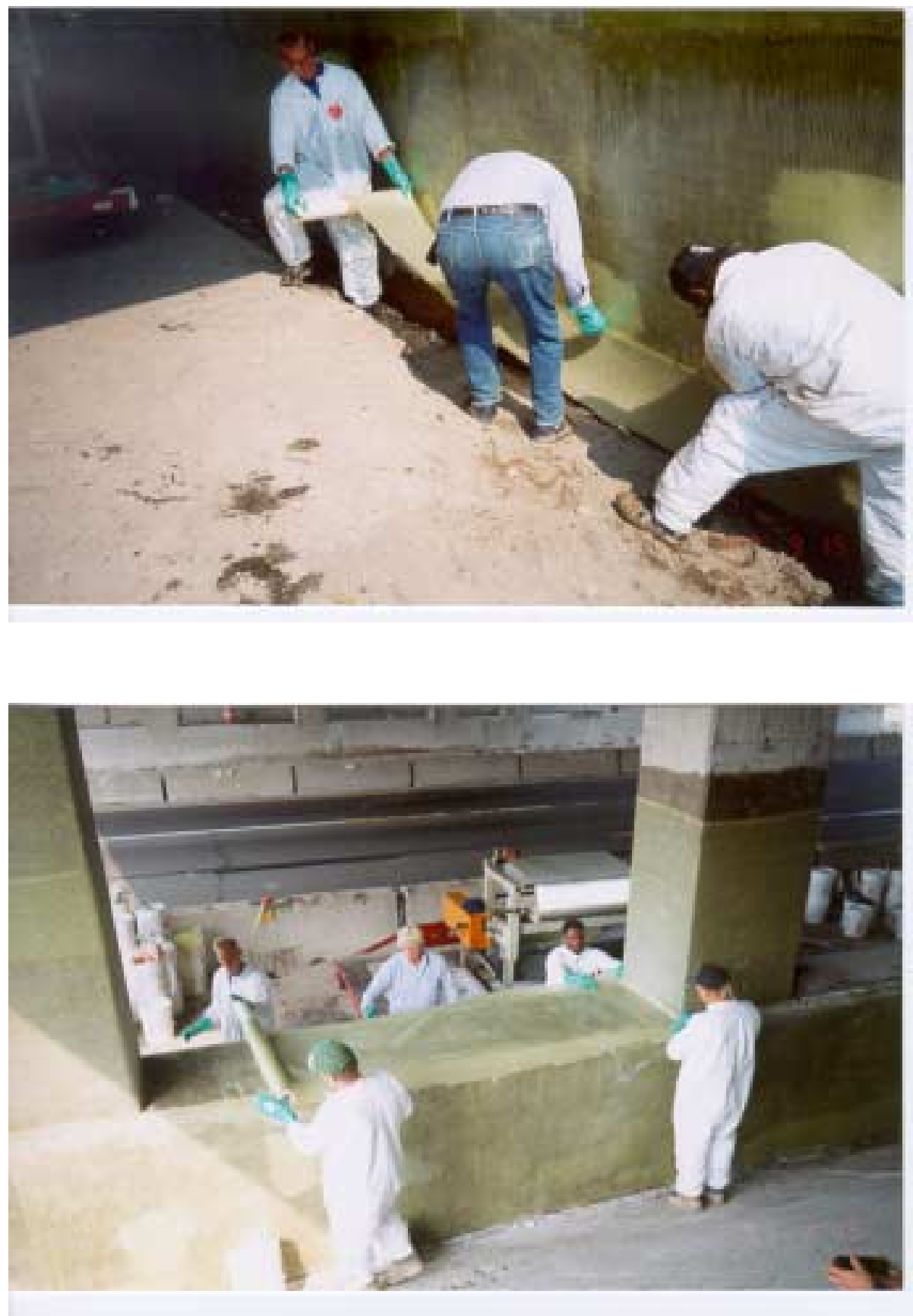

Figure 2-4 Easy to handle. 

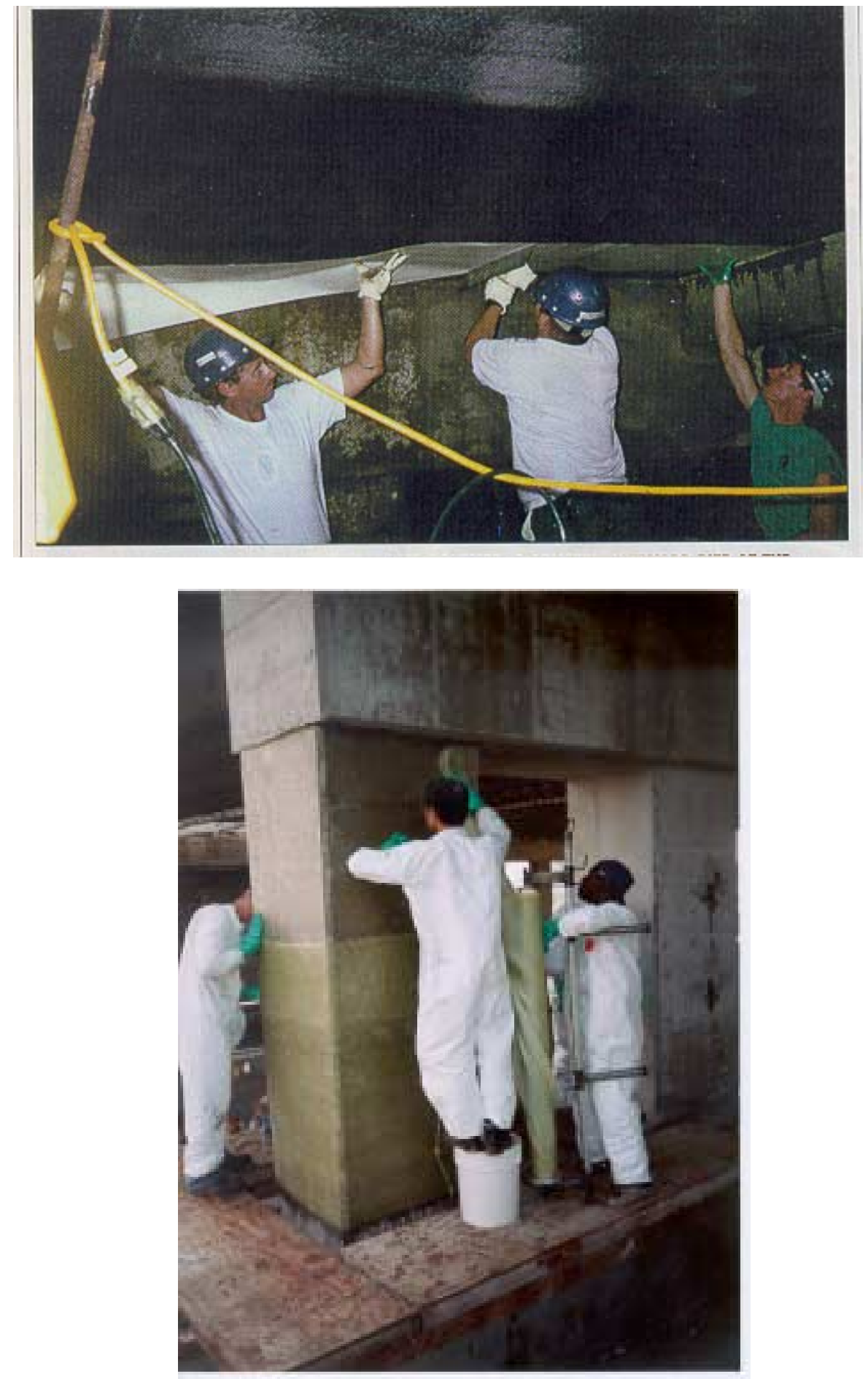

Figure 2-5 Easy to handle. 

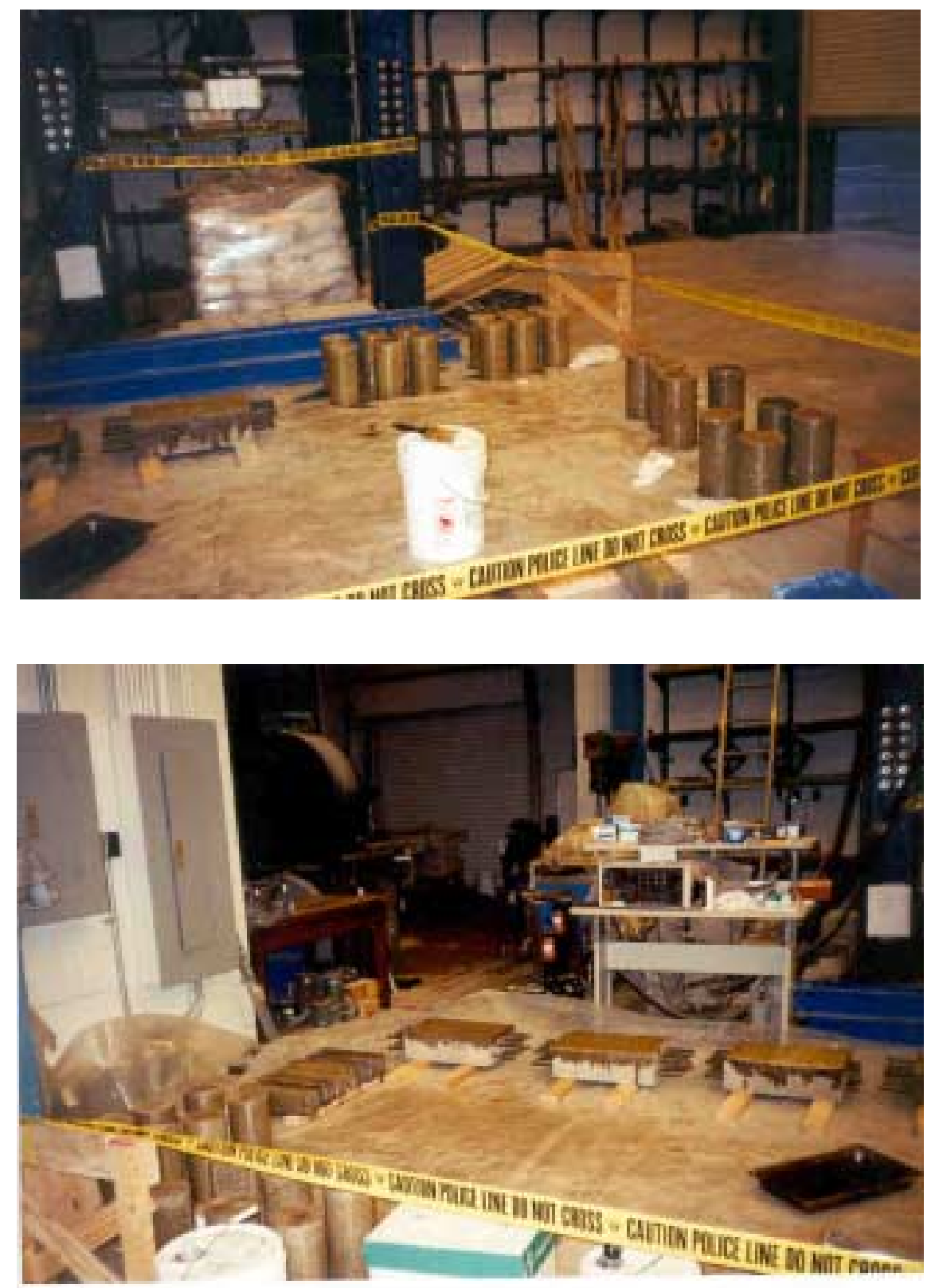

Figure 2-6 Specimens during curing. 

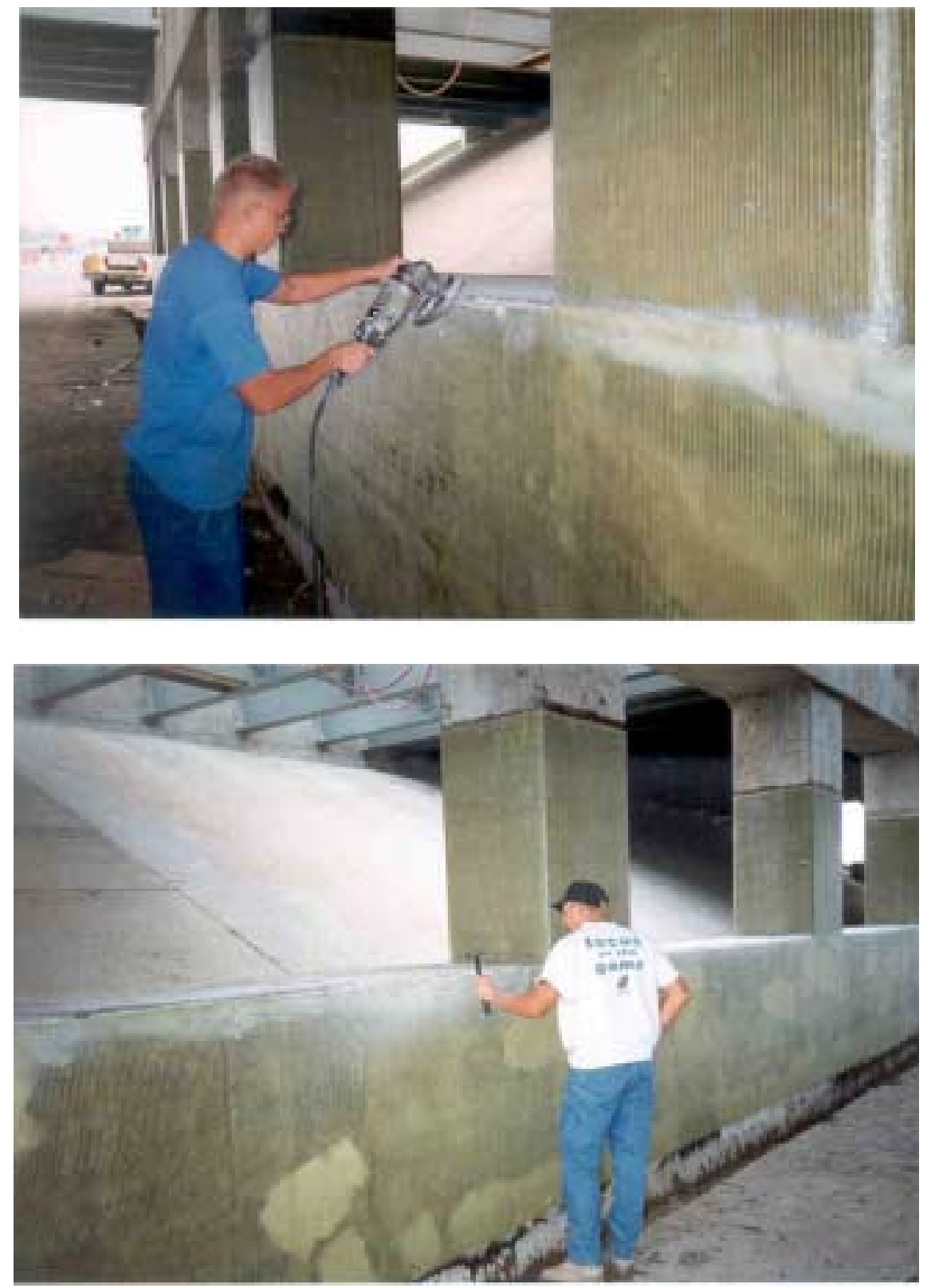

Figure 2-7 Surface preparation. 

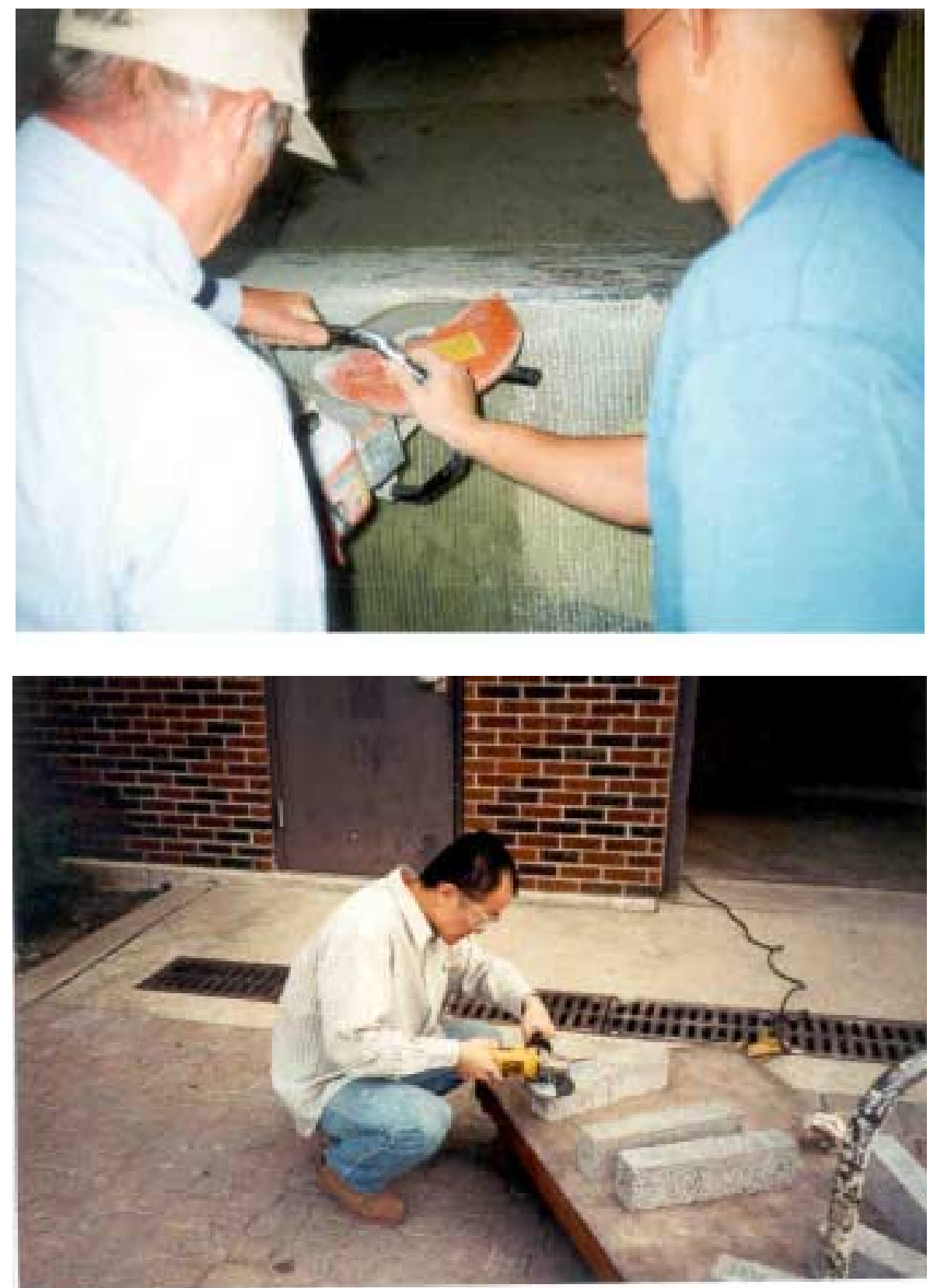

Figure 2-8 Surface preparation 


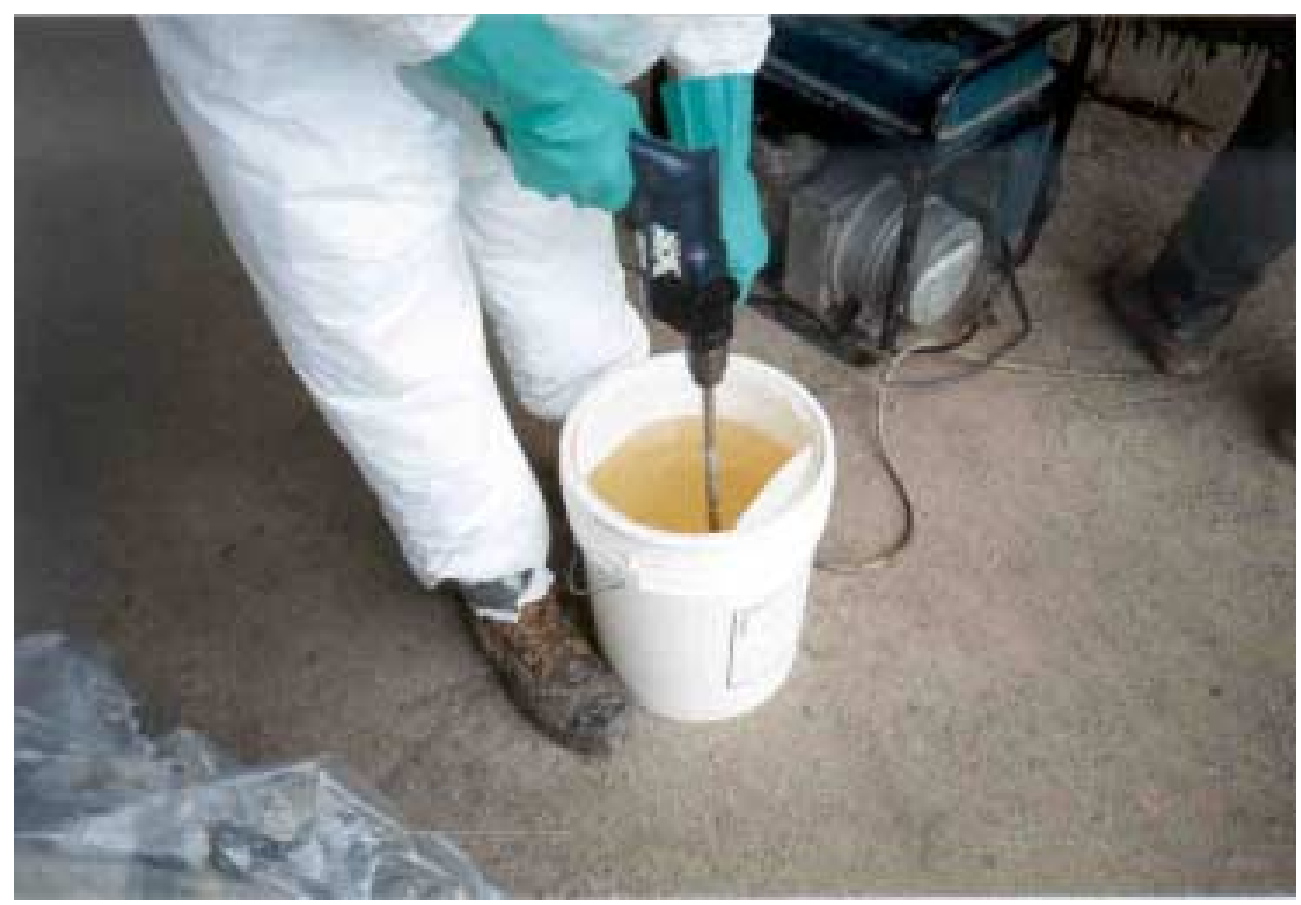

Figure 2-9 Epoxy Mixture 

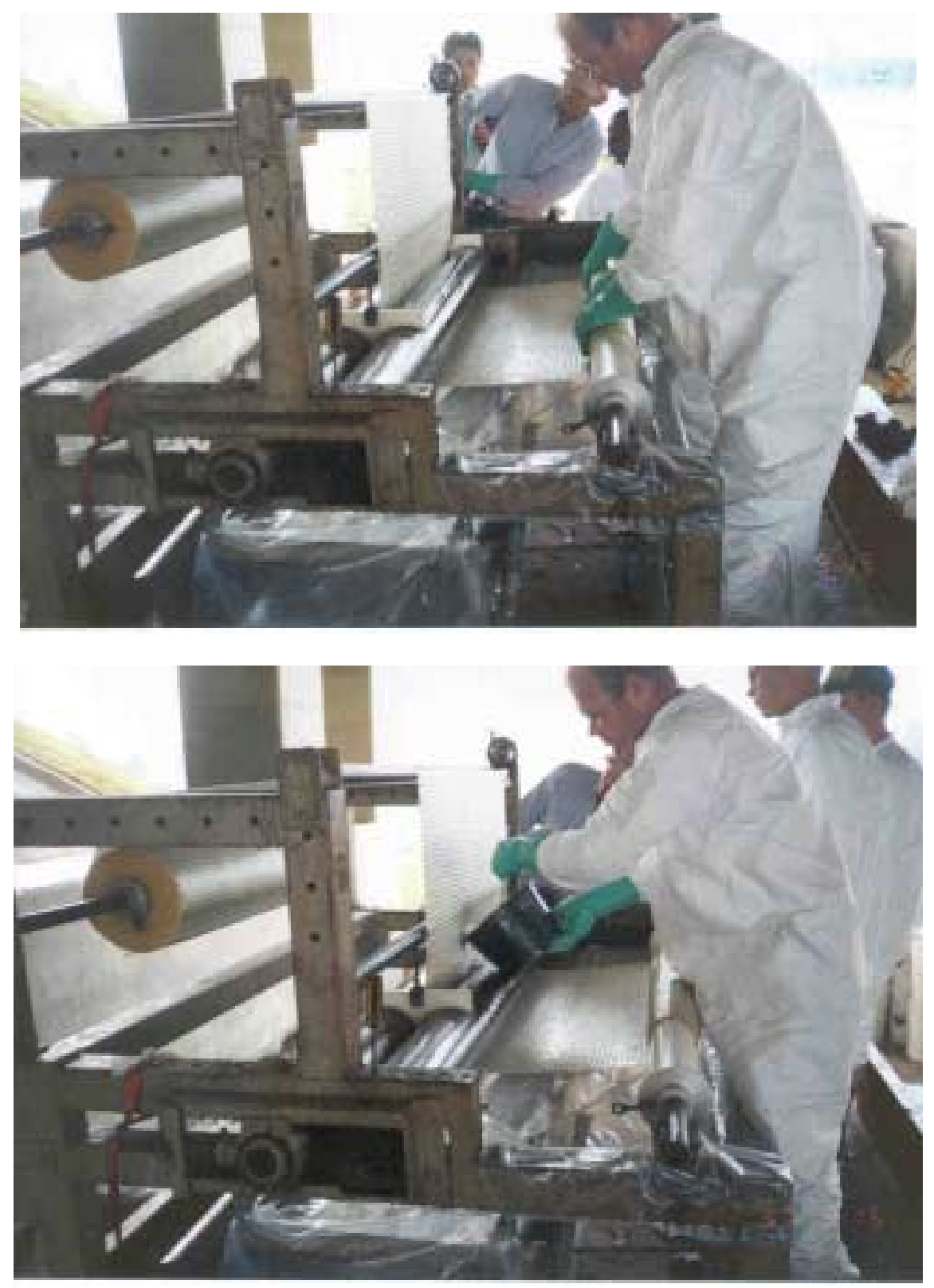

Figure 2-10 Soaking the FRPs 

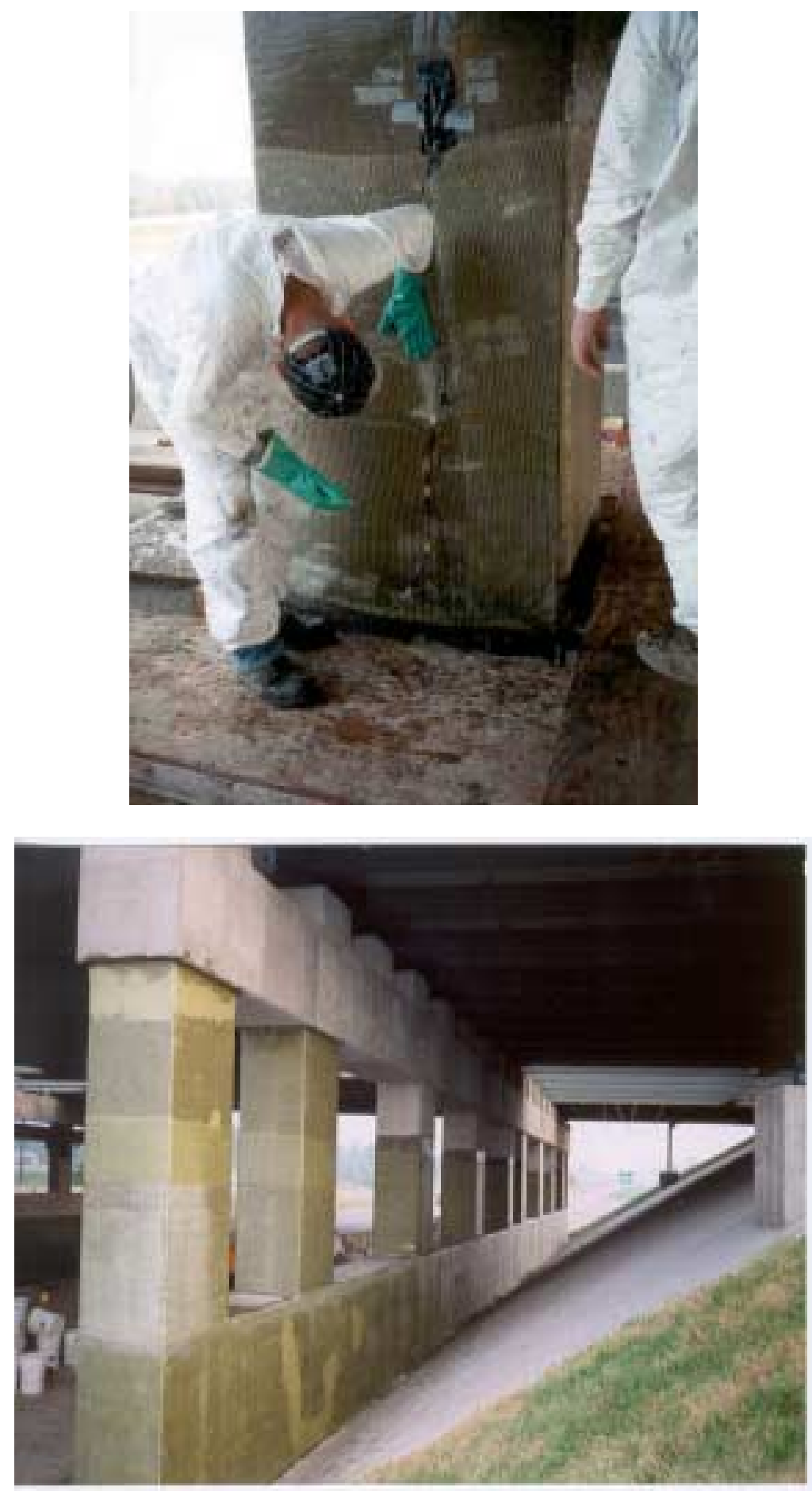

Figure 2-11 Release the entrapped air and the finalized application. 

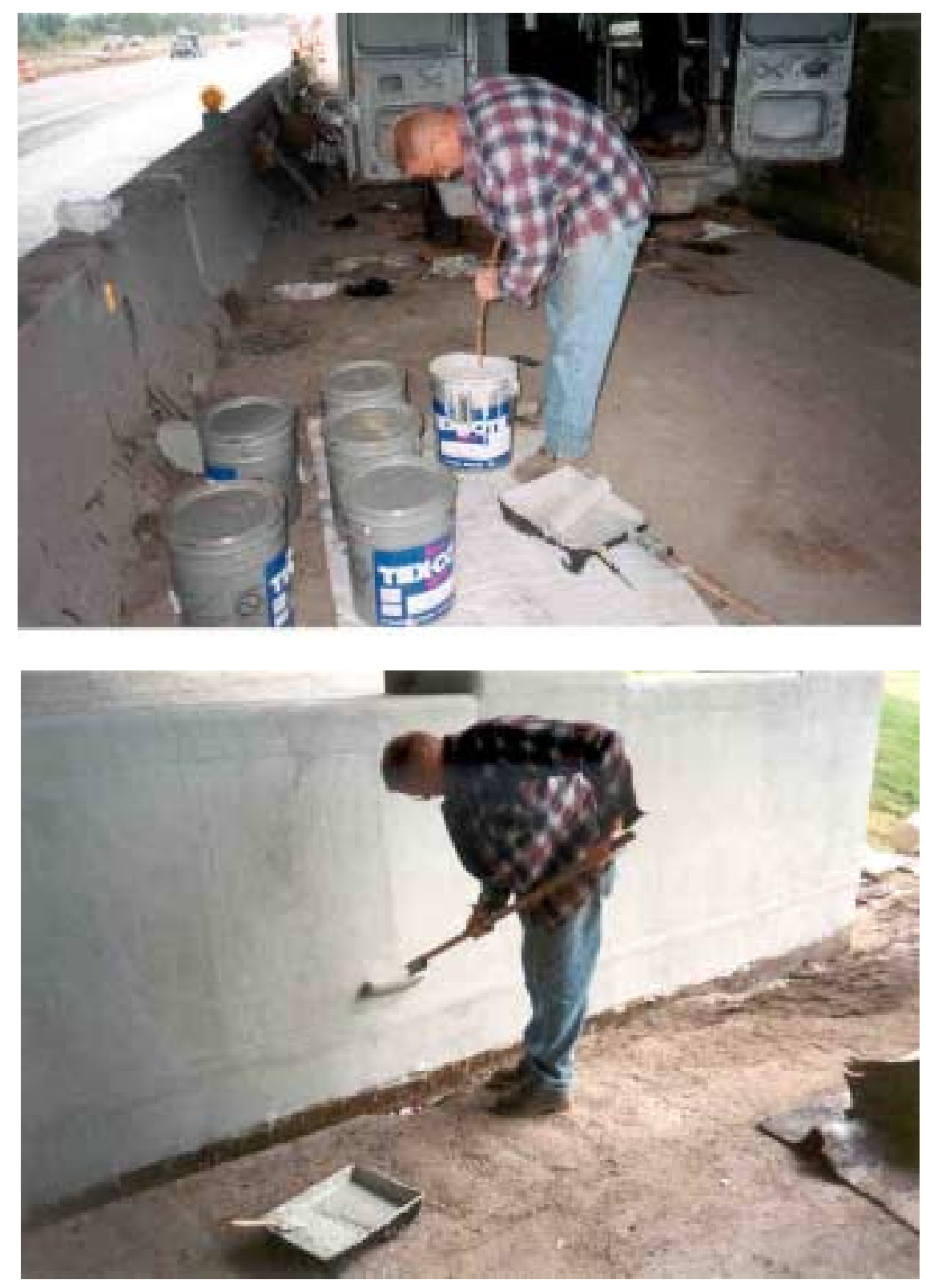

Figure 2-12 Coating. 


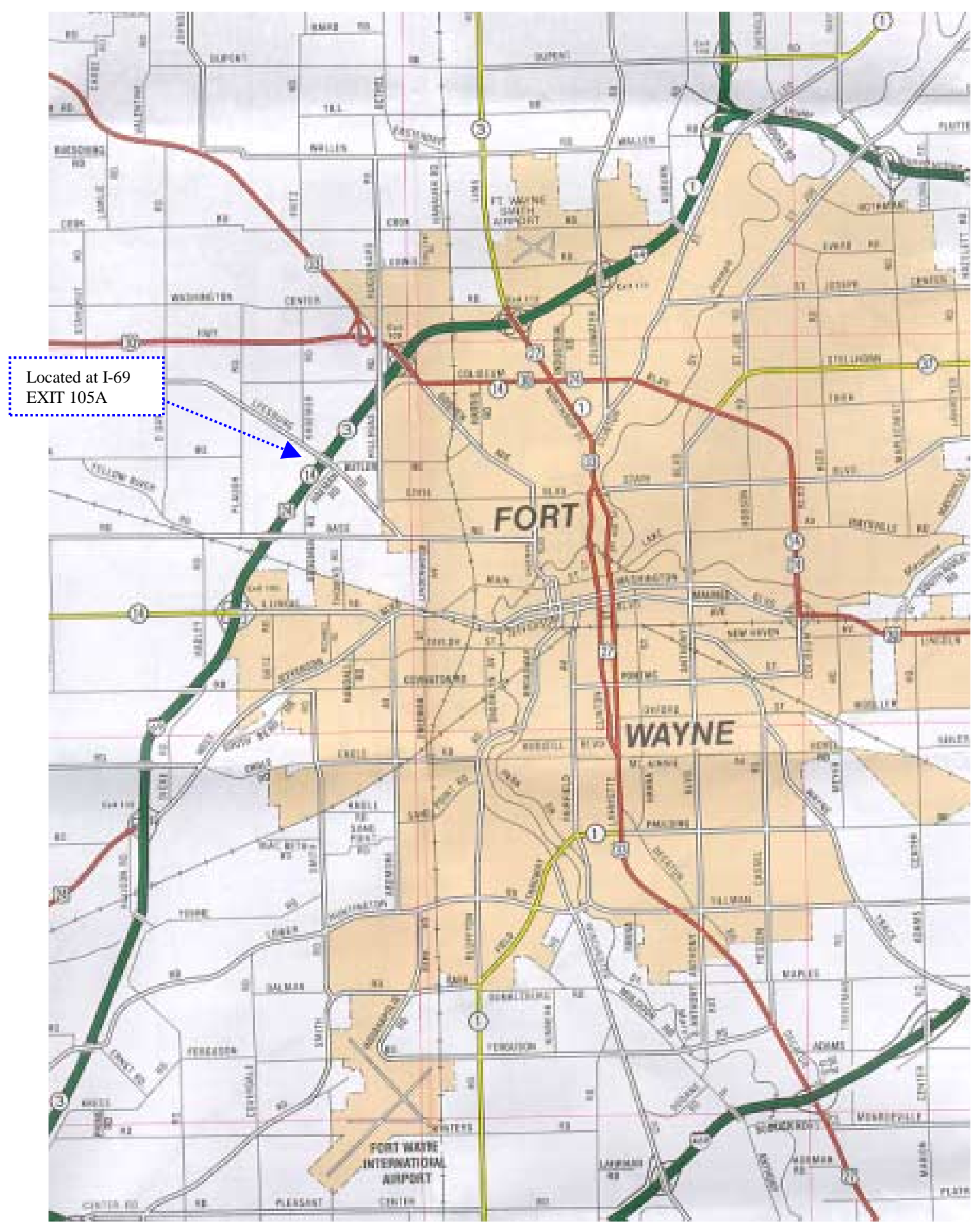

Figure 2-13 Location (I-69 \& US.14, EXIT 105A) 


\section{Chapter 3 Field Evaluation}

In an attempt to evaluate the field performance of bridge columns wrapped with FRP, three major approaches have been used. First, a survey on the use of FRP applications by Departments of Transportation in Indiana and other states was conducted. Second, two field inspections of FRP wrapped bridge columns, one located in Gary and the other in Fort Wayne were carried out. The final approach of the field evaluation of this technology consisted of the field monitoring of the concrete bridge columns in Fort Wayne. More specifically, the temperature variation and the strain values throughout the columns were collected and stored in a database. The results from all the three approaches to the field performance evaluation of FRP wrapped applications are presented in this chapter.

\section{Survey of Departments of Transportation}

A survey in the form of a questionnaire was created and sent out to all state Departments of Transportation (DOTs). This survey was intended to collect information on their use of FRP applications. A total of fifty-three surveys were sent out, and thirtynine were returned. The blank form used for the survey is shown in Appendix C. A summary of the responses is provided in Table 3-1. The detail information has been stored in the database, and has been stored in a CD-ROM.

The results from the survey show that FRP applications are widely used for corrosion

protection, structural update/strengthening, and seismic retrofitting. All of the responding DOTs indicated that FRP wraps have performed satisfactorily to date, except in one case 
in Houston, Texas, due to improper installation. Also, 24 out of 39 states responded that they plan to continue using FRP wraps. The superior performance of these materials is reflected in their widespread use by many DOTs in the USA.

\section{Visual Inspection}

Visual inspection of the two field applications has been performed periodically for the past two years. For the bridge columns located in Gary, Indiana, a detailed report is provided in Appendix D.

Two important issues are discussed here, which related to the bridge columns in Gary. The first one is concerned with the fact that the wrapped columns did not receive a final coating. Their long-term performance might be jeopardized, since FRP might be sensitive to ultraviolet rays. Another issue is concerned with the fact that some columns may present stress concentration due to poor surface smoothing.

For the application in Fort Wayne, it has been observed that due to auto accidents one of the columns wrapped with FRP has experienced some damage to the wraps themselves (see Figures 3-1 to 3-5). Figures 3-1 and 3-2 show the damaged FRP on the edge of column and on the middle side of footing in bend 2. Figure 3-3 illustrates how the aggressive environmental conditions have worsened the original damage on the middle side of footing. One picture shows the damage in the summer of 1999 and in the winter of the same year. Figure 3-4 shows the damaged FRP on the edge of column in bend 4 in the summer of 1999, and Figure 3-5 shows the same damaged spot in winter, 1999. Once again, the comparison between these two figures illustrates how the harsh environmental conditions have negatively affected the damaged area. This can be explained because the 
glass fiber is sensitive to water (moisture), once the epoxy cover is damaged, the glass fiber might absorb water causing volume expansion and consequently further damage other fibers.

\section{Field Monitoring}

Field monitoring of the Fort Wayne application has been conducted on average every two months for two years. This field monitoring was intended to study the environmental effects on the long-term performance of the FRP composites wrapped columns. The parameters measured are temperature variations and strains throughout the columns.

Instruments Installation

Thermal couples and strain gauges were installed in the first and third section of column, as shown in Figure 3-6. Each section was then cut into seven parts through the width of the wrapped column and the instruments were installed on them (Figure 3-6). The strain gauges were installed on the surface of auxiliary \#3 rebars, which were attached to the main rebars before the pouring of concrete in the columns. This is shown in Figure 3-7. A total of three columns were instrumented. The installation of strain gauges on the surface of the FRP wraps was conducted after two days of curing of the wrapped columns. The method of installation described in Chapter 2 was slightly modified with respect to surface smoothing. The original method, which consists of paper sanding the surface of the wraps is not advisable, since it may cause damage to the fibers themselves. Instead a very thin epoxy was applied to smooth the surface, which was then sanded to further improve its smoothness. It is important to mention that the applied epoxy was made as thin as possible, so that load transfer to the core could occur. 
In this project, EGP-5-350 strain gauges were also installed into the concrete for each section. This type of strain gauges is designed specifically for concrete applications. However, due to their high cost, in most applications we have elected to use electrical resistance strain gauges (see Figure 3-8). Our research team was present during concrete pouring in order to prevent unexpected damages to the instrumentation. In addition, our research team participated in the installation of the wraps, which were conducted by Infrastructure System, Inc. To ease the wrapping job, the instruments' wires were cut and labeled in the field. Furthermore, to guarantee safe monitoring, after the wrapping job was finished, we reconnected all the wires to the side of bridge (about 30 feet long). This task took about two months due to the large number of wires that needed to be reconnected.

\section{Data Collection}

All data collected from the field instrumentation have been stored in a database, which was created using the Microsoft Access software. In particular, temperature variations, strains, environmental conditions and construction conditions have been recorded in the database. The details of this database are provided in Appendix B. Also a "readme" file has been created, which details the procedures involved in the use of the developed database. For example, using a single command we can retrieve the temperature at a certain location for a specific date. Table 3-2 provides an example of the temperature variation throughout the columns. Another example is that the pictures were scanned and have been kept into the database such as during construction (Figure 3-9), wrapping procedure (Figure 2-4 to 2-12) and field inspection findings (Figure 3-10). The entire database has been copied into a CD-ROM, due to the large amounts of data. 
Table 3-1 Survey response summary

The surveys of the feasibility of FRP applications in DOTs of United States

53 surveys were sent out, and 39 were returned

\begin{tabular}{|l|}
\hline \multicolumn{1}{|c|}{ Non-responding DOTs } \\
\hline Alabama, Connecticut, Washington D.C., Hawaii, Kansas, \\
Louisiana, Maine, Missouri, North Dakota, Puerto Rico, South \\
Carolina, South Dakota, U.S. DOT, Utah. The total is 14 \\
states' DOTs.
\end{tabular}

\section{DOTs that never considered this technology} 6 states: NM, MS, RI, VA, IA, and NE. 
Table 3-1 Survey response summary (Contd.)

The knowledge of FRP application from

FHWA: 4 states - WA, IL, MS, and MA.

Contractor: 16 states - IN, WA, FL, NH, OR, etc.

Others: publications, researches, seminars, AASHTO

meetings, etc.

FRP is used in this state.

23 states: CA, NY, MD, WA, WI, IN, IL OH, KY etc.

Application for components of bridge structures.

Columns: 18 states - TX, WA, CA, DE, IN etc.

Beams: 10 states - OH, KY, TX, WA, CA etc.

Pier caps - MN, GA and FL. 
Table 3-1 Survey response summary (Contd.)

\section{Application for new/damaged structures:}

New structure: 6 states - IN, NY, WV, KY, CA, and PA. Damaged structure: 21 states - MD, WA, OR, IL, CA etc.

\section{The reasons for rehabilitation:}

Corrosion protection: 11 states - IL, NY, IN, MN, etc. Corrosion repair: 11states - WA, OK, IL, NY, etc. Shear strengthening: 5 states - IL, FL, TN, NV, and OR. Overloading strengthening: 4 states - GA, OH, TN, and IL. Seismic strengthening: 7 states - IL, PA, CA, NV, etc. Others: upgrade, crack, etc.

\section{Type of FRP}

GFRP (Glass): 15 states - IN, NY, OR, OK, ID, etc. CFRP (Carbon): 14 states - MN, OR, OH, WI, etc. 
Table 3-1 Survey response summary (Contd.)

\begin{tabular}{|l|}
\hline Check the performance? \\
\hline Visual inspection: 18 states - IN, NY, MD, WA, KY, etc. \\
Installation of expensive instruments (e.g. humility, corrosion, \\
or temperature sensors): 4 states - IN, MN, NY, OH \\
Others: cores, hammer, etc.
\end{tabular}

Future applications for FRP.

Future applications: 24 states - NV, MD, WV, MI, CA etc. 
Table 3-2 Temperature variations throughout the columns.
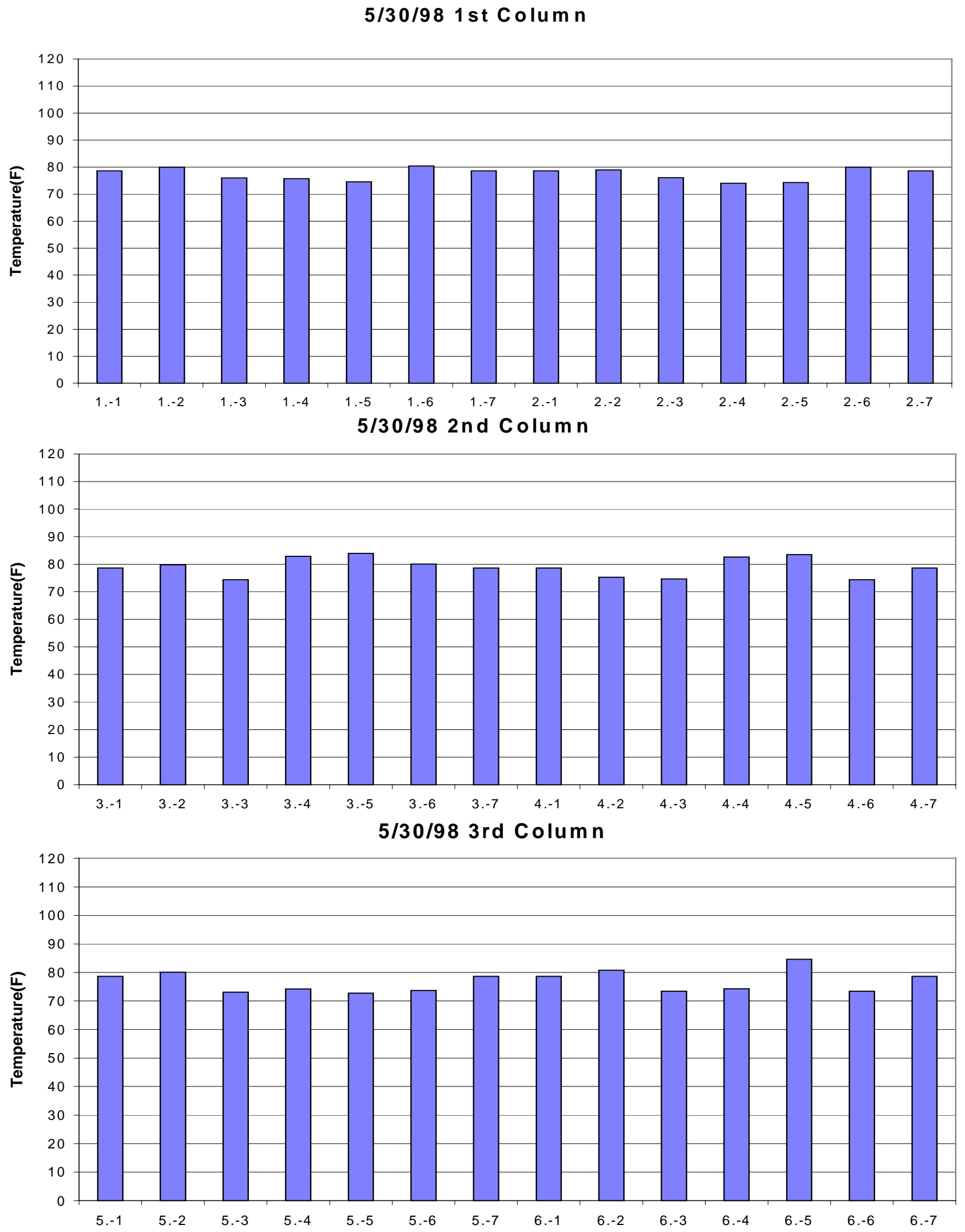

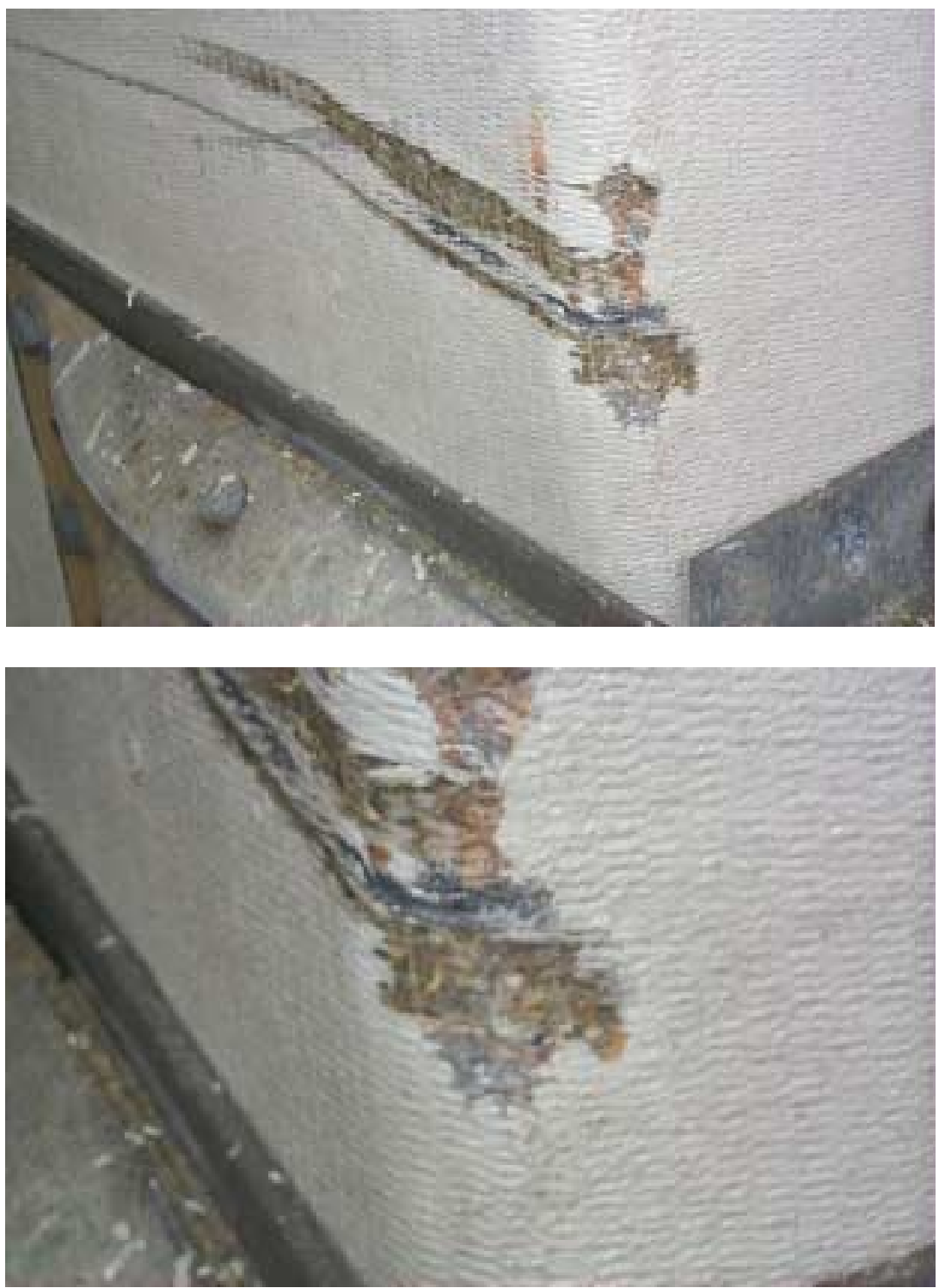

Figure 3-1 Damaged FRP on the edge of a column, Bend 2, October 9, 1999. 


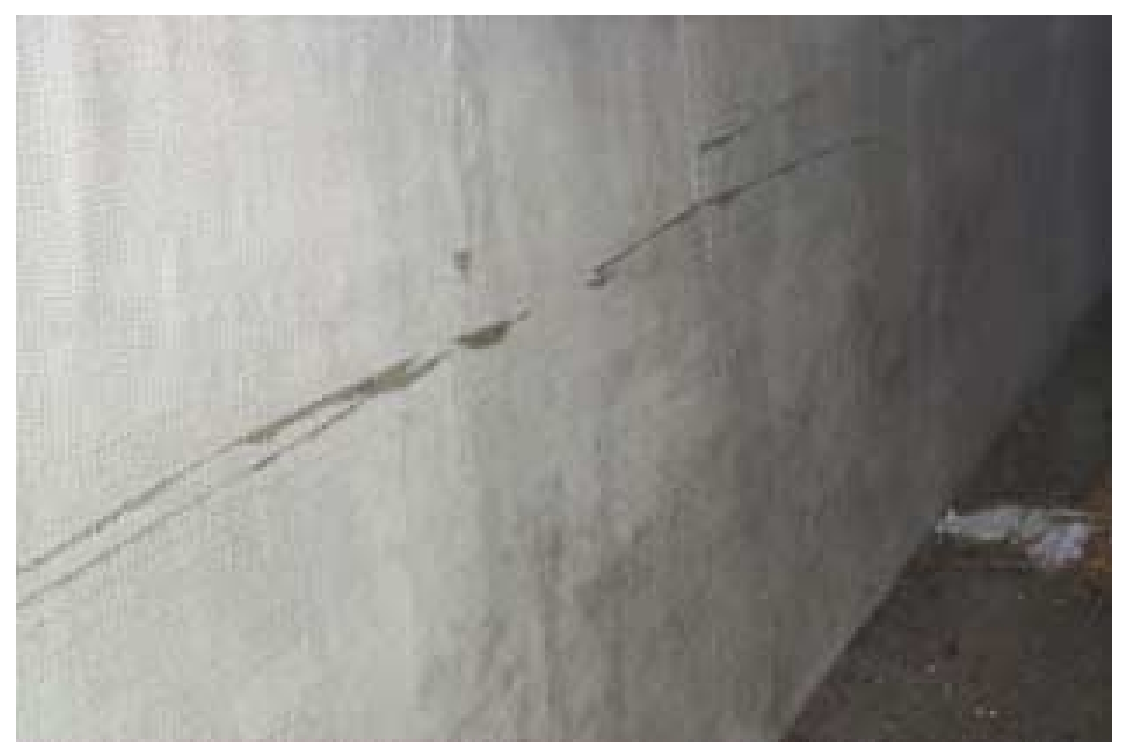

Figure 3-2 Damaged FRP on the side of the footing, Bend 2, October 9, 1999. 

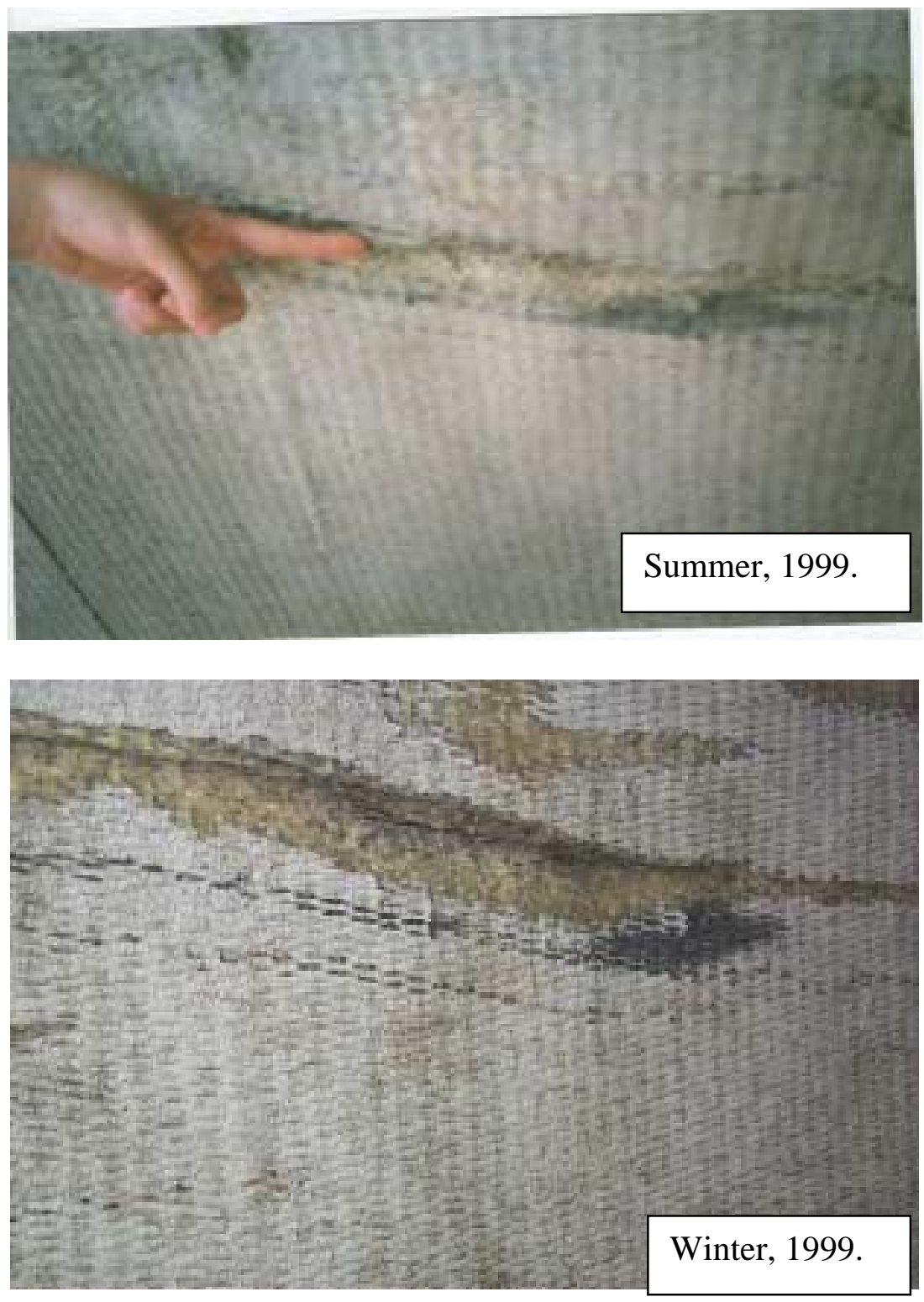

Figure 3-3 Damaged on the middle side of the footing at bend 4 between the summer and winter, 1999. 

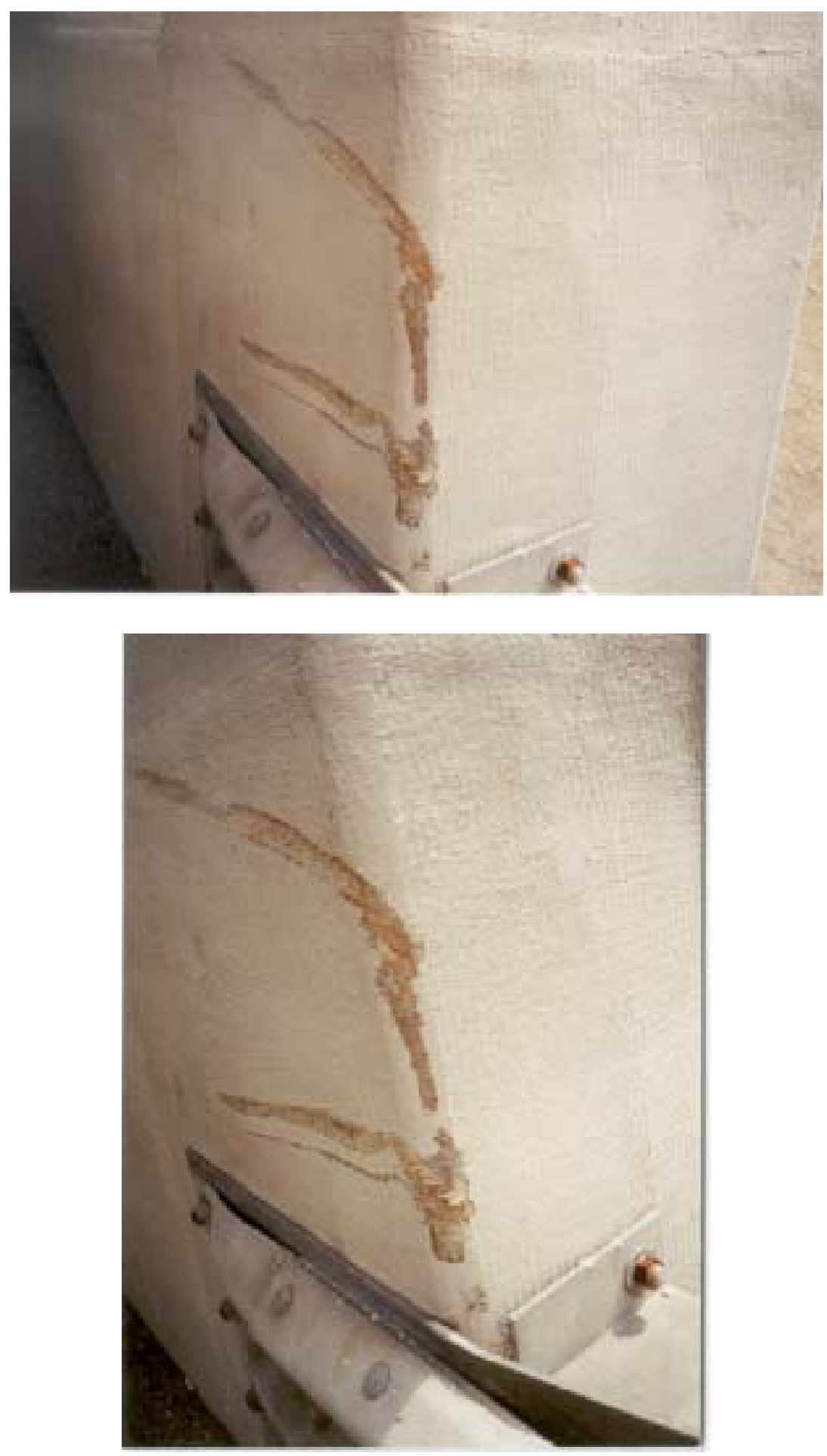

Figure 3-4 Damaged FRP on the edge of a column, Bend 4, summer, 1999 

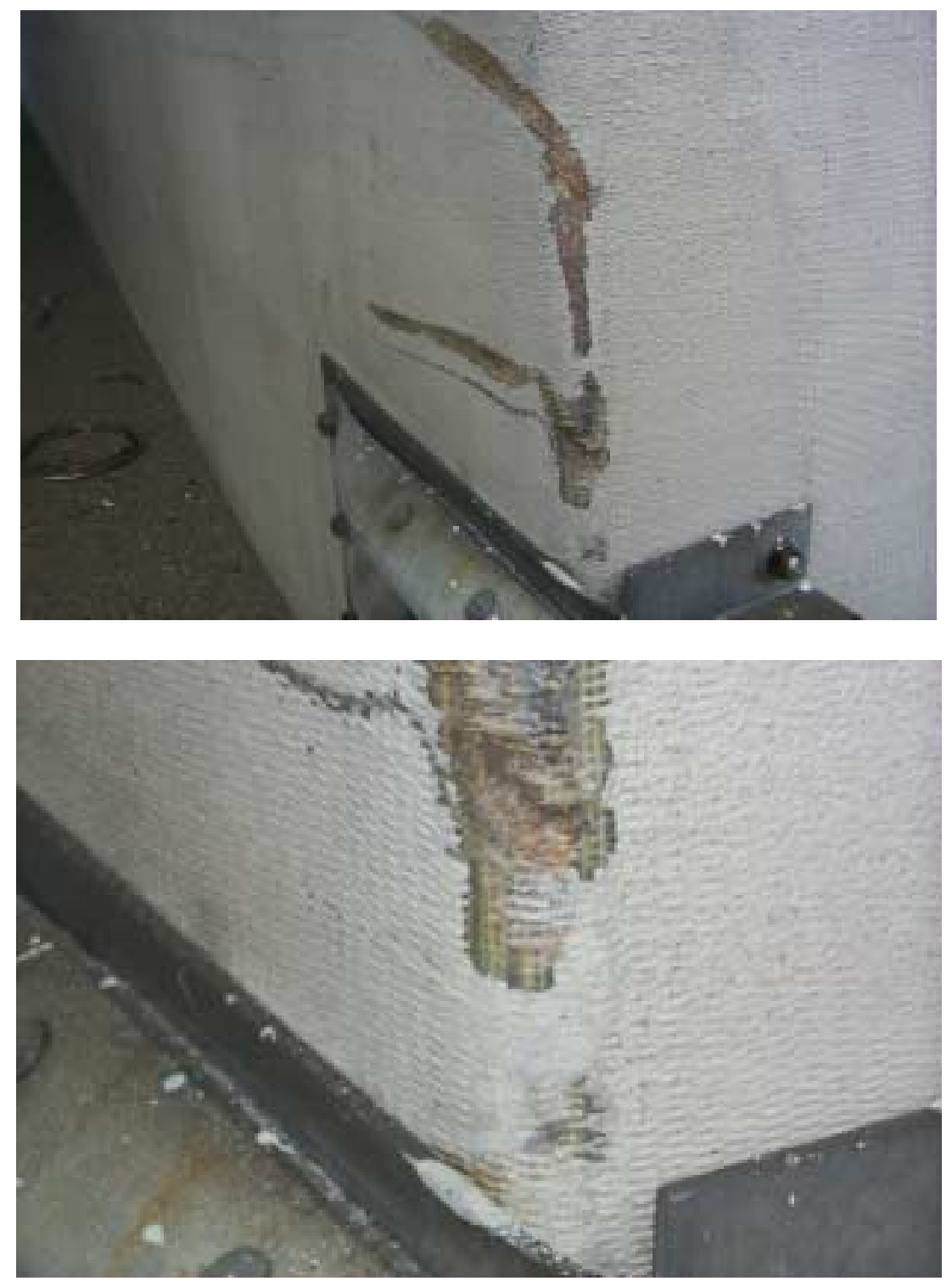

Figure 3-5 Damaged FRP on the edge of a column, Bend 4, October 9, 1999. 


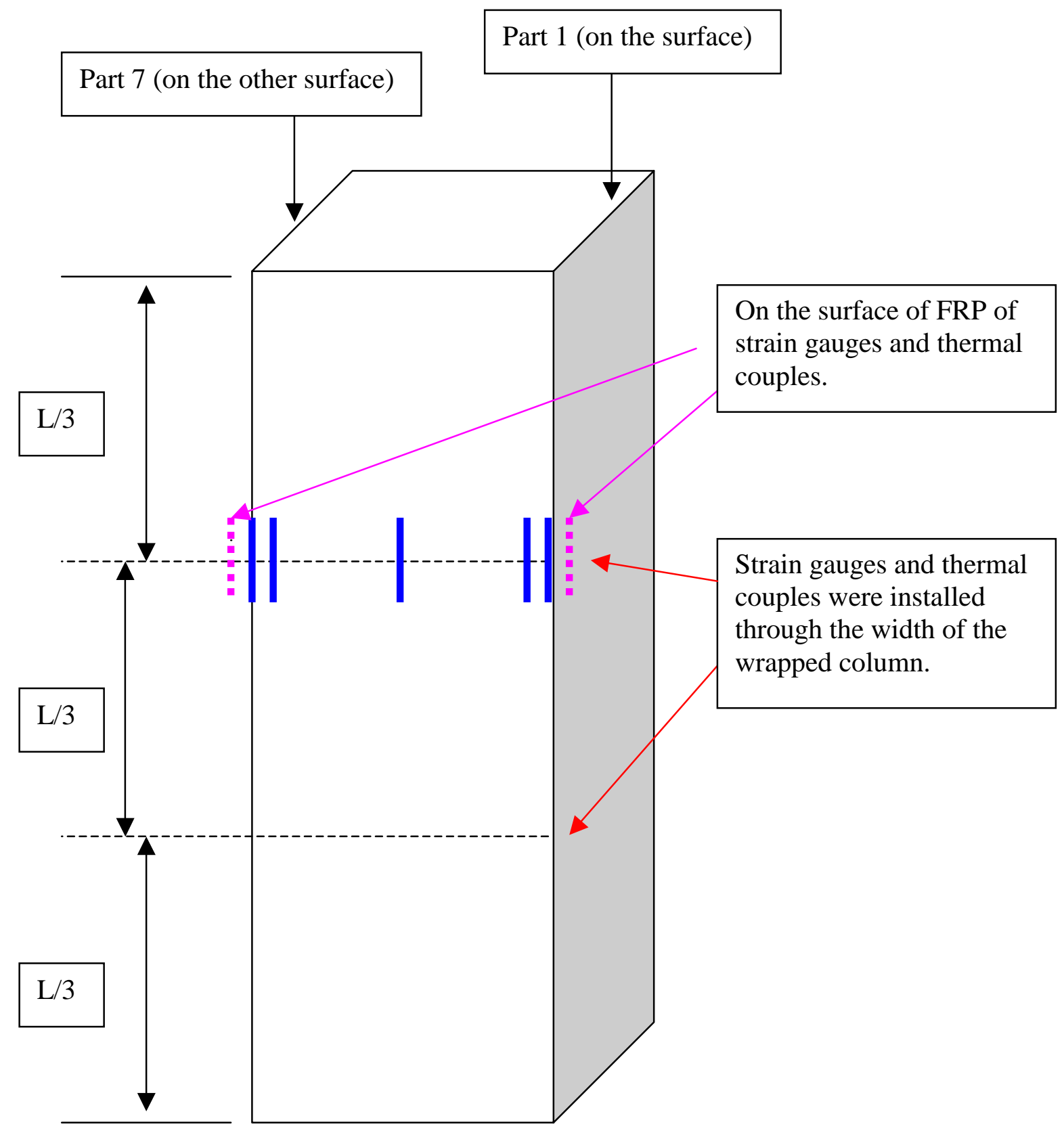

Figure 3-6 Installation locations of strain gates and thermal couples. 

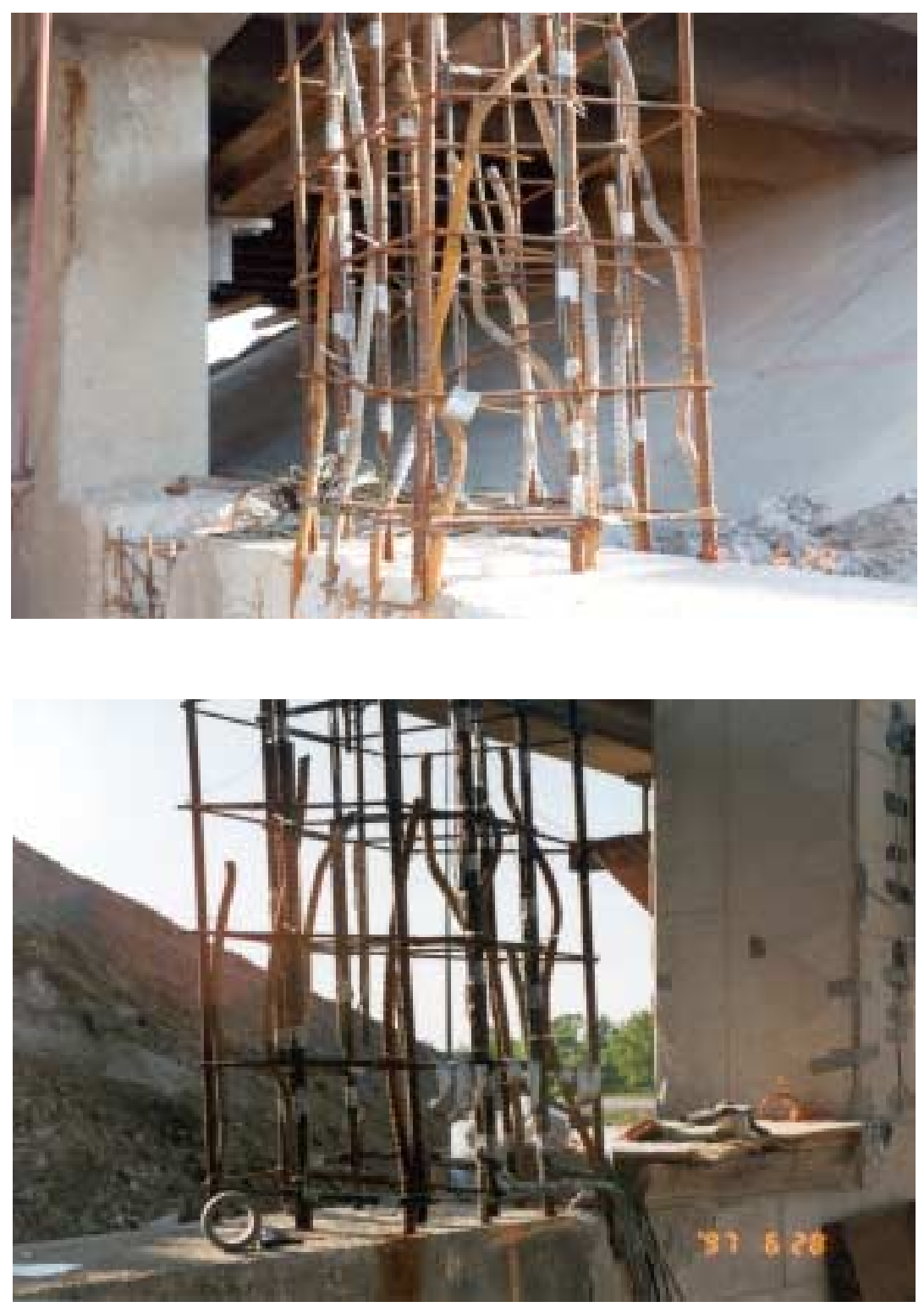

Figure 3-7 Set up instruments in the field. 

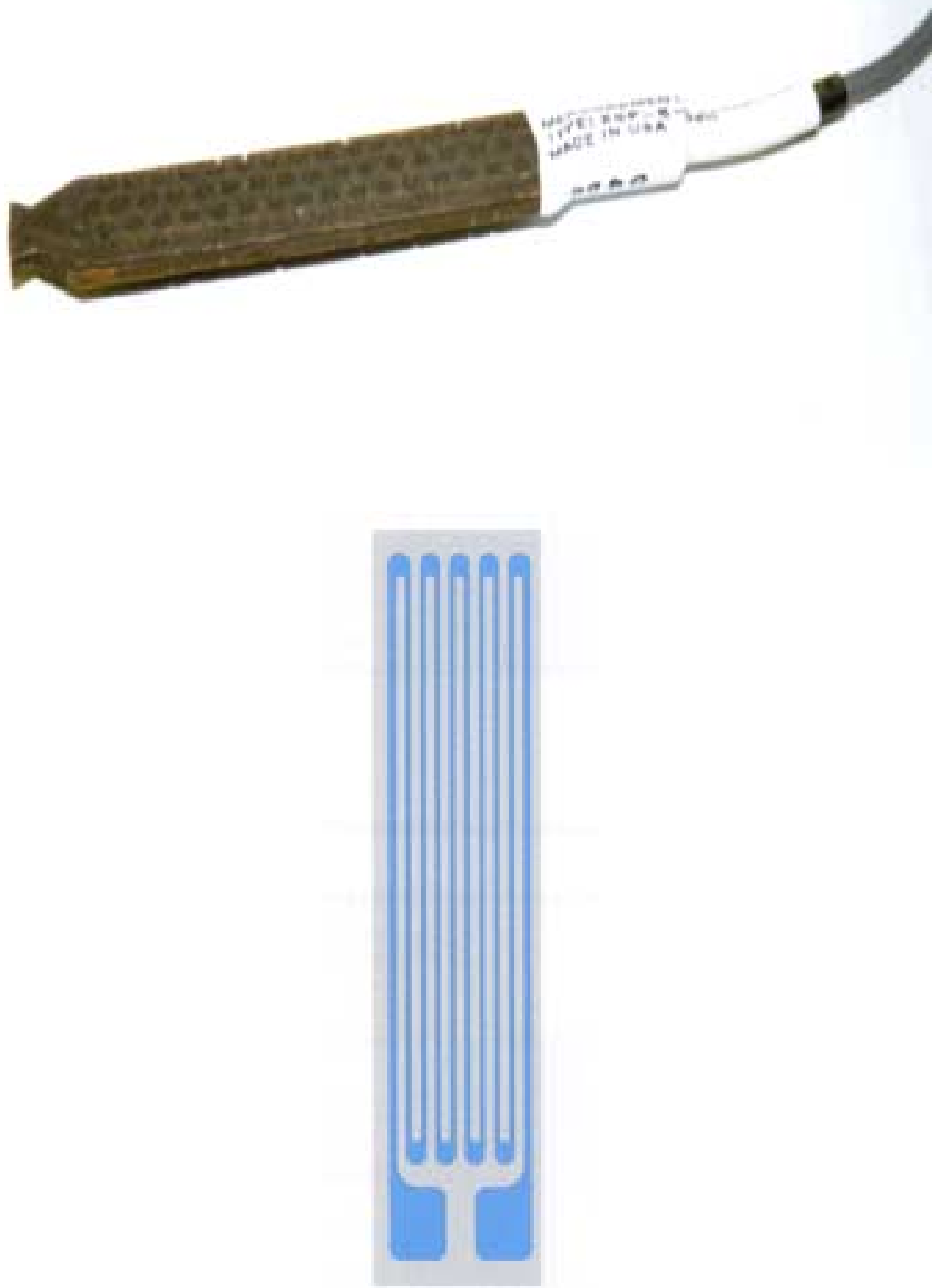

Figure 3-8 EGP-5-350 strain gauge and electrical resistance strain gauge. 

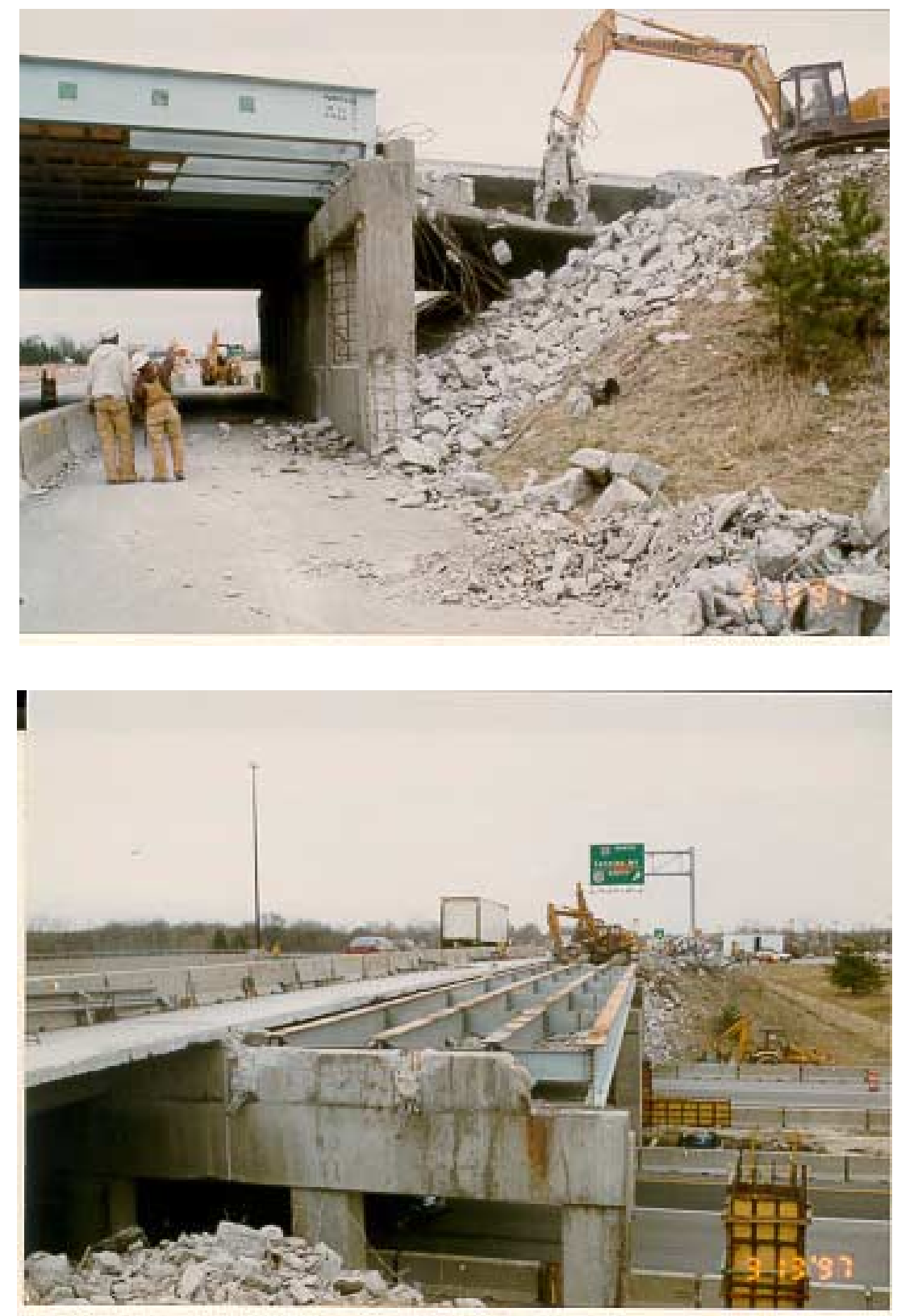

Figure 3-9 Bridge constructions. 

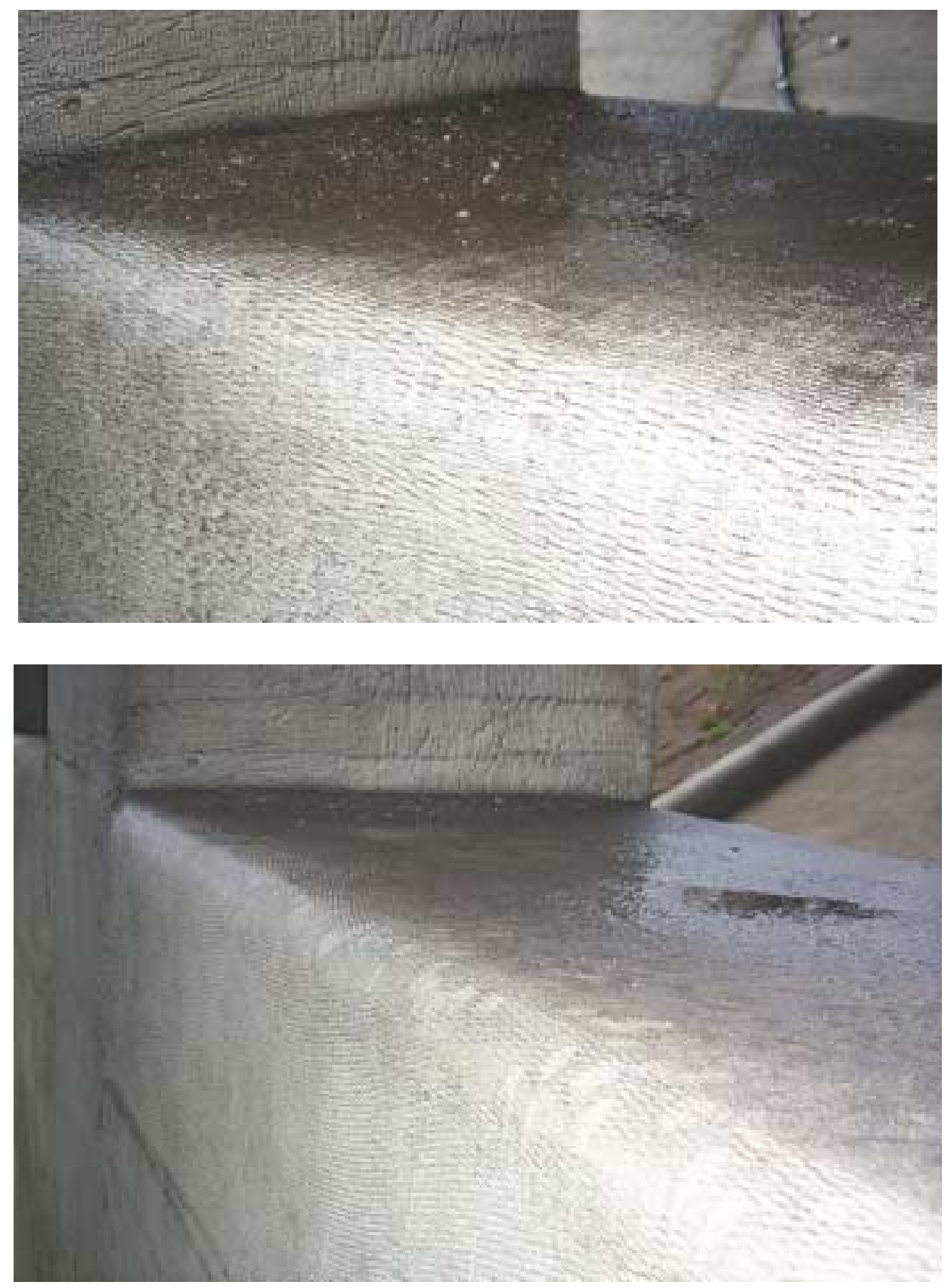

Figure 3-10 Accumulate some aggressive materials, Bend 2. 


\section{CHAPTER 4 Laboratory Tests for Corrosion Assessment}

\section{Problem statement and Literature review}

Corrosion of the steel in reinforced concrete structures is a major problem worldwide. In developed countries, a conservative estimate is that one-half of their highway bridges are deteriorating due to reinforcement corrosion. In fact, in the United States, this type of deterioration constitutes one of the most expensive infrastructure-related costs. Millions of dollars have been spent to keep facilities functional through repair and maintenance. The potential risks of corrosion to the safety of a structure are unpredictable. In the late 1950 's, in the United States, deicing salts were first used after snow events. With this practice, it was observed that the corrosion of the steel reinforcement became a more common problem. Therefore, it is believed that the corrosion of the steel reinforcement of bridges is caused mainly by the salt application during snow events. As a consequence, if a structure is expected to be subjected to severe environmental conditions, its reinforcement is usually pre-treated either with a cathodic or anodic protective coating. However, these methods do not permanently protect the reinforcement. That is, with time the treated reinforcement will corrode again, thus affecting the long-term durability of the structure. Alternatively, the steel can be replaced by Fiber-Reinforced Plastic (FRP) made with glass, carbon or aramid fibers set in a suitable resin to form a rod or a grid.

Many deterioration problems require only proper rehabilitation rather than rebuilding,

which is, in general, a more costly option. Traditional methods consist of eliminating the chloride contamination from the corroded areas, which are then patched with a special or a good quality concrete mixture. However, as mentioned above, these methods provide 
only a short-term solution. A non-traditional and potentially long-term solution consists of using FRP composite wraps to retrofit damaged structures or as a preventive measure for undamaged structures. In both cases it is expected that this solution can prevent further corrosion problems. Furthermore, this type of retrofit improves the strength and ductility of the wrapped structural components, and therefore of the structure as a whole. This is particularly important in high-risk seismic regions.

The use of composites in civil engineering infrastructure is still in its infancy. However, these materials have been widely used in other industries with an excellent track record. These other industries include the aerospace, the automotive, the chemical, and the shipbuilding industries. Most of the current use of FRP wraps has been for improving structural strength. Appendix A lists some of the Departments of Transportation in the United States that have been using FRP for this purpose. To date most of the research being carried out on the application of FRP to civil infrastructure has concentrated on strength issues and has not addressed corrosion prevention and durability issues. The argument for this lack of research is that it is believed that aggressive agents or water/moisture cannot penetrate these materials and therefore no corrosion should occur. In the present work, a comprehensive study is performed to evaluate this assumption. More specifically, the long-term behavior of FRP wraps under extreme environmental conditions is studied. This is done via laboratory experiments, which are aimed to simulate the long-term behavior of these retrofits, and via the field monitoring of a highway bridge in Fort Wayne, Indiana. This chapter focuses on the laboratory experiments. 
In this work, experimental tests were developed with the goal of simulating the longterm corrosion process due to chloride contamination and moisture. Five different specimens were made for the laboratory testing. All specimens were built using reinforced concrete. The surface of one of the specimens was left unprotected, while the surface of another was covered with epoxy, and the surfaces of the remaining three were covered using varying numbers of FRP layers. The findings from this study are provided in this chapter together with some practical recommendations.

\section{Corrosion of the reinforcing steel in concrete $[13,14,15]$}

Generally, three basic processes are necessary for the corrosion of a metal.

1.) A depolarisation reagent arrives at the surface of the metal through the medium surrounding it. For example, the oxygen dissolved in the medium.

2.) Electrochemical (anodic and cathodic) reactions occur at the interface between the metal and the surrounding medium. For example, the oxidation of a metal.

3.) Reaction products (or corrosion products) are accumulated at the surface of the metal or moved away from the surface into the medium. For example, iron rust is formed at the surface of a metal or $\mathrm{Fe}^{2+}$ moves away from the metal into the solution.

These three processes are illustrated in Figure 4-1.

In reinforced concrete, due to the porosity of concrete, oxygen can easily get into the pores and dissolve in the pore solution. Eventually it can reach the surface of the steel reinforcement, thus initiating the corrosion process [16]. 
Corrosion of steel in concrete is an electrochemical process; that is, one or more chemical processes and electricity flow are both involved in the formation of corrosion cells. There are two electrodes at which these processes occur. The one in which metals tend to go into solution as positively charged ions and simultaneously develop corresponding negative charges (electrons), is called the anode. The other electrode in which the electron current from the anode flows through the metallic electrical connection, and in which various chemical reactions involving oxygen may occur, is called the cathode. In reinforced concrete, when there exists a difference in electrical potential along the steel in the concrete, the electrochemical cell is set up, and anodic and cathodic regions form there. These regions are connected by the electrolyte in the form of the pore water. Corrosion begins when a current flow is established between the two electrodes. The principal chemical reaction at the anode may be written as,

$$
\begin{aligned}
& \mathrm{Fe} \rightarrow \mathrm{Fe}^{++}+2 \mathrm{e}^{-} \\
& \text {(Iron) Iron in the solution Two electrons }
\end{aligned}
$$

This is a very important process because it can cause the loss of the cross section of the steel rebar. The positively charged ferrous ions $\mathrm{Fe}^{++}$at the anode pass into solution, while the negatively charged free electrons $\mathrm{e}^{-}$pass through the steel into the cathode where they are absorbed by the constituents of the electrolyte and combined with water and oxygen to form hydroxyl ions $\left(\mathrm{OH}^{-}\right)$. The principal chemical reaction at the cathode may be written as,

$$
\mathrm{O}_{2}+2 \mathrm{H}_{2} \mathrm{O}+4 \mathrm{e}^{-} \rightarrow 4(\mathrm{OH})^{-}
$$

Also, concrete normally provides a natural protective barrier against the corrosion of the reinforcing steel. A thin iron-oxide film is a passive film, which becomes impermeable and strongly adherent to the steel surface, covering the ordinary iron and 
steel products. This film acts as a barrier against corrosion in an alkaline environment ( $\mathrm{pH} 13.5$ to 12.8). When the $\mathrm{pH}$ in concrete is reduced to less than 11.5 , this protective film is destroyed, thus, setting the stage for initiation of the corrosion process.

When concrete is saturated with water, $\mathrm{Fe}^{2+}$ may be removed from the steel surface to form a rust stain on the surface of concrete. This phenomenon can be easily detected because of the presence of rust stains on the concrete surface. However, this process has no significant impact on the surrounding concrete cover.

The most severe case occurs when the corrosion product cannot move out of the steel surface because the rate of corrosion is too high. There are two major consequences of the corrosion of reinforcing steel. First, the transformation of metallic iron to rust is accompanied by an increase in volume, which depending on the state of oxidation may be as large as 600 percent of the original metal. This volume increase results in cracking (typically parallel to the reinforcement), spalling or delamination of the concrete (see Figure 4-2). This makes it easier for aggressive agents to ingress toward the steel, with a consequent increase in the rate of corrosion. Second, the progress of corrosion at the anode reduces the cross-sectional area of the steel, thus reducing its load-carrying capacity. Figures 4-3 and 4-4 show two cases of Indiana bridges, which have suffered from corrosion problems.

FRP wraps have the potential to provide a good long-term solution for the corrosion problems present in civil infrastructure. To evaluate the corrosion prevention capacity of this technology, three methods have been used. They are the half-cell potential method (ASTM C876-91) [17], the corrosion current method (ASTM G109-92) [18] and the 
corrosion resistance method (modified ASTM G109-92). These methods are described in detail in the following subsections.

\section{Acceleration of the corrosion process and simulation}

The corrosion of the steel in reinforced concrete might take several years to occur. This amount of time is not suitable for effective research and laboratory studies. Therefore, the acceleration of the corrosion process is necessary. The process used in this work is described next.

- Five 20" $\times 10$ " beams (see Table 4-1) using \#5 rebars were subjected to weekly cycling. The two weekly cycles consisted of one week of exposure to a $5 \%$ sodium chloride solution followed by one week of drying at a minimum of $100^{\circ} \mathrm{F}\left(38^{\circ} \mathrm{C}\right)$. To contain the sodium chloride solution was contained in the specimens by means of a 3M type silicone caulk, and by constructing a 2.5 " waterproof epoxy barrier on the surface of the beams using a wood cover. The sodium chloride solution was mixed thoroughly using a mixer, and the solution was then poured on and off the beams on selected days. A siphon was used to remove the tap water, and the beam surface was dried using a sponge (see Figures 4-5 and 4-6). Heat was then applied to the beam surface to raise the concrete temperature above $100^{\circ} \mathrm{F}\left(38^{\circ} \mathrm{C}\right)$. This was done using halogen lamps (Figure 4-7). The purpose of the accelerated exposure cycling was to determine the potential for chloride accumulation at the interface between of the steel and the concrete, and to evaluate the resistance to reinforcement corrosion. Weekly visual inspection and half-cell potentials and corrosion current/resistance measurements were used to assess the resistance to reinforcement corrosion. 
- Visual Inspection:

During the weekly measurements, visual inspection was also performed to detect any defects on the beams.

- Half-cell potentials: [17]

Corrosion happens as the current flows between two electrodes having different electrical potentials. This difference, or voltage, between the anode and cathode can be measured using a voltmeter. However, since the difference in measured voltage between the two unstable electrodes (or half-cell) is not meaningful, a standard reference point must be used. The standard hydrogen half-cell is the most commonly used reference point and it was, thus, set as the zero point on the potential scale.

The Copper-Copper-Sulfate Electrode is commonly used for reinforced concrete in civil engineering. It consists of a copper rod in a saturated copper sulfate solution, which is contained in a plastic tube with a porous end plug. The copper rod is stable in the solution and its potential remains constant regardless of changing conditions. Therefore, the copper rod represents a half-cell of constant electrical potential $\left(-0.36 \mathrm{~V}\right.$ at $72{ }^{\circ} \mathrm{F}(22$ ${ }^{\circ} \mathrm{C}$ ) as referenced to the hydrogen electrode).

The corrosion potential of the reinforcing steel embedded in the concrete is compared to that of the copper rod by a positive terminal of a voltmeter connection to the top mate of reinforcing steel, and the reference electrode to the negative terminal. A voltmeter is then included in the circuit to measure the potential difference (see Figure 4-8) between the top steel mate and the reference. The type of reference electrode, and the magnitude and sign of the voltage difference should be recorded. The potentials for the uncoated steel bar are interpreted according to the following standard guidelines: 
- If the potentials over an area are more positive than $-0.20 \mathrm{~V}$, there is a greater than $90 \%$ probability that no reinforcing steel corrosion is occurring in that area.

- If potentials over an area are in the range of $-0.20 \mathrm{~V}$ to $-0.35 \mathrm{~V}$, corrosion activity of the reinforcing steel in that area is uncertain.

- If potentials over an area are more negative than $-0.35 \mathrm{~V}$, there is a greater than $90 \%$ probability that reinforcing steel corrosion is occurring in that area (see Table 4-2).

Because this test method is limited by electrical circuitry, surfaces that are coated with a dielectric material, such as FRP wraps or Epoxy coating will not provide an acceptable electrical circuit. Because of this limitation half-cell measurements were taken only in the uncovered specimen. These measurements were taken weekly on the pounded in 12 points throughout the exposure cycling. Figure 4-9 shows the location of these points for the weekly measurements. Electrical connections were made to the rebar at the places shown in Figure 4-10. Tables 4-3 through 4-8 show the half-cell potentials recorded of the pounded region during the weeks of exposure cycling.

- Measured corrosion current/resistance: [18]

A macrocell is a case in which the sites of anodic and cathodic activity are remote from each other, but they occur in the same metal. Based on this model, the cell can involve in two different regions on a single piece of steel. If the steel in concrete is active to corrosion, corrosion can occur in the most negative regions and the oxidation can happen in the more positive regions. Therefore, the macrocell current can be defined as the current between the corroding and the cathodic region. Macrocells can be readily created and the measurement of the corrosion rate through the steel can be conducted. 
Macrocell corrosion currents between the wires connected to the steel rebars were monitored weekly during the exposure cycling. A $100 \Omega$ resistor was placed between the wires connected to the top steel rebars and the bottom steel ones to achieve this. Figure 411 illustrates this procedure. Voltage drops and the resistance across the resistors were measured at the end of the drying phase of the weekly cycle. Corrosion current was then calculated using Ohm's Law, I=V/R (in the present study $\mathrm{R}=100 \Omega$ ). These currents are proportional to the rate of corrosion occurring at the time of measurement, and the resistances have an inverse relationship to the rate of corrosion. It is known that the corrosion resistance of concrete is affected by its pore sizes, distribution and its solutions It is also affected by the moisture and salt content as well as by the temperature. However, since this work is concerned with the use of FRP wraps, only the temperature and the chloride content are considered. This is because these are the only two factors that can directly affect the corrosion resistance of concrete wrapped with FRP.

Concrete, which contains a high concentration of chloride and that is subjected to a relatively high temperature, usually corresponds to a low resistivity. Some researchers have attempted to establish the criteria relating the resistivity of concrete with the possibility of corrosion of the reinforcement in concrete, however the application of the different criteria can provide significantly disparate results. For example, if the resistivity value is equal to $15 \mathrm{~K} \Omega$, according to the Vassie criterion [19] corrosion is unlikely. However, according to the Langford criterion [20] it has a high corrosion rate, and to the Broomfield criterion [21] it has a low to moderate corrosion rate. For this reason, in this work, the three methods were used in an attempt to establish a more accurate relationship for the systems under consideration. 
The corrosion current test is for the macrocell corrosion between the top and bottom mats of steels, and not for microcell activity. These two methods only need a $100 \Omega$ resistor and a high resistance impedance voltmeter capable of measuring to $0.01 \mathrm{mV}$, and the measurement often provides a good warning that corrosion has occurred. Table 4-2 shows the corrosion criterion used in this work, which states that if the current value is higher than $10 \mu \mathrm{A}$ then corrosion has occurred. Tables 4-8 and 4-9 show the results of corrosion current and resistance tests.

\section{Conclusions and recommendations}

From the testing results for the half cell and corrosion current, it can be seen that the specimen with uncovered concrete surface has exceeded the limit value. In other words, in this case, the half-cell value is smaller than $-350 \mathrm{mV}$, the corrosion current is greater than $10 \mathrm{~mA}$, and the resistance drops gradually. The other specimens, on the other hand, remained unchanged. We expect that more corrosion will continue to occur in this specimen as time goes by. With time a better relationship between resistance and corrosion behavior will be obtained. Even though we recognize that the macrocell current can measure only a fraction of the total corrosion activity, it provides a simple corrosion measurement. This is especially valuable for field applications. In fact, using the corrosion current and resistance methods together can provide more reliable assessments, since these two measurements can provide a good insight on whether further corrosion has happened or not.

Based on the results obtained in the present work, we conclude the following: 
1. From the test results, it can be seen that FRP wraps provide an excellent corrosion protection even when a single layer is used. Thus, retrofitting damaged structures with FRP wraps is a good temporary solution if budget constraints prevent complete renovation of the structure.

2. The test results have also shown that epoxy can also provide a good corrosion protection. Since when wraps are applied in the field, there is usually some epoxy left over. Thus, we recommend that the areas above the wraps should be protected using this excess epoxy.

3. The results of the laboratory tests are limited to five specimens. More specimens should be tested in order to obtain more accurate results, and to develop a practical way to check for corrosion in FRP wrapped reinforced concrete structural components.

4. The application of FRP wraps to damaged structures should be considered, since it may provide an economical way of repairing these structures. In addition to providing additional load carrying to damaged structural components, FRP wraps have the potential to stop the progress of corrosion, since they isolate the structural component from aggressive agents. In this case an easy and inexpensive instrumentation set up should be developed to further monitor the progress of the corrosion. 
Table 4-1. Five 20" $\times 10$ " beams using \#5 rebars for the corrosion test.

\begin{tabular}{|c|c|c|c|}
\hline Specimen & Quality & Half-Cell & Corrosion Current \\
& & Method & Method \\
\hline Plain Concrete & 1 & Yes & Yes \\
\hline Epoxy on the top & 1 & No & Yes \\
\hline 1 FRP Layer & 1 & No & Yes \\
\hline 2 FRP Layers & 1 & No & Yes \\
\hline 2 FRP Layers & 1 & No & Yes \\
(After Freeze-Thaw) & & & \\
\hline
\end{tabular}


Table 4-2. ASTM criteria for the corrosion of steel in concrete for the standards Half-Cell \& corrosion current methods

\begin{tabular}{|c|c|c|}
\hline Risk of corrosion & $\begin{array}{c}\text { C876-91 } \\
\text { Potentials }(\mathbf{m V})\end{array}$ & $\begin{array}{c}\text { G109-92 Corrosion } \\
\text { Current }(\boldsymbol{\mu A})\end{array}$ \\
\hline $\begin{array}{c}\text { Low (10\% risk of } \\
\text { corrosion) }\end{array}$ & $>-200$ & ------ \\
\hline $\begin{array}{c}\text { Uncertain (Intermediate) } \\
\text { High (90\% risk of } \\
\text { corrosion) }\end{array}$ & $-350<$ value $<-200$ & ------ \\
\hline Severe corrosion & $<-350$ & Value $>10$ \\
\hline
\end{tabular}




$$
\text { HST }
$$



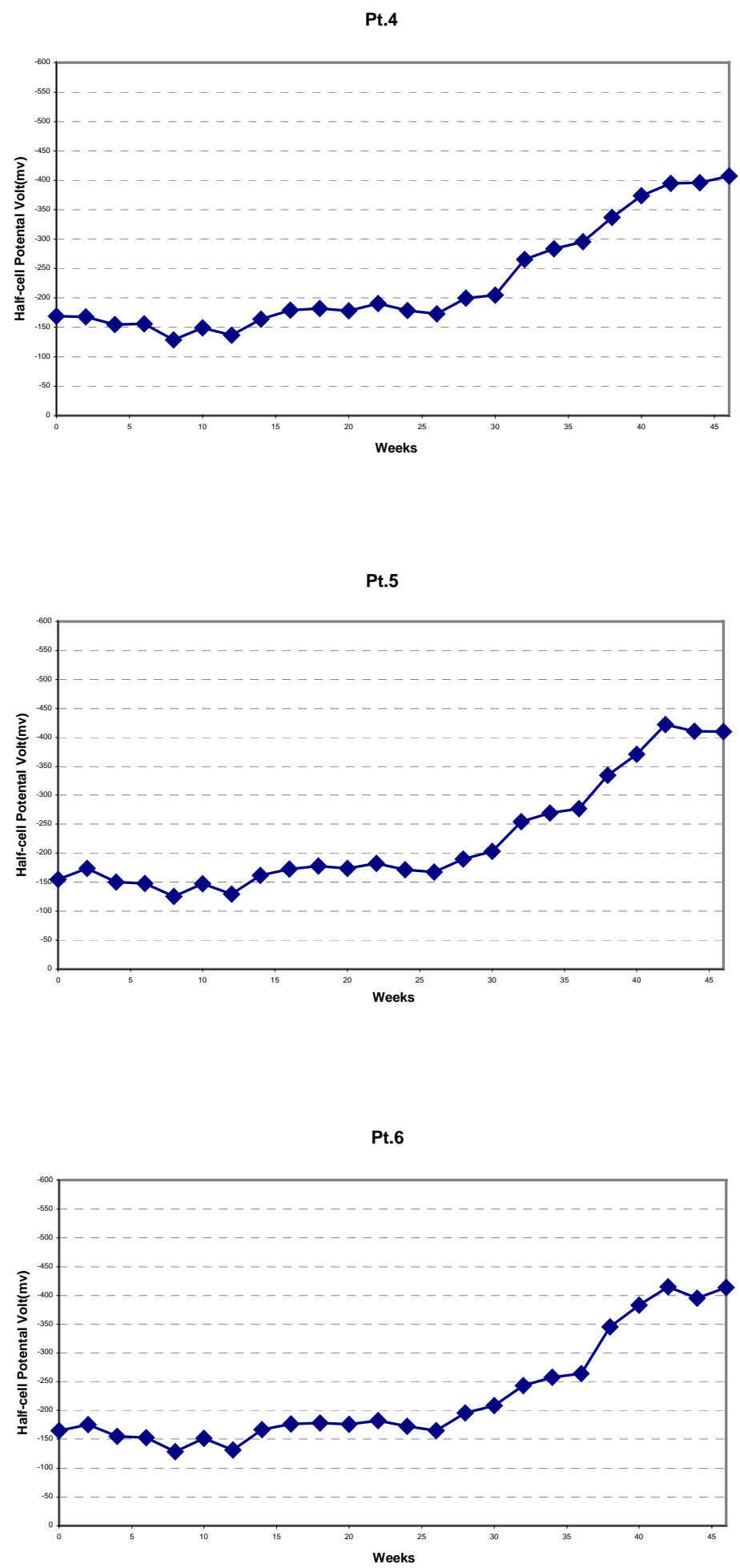

Table 4-4 Half-cell potentials for point 4 to point 6. 

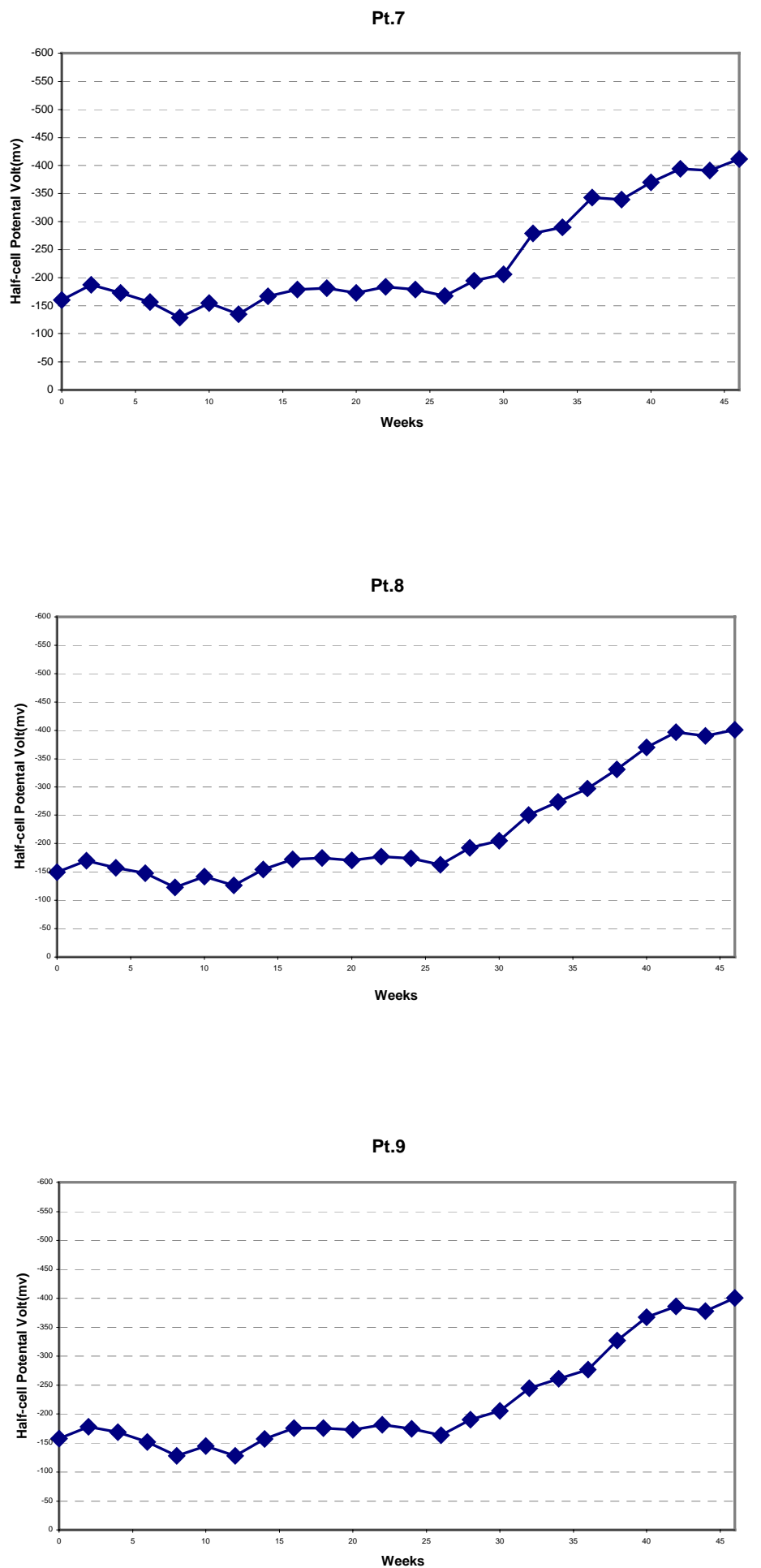

Table 4-5 Half-cell potentials for point 7 to point 9. 

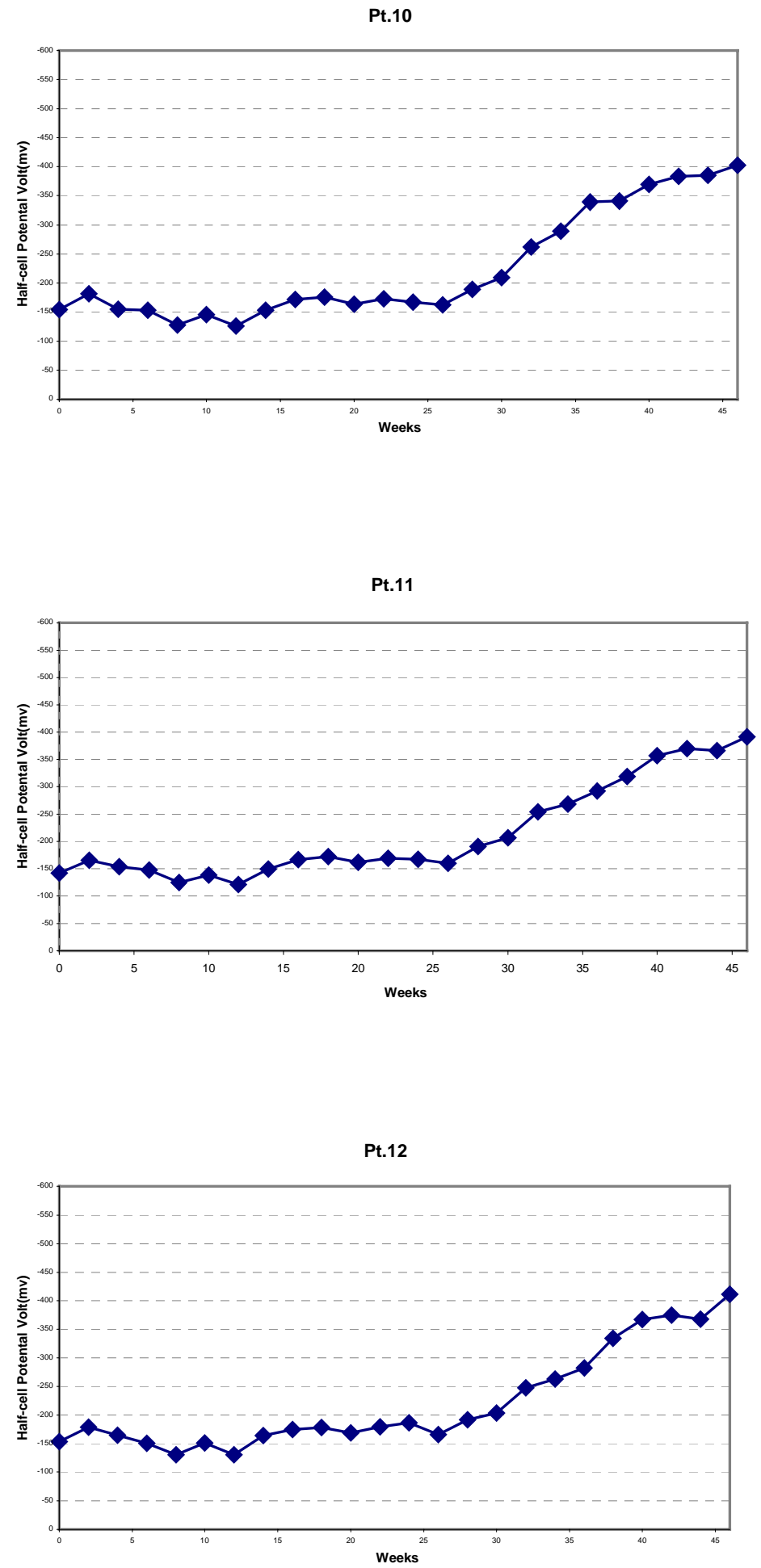

Table 4-6 Half-cell potentials for point 10 to point 12. 

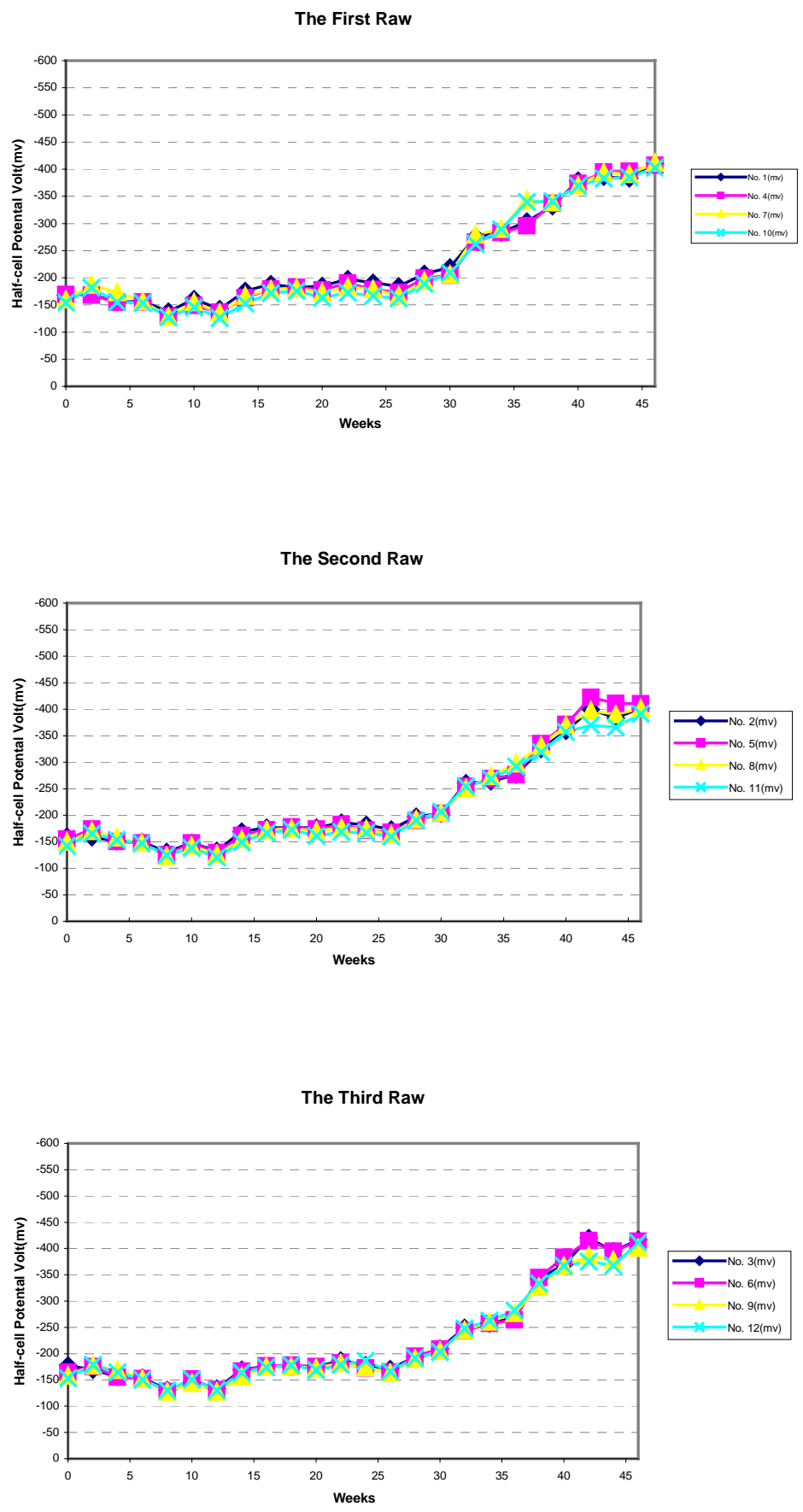

Table 4-7 Half-cell potentials for point 1 to point 12. 

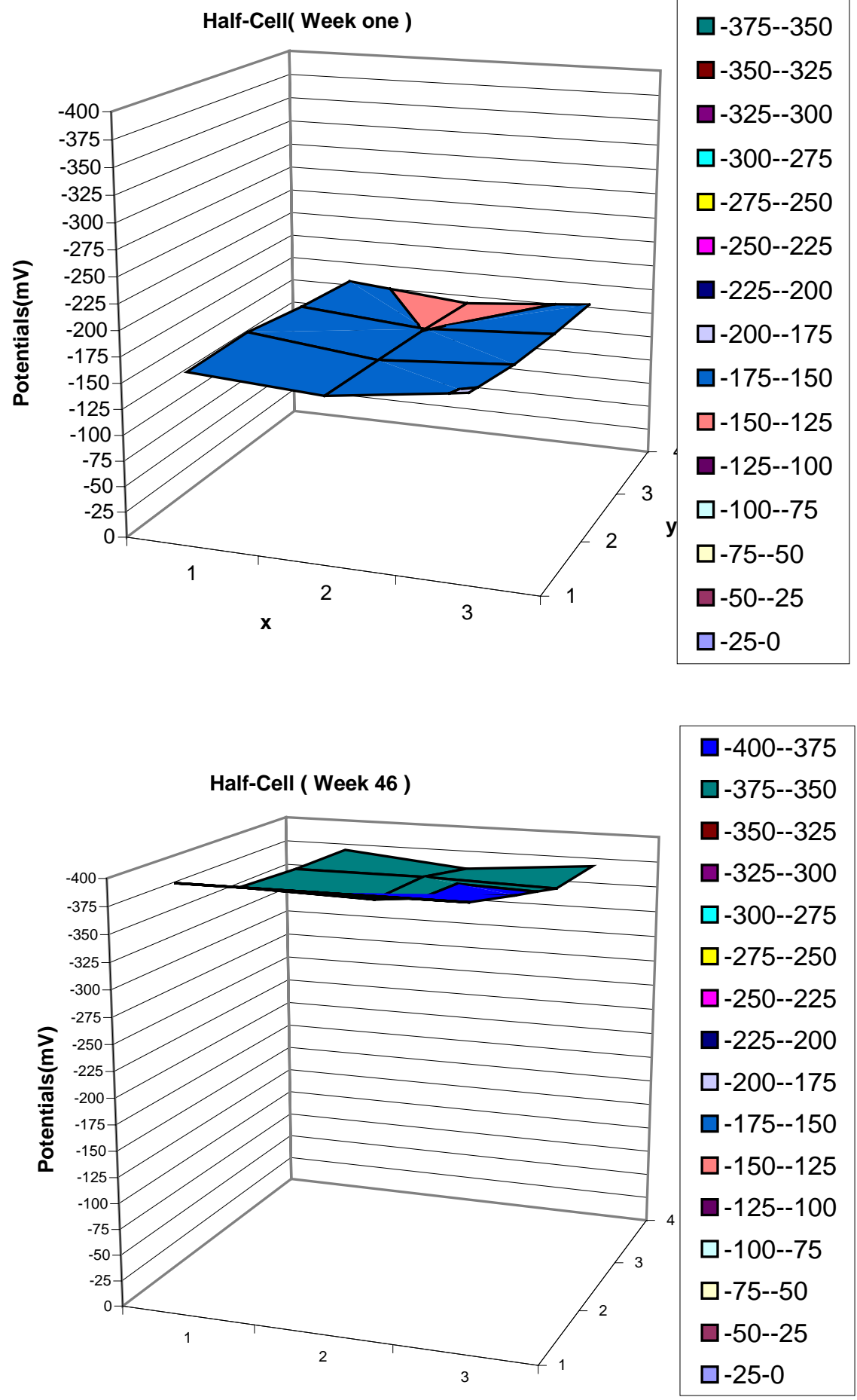

Table 4-8 Half-cell potentials between the first week and $46^{\text {th }}$ week. 


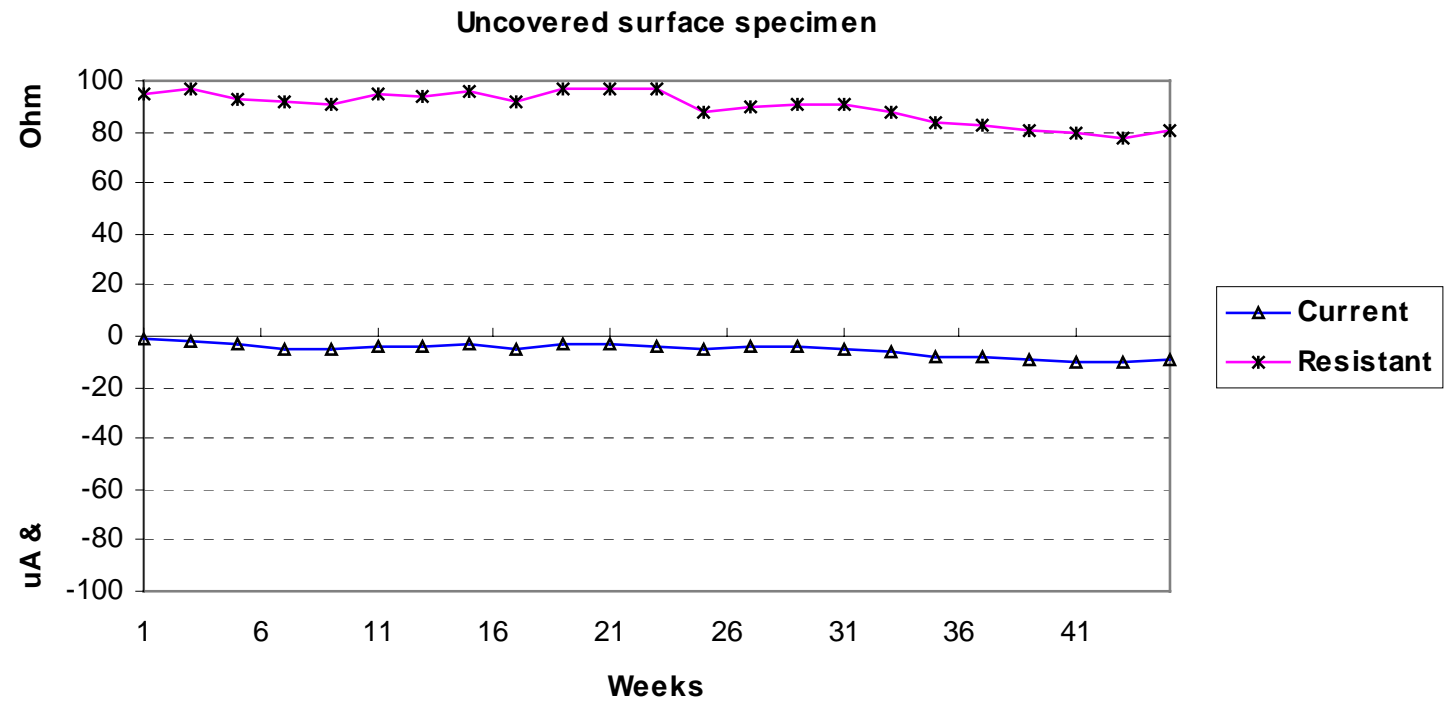

Epoxy covered specimen

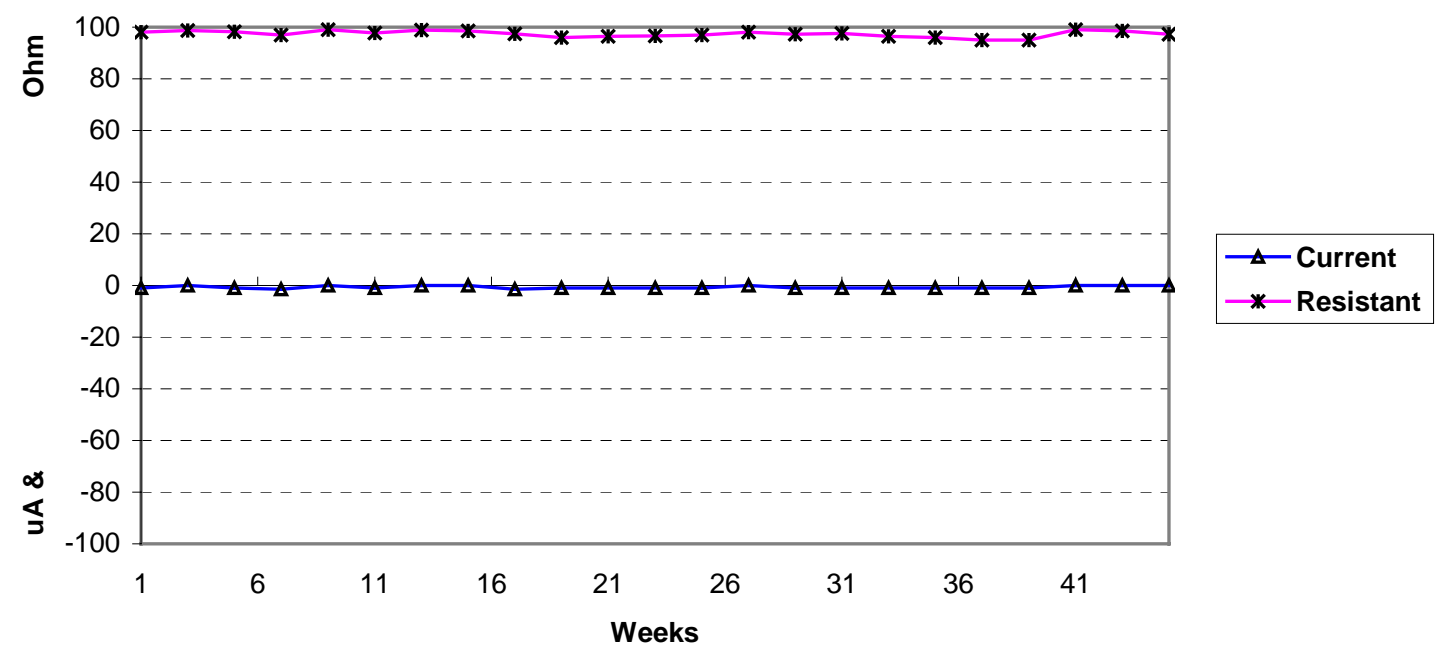

Table 4-9 Corrosion current results 


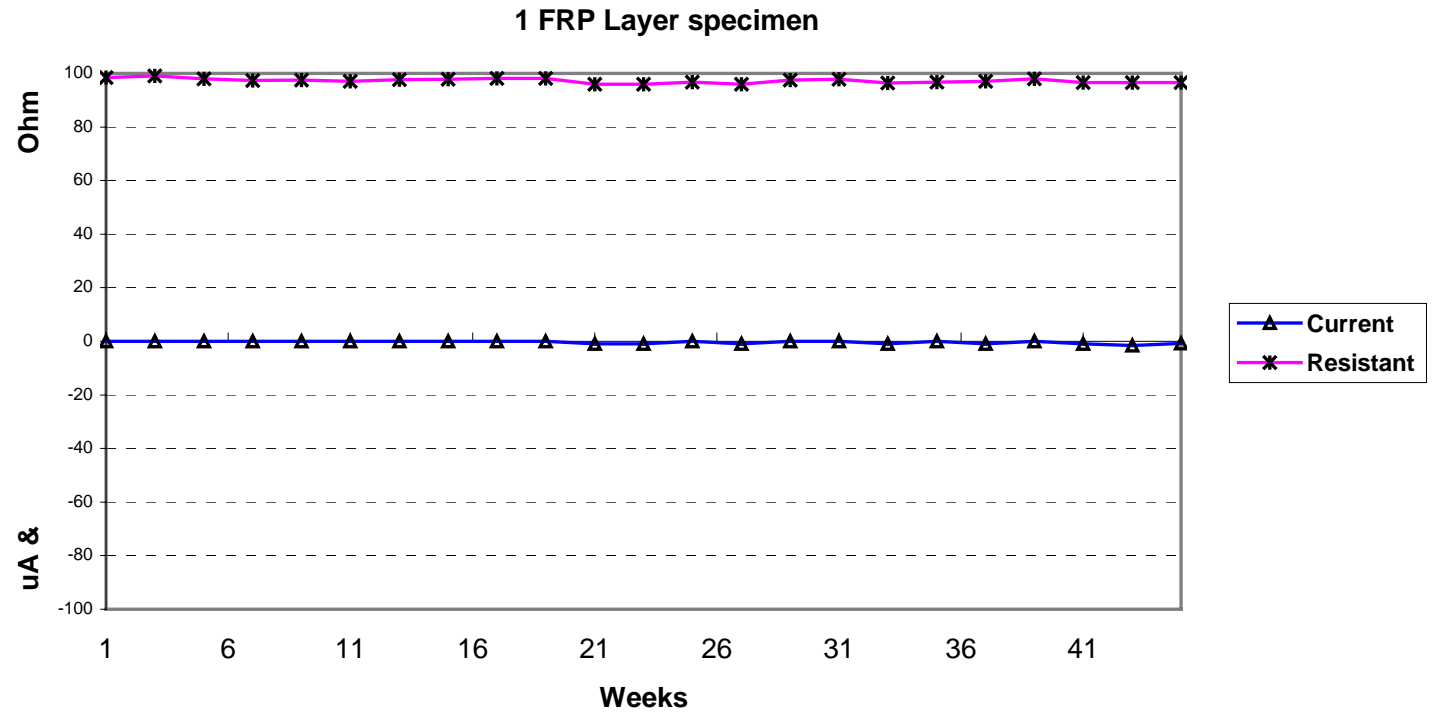

2 FRP Layers specimen

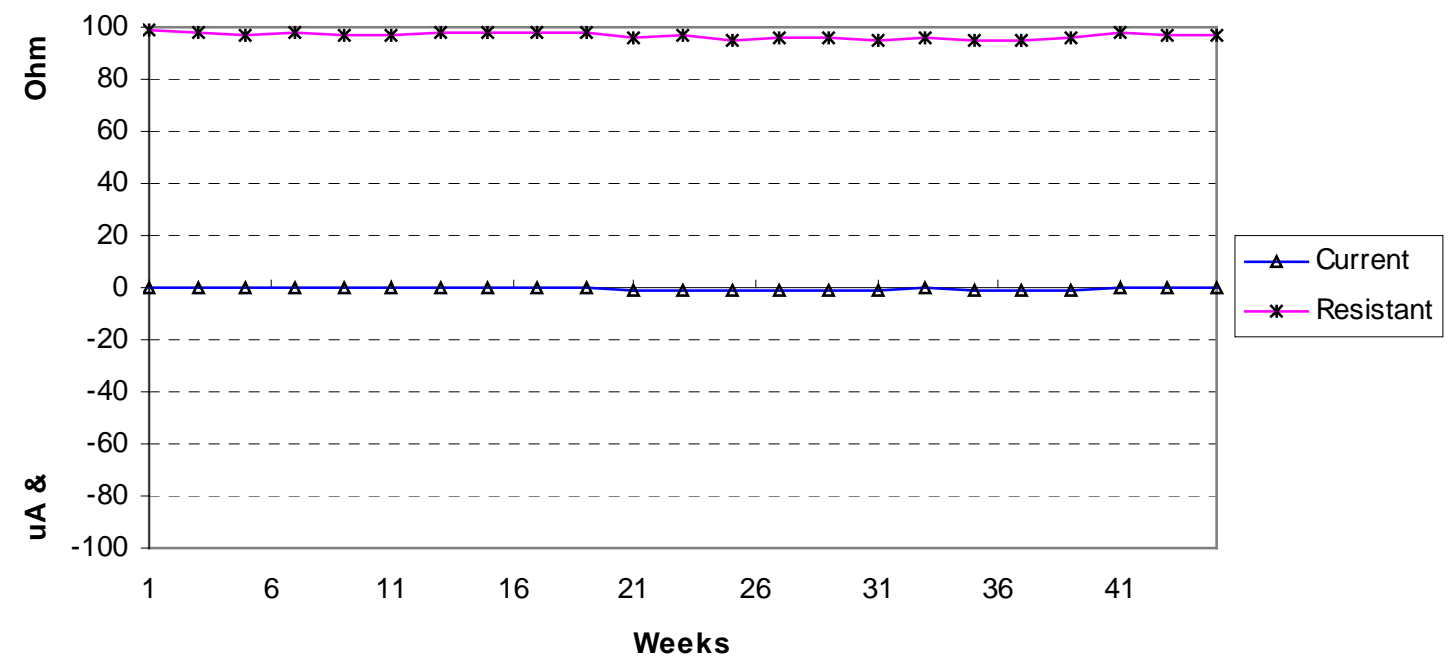

Table 4-10 Corrosion current results 
2 FRP Layers specimen(F-T)
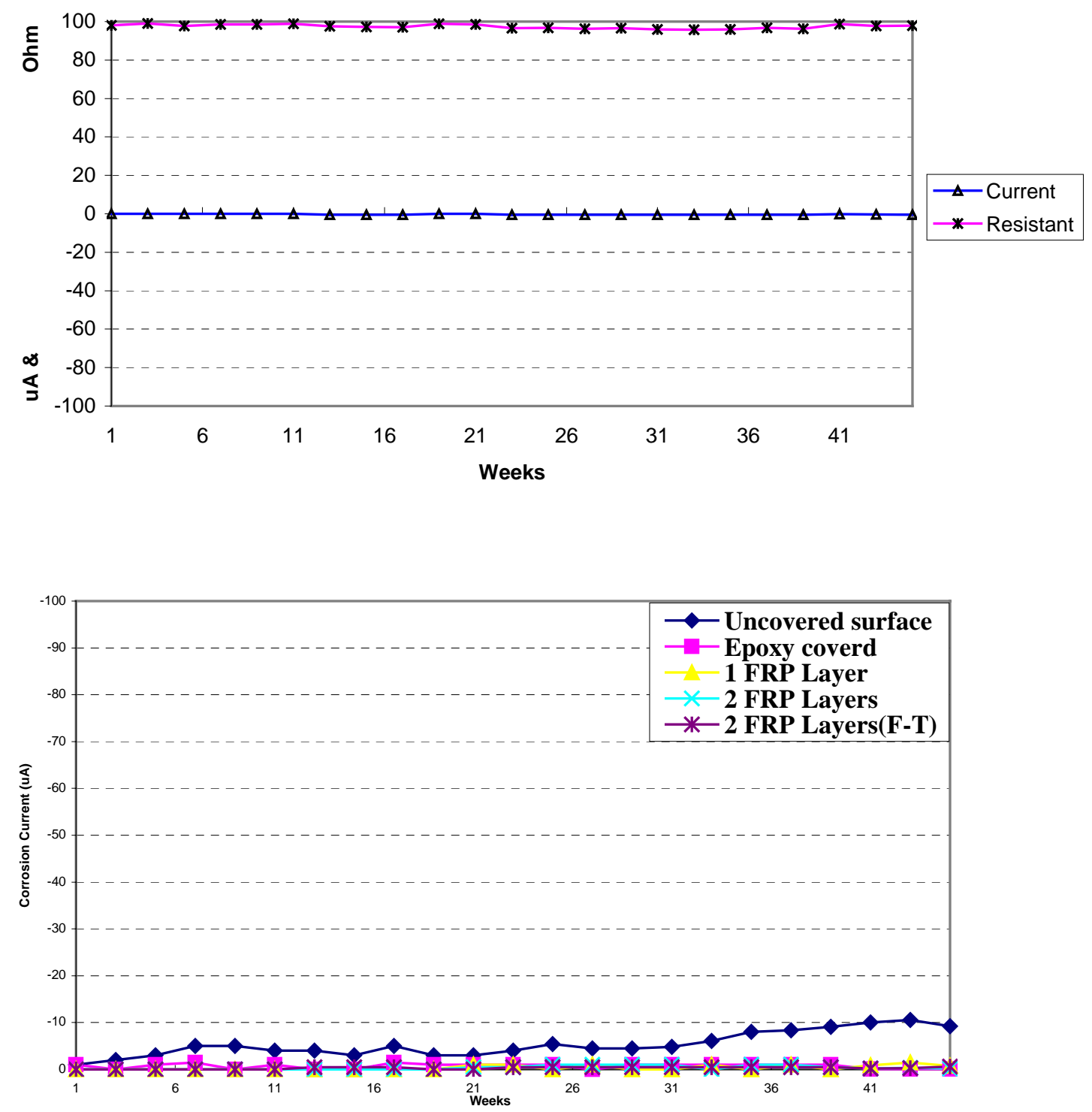

Table 4-11 Corrosion current results 


\section{Anode:}

$\mathrm{Fe} \rightarrow \mathrm{Fe}^{++}+2 \mathrm{e}^{-}$

$\mathrm{Fe}^{++}+\mathrm{OH}^{-} \rightarrow \mathrm{FeO} \cdot\left(\mathrm{H}_{2} \mathrm{O}\right)_{x}$

\section{Rust}

\section{Cathode:}
$\mathrm{O}_{2}+2 \mathrm{H}_{2} \mathrm{O}+4 \mathrm{e}^{-} \rightarrow 4(\mathrm{OH})^{-}$

Air Water

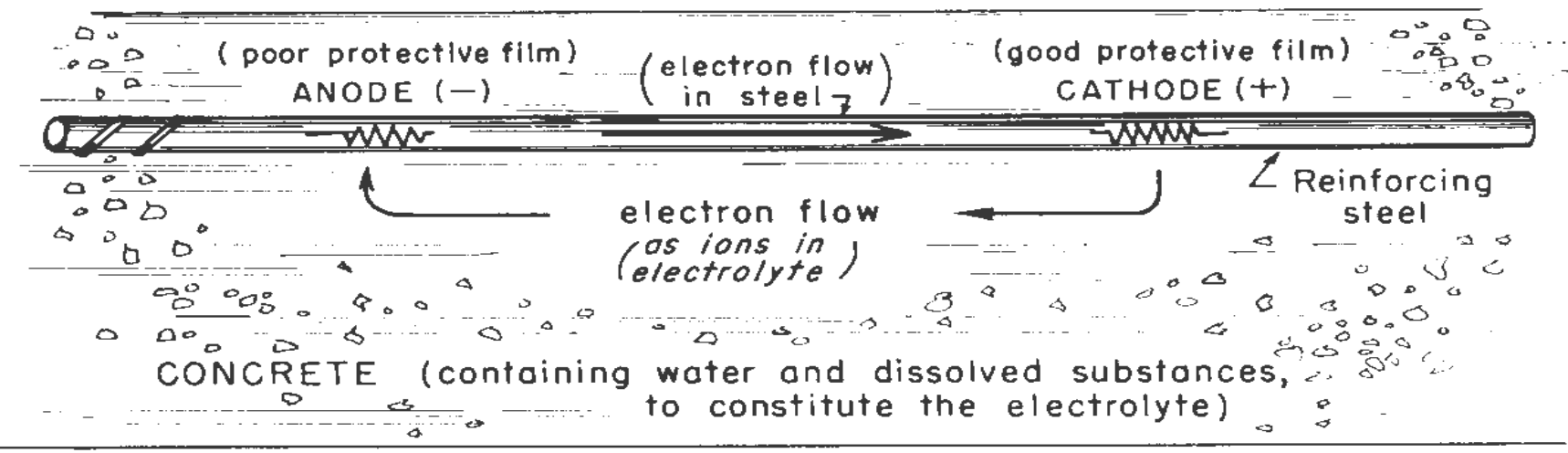

Figure 4-1. Basic processes of corrosion of steel in reinforced concrete 

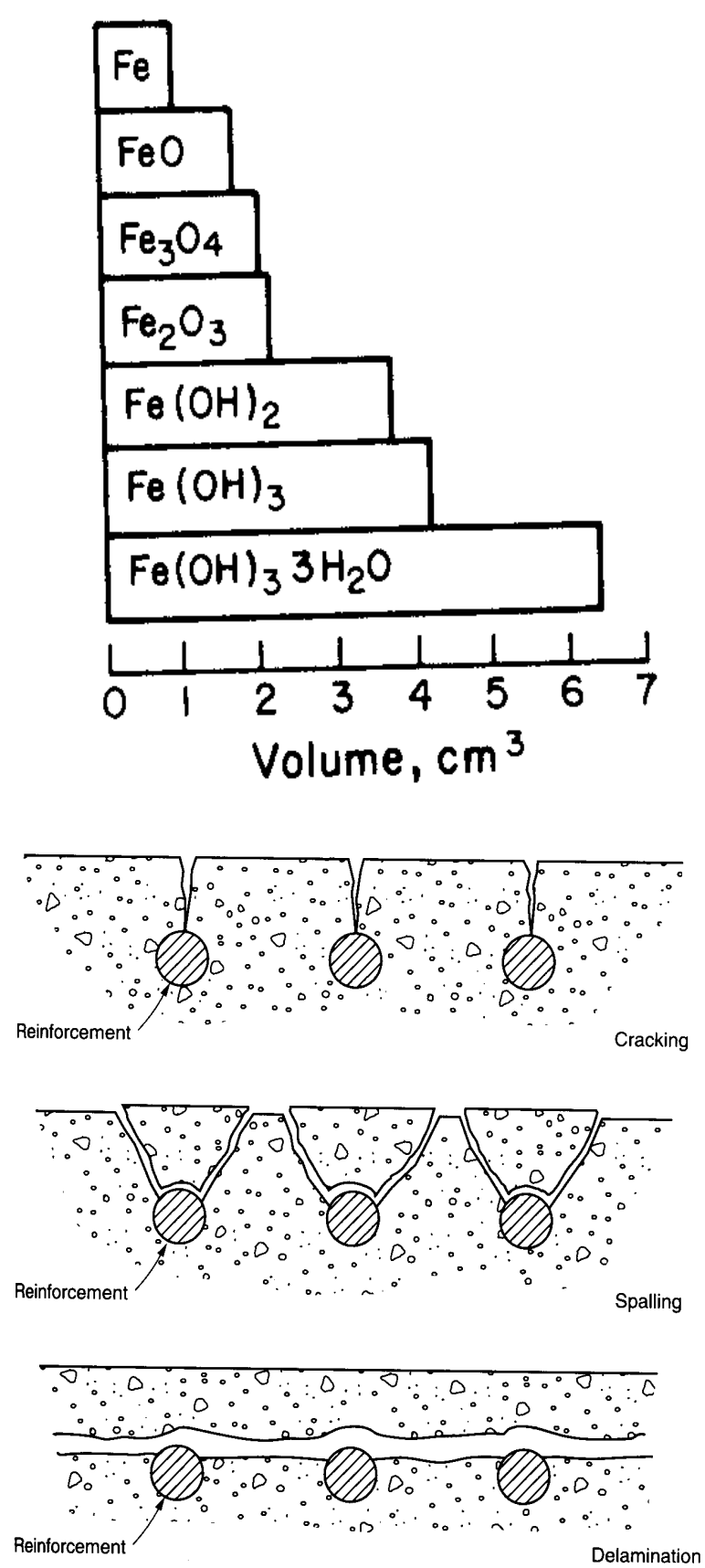

Figure 4-2. Typical consequences of corrosion 

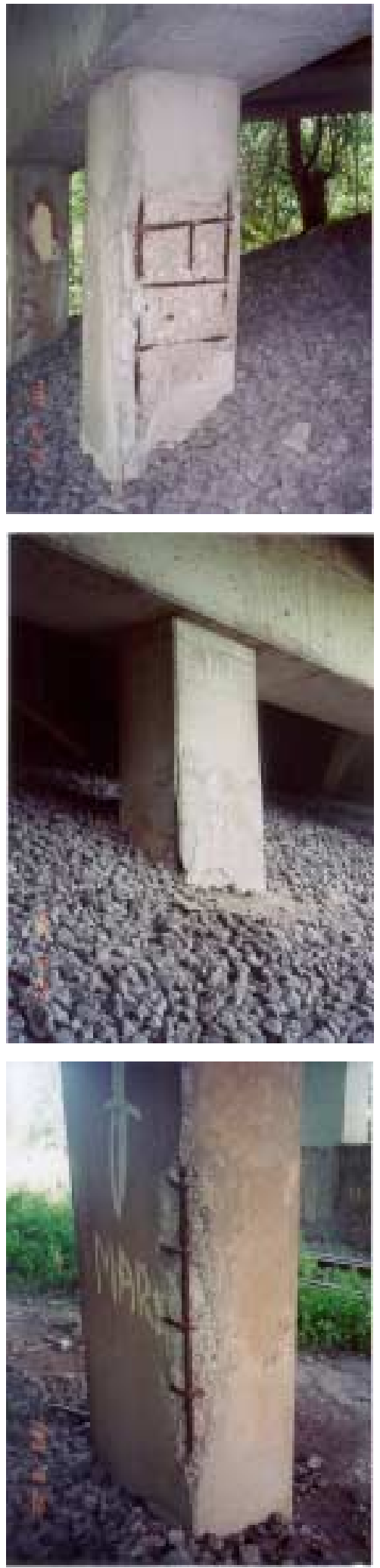

Figure 4-3. Bridge in Gary in Indiana 

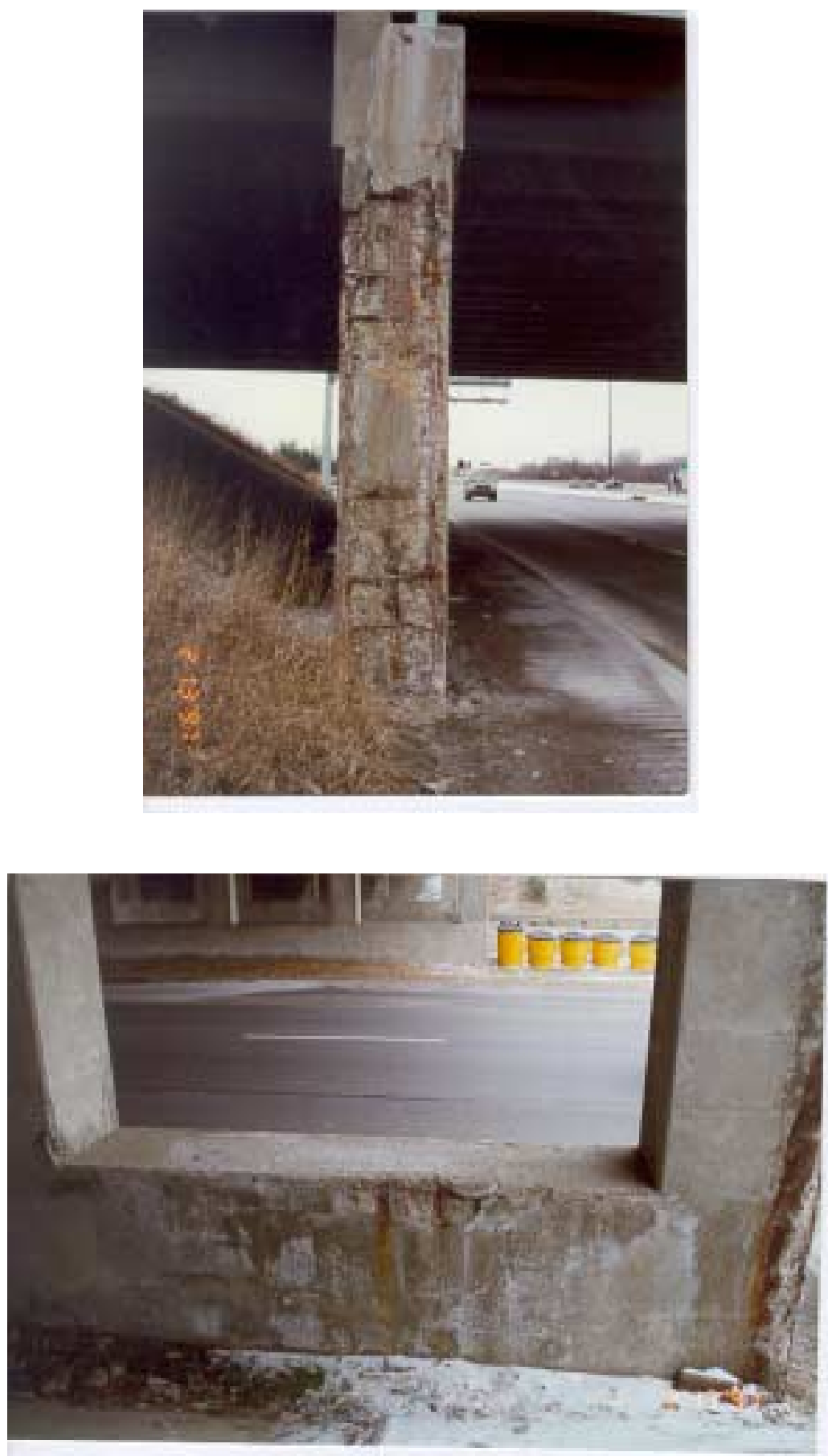

Figure 4-4. Bridge in Fort Wayne in Indiana 

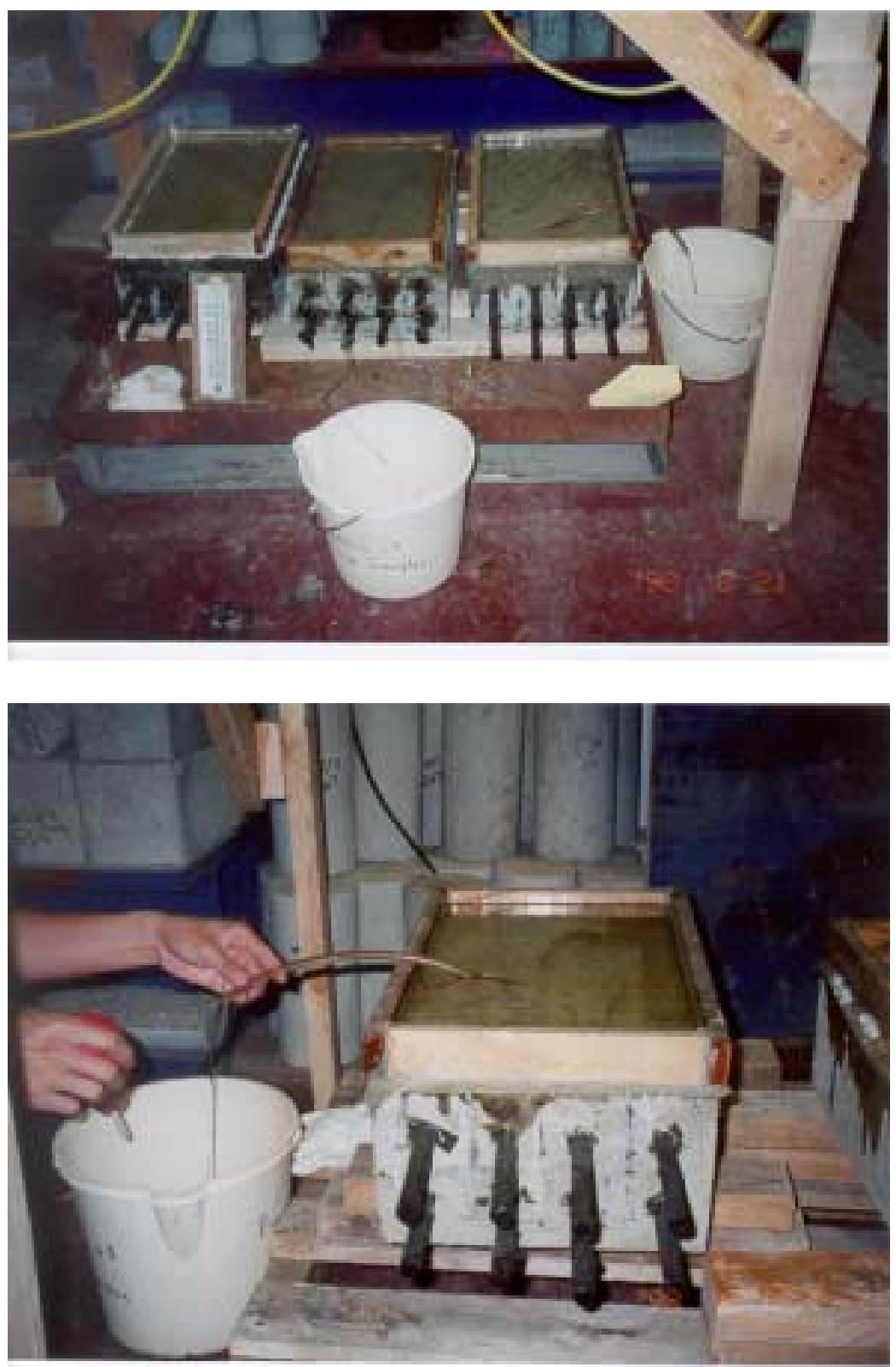

Figure 4-5. Removal of the tap water 

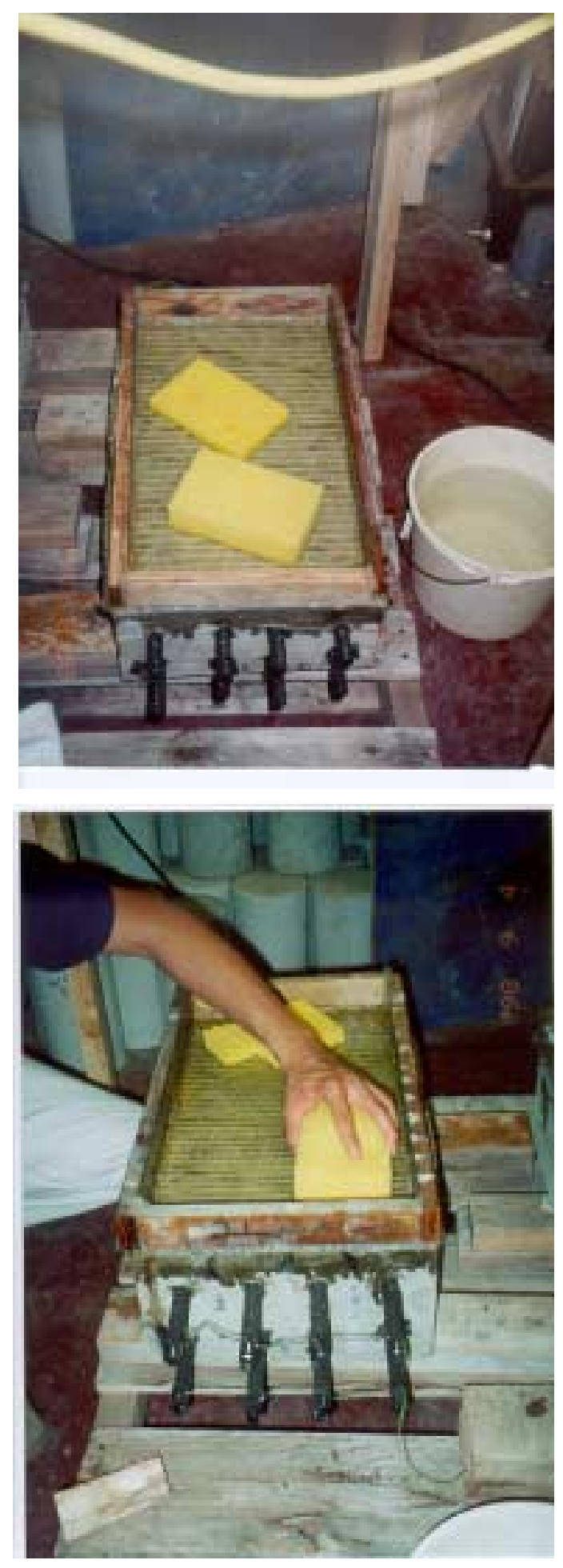

Figure 4-6. Surface drying 

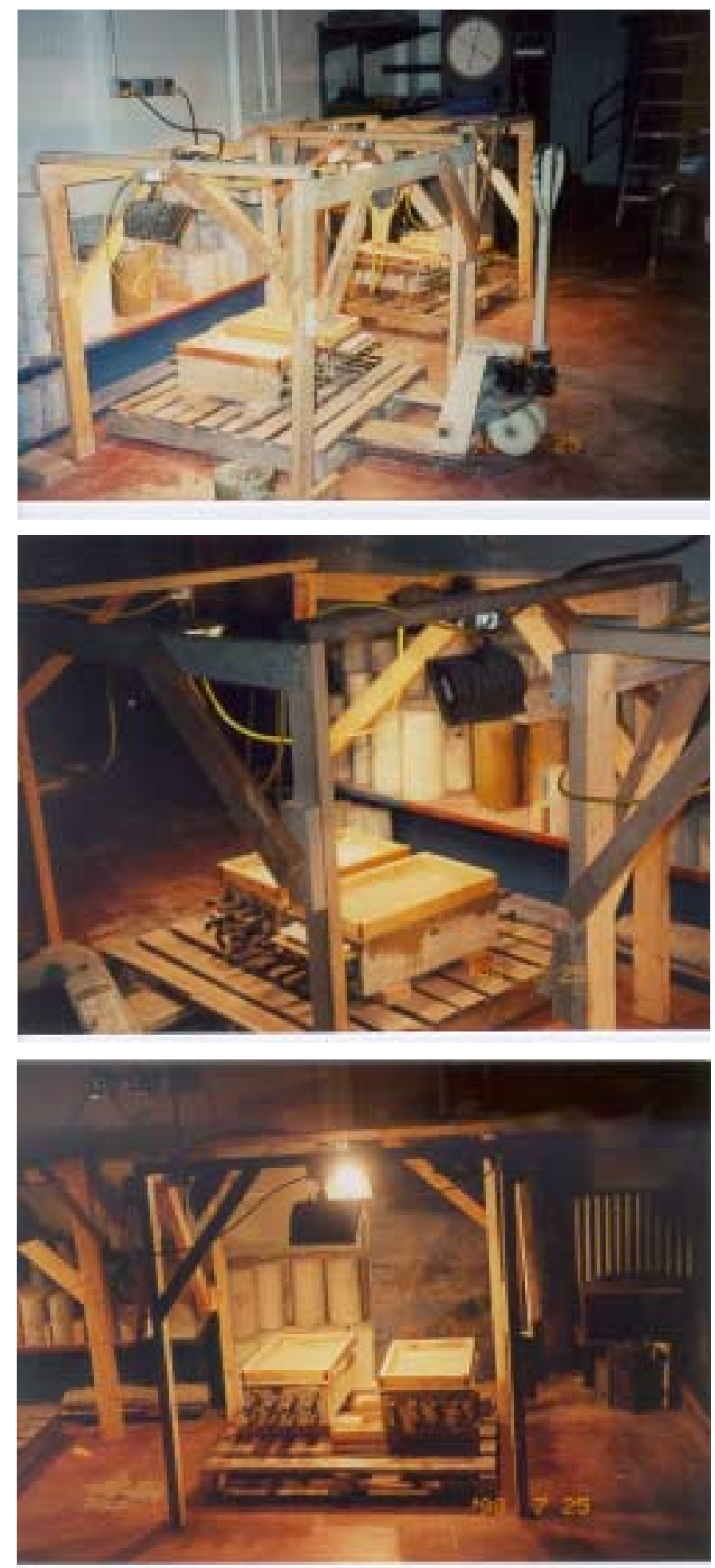

Figure 4-7. Acceleration of the corrosion process and sunny condition simulation 


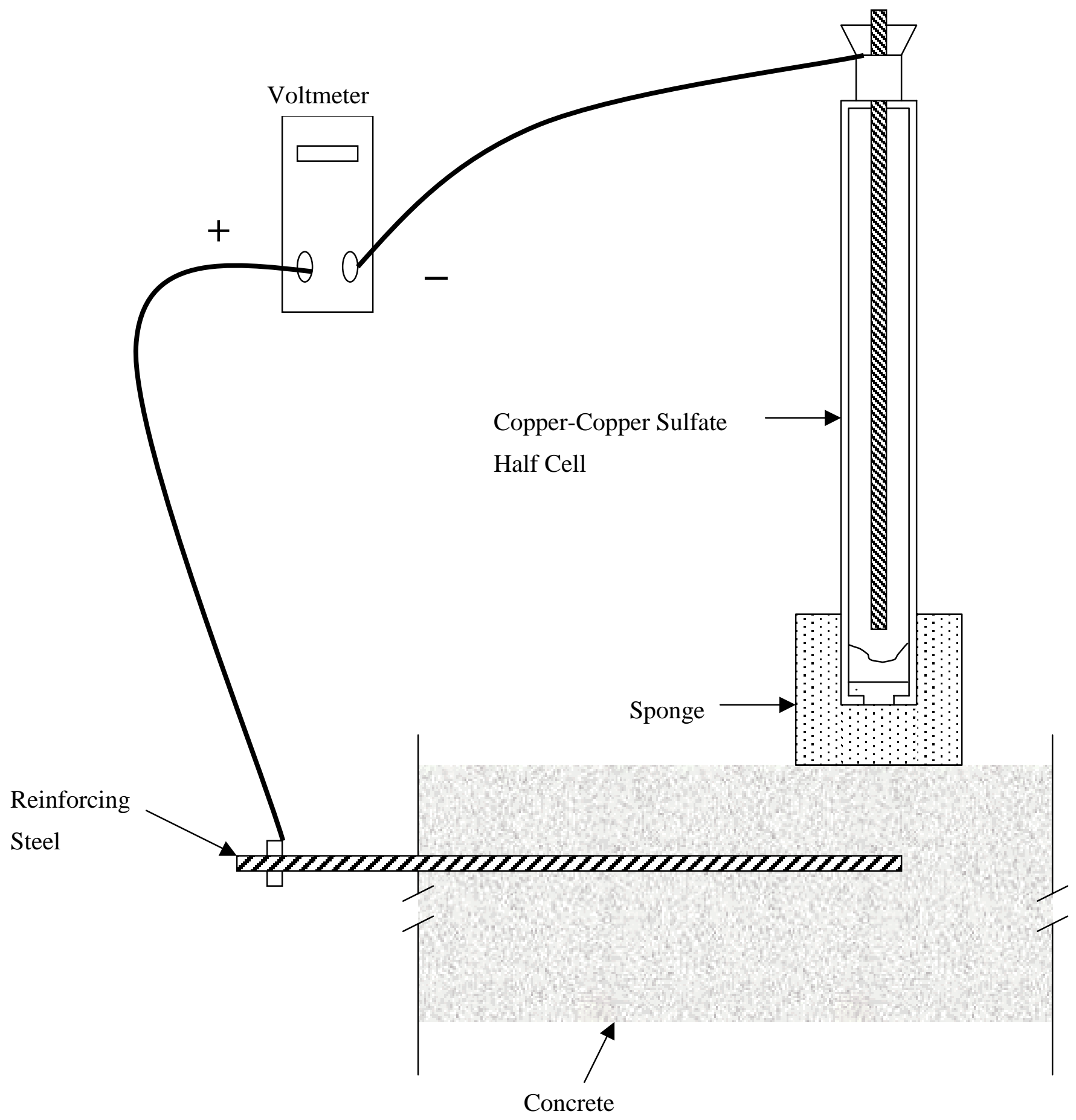

Figure 4-8. Half-Cell Potentials method 


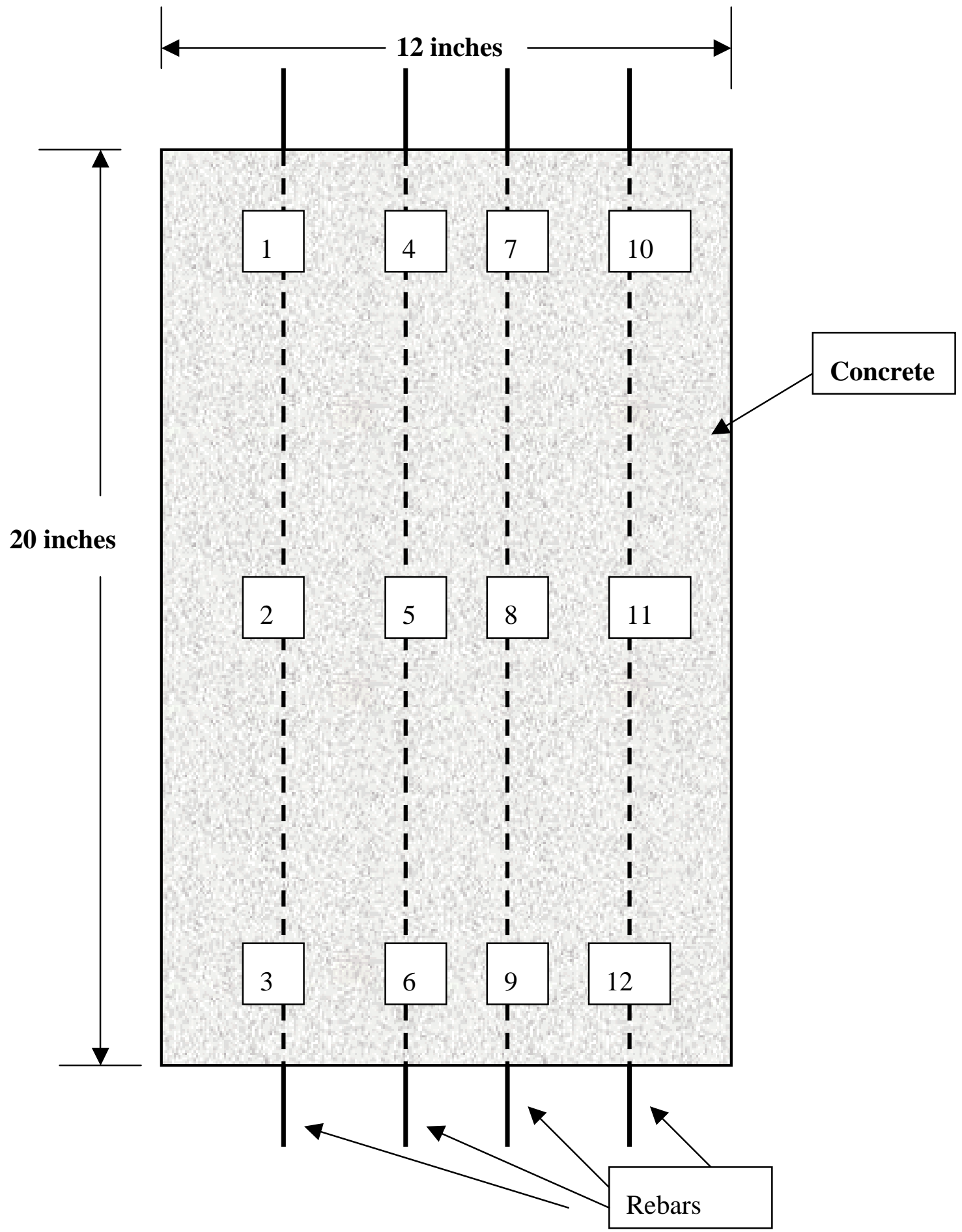

Figure 4-9. Point locations for the half-cell potentials method 

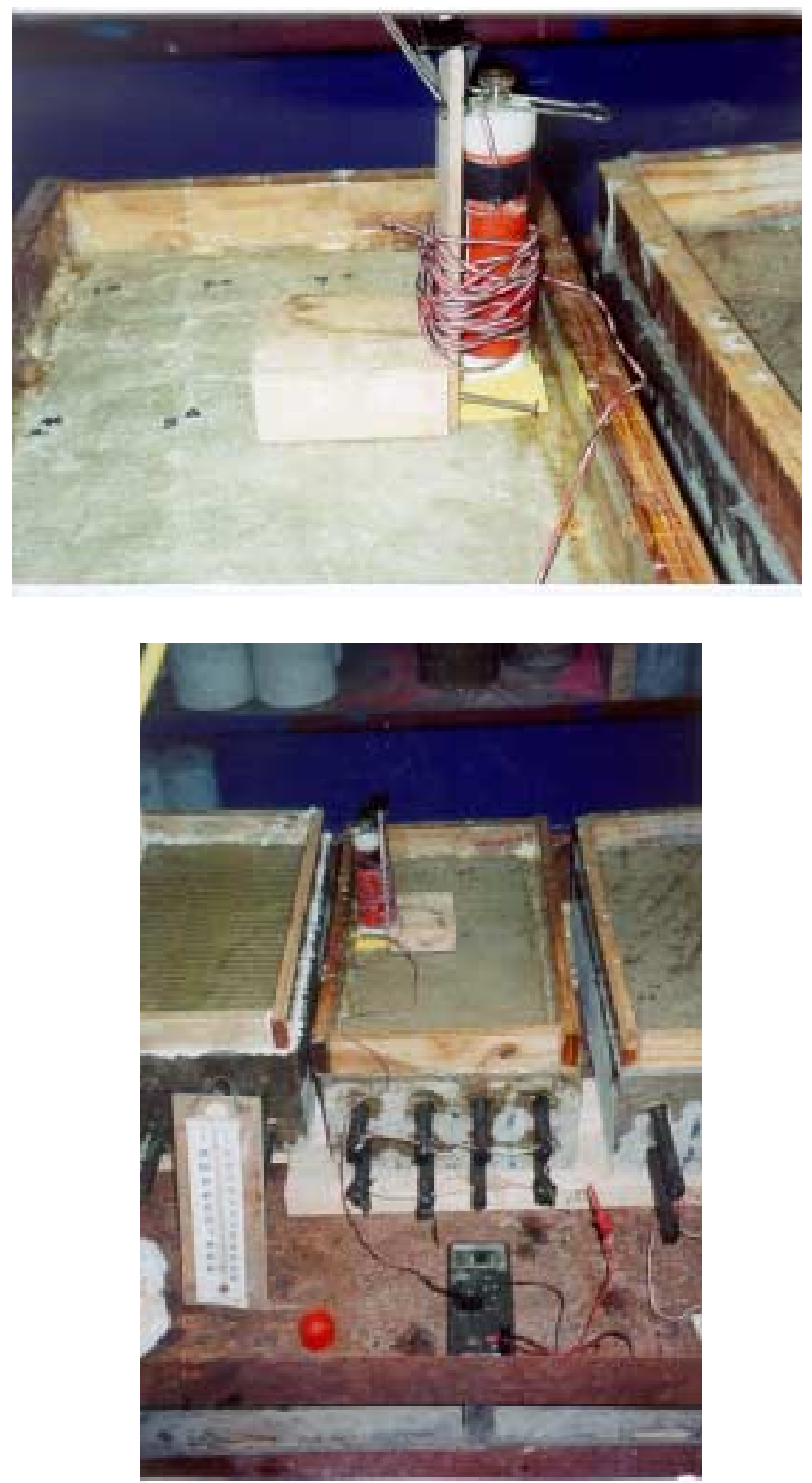

Figure 4-10. The half-cell potentials measurements 


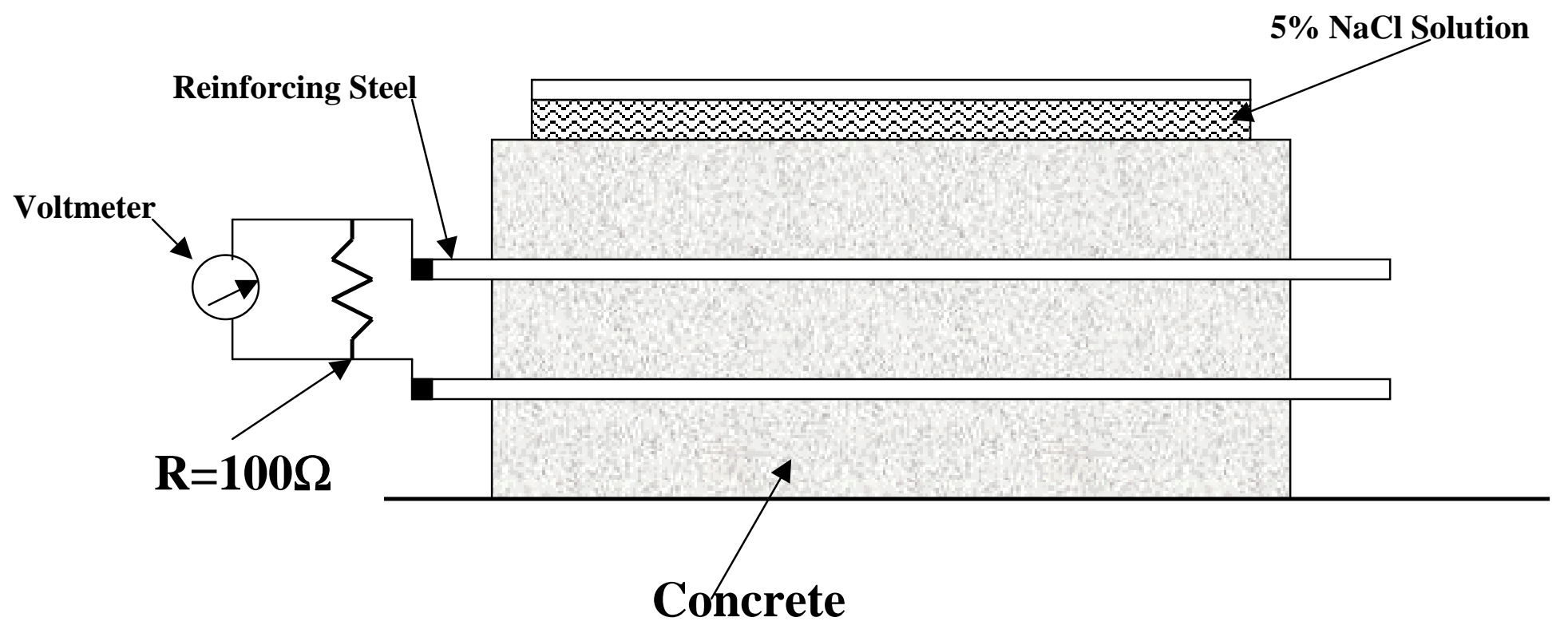

Figure 4-11 The corrosion current method 


\section{CHAPTER 5 Laboratory Tests for Freeze-Thaw Assessment}

\section{Problem statement}

The effective repair or strengthening of civil infrastructure is a major issue worldwide. In the United States, in regions affected by severe weather conditions and where deicing salts are widely used, serious deterioration of existing structures have been occurring. FRP wraps provide an alternative technology for repairing or retrofitting damaged structures. These wraps are made of at least two different materials (for examples: Glass Fibers and Epoxy Resins). So far, most of the research in this area has investigated primarily their strength behavior. While its strength and ductility gain is an important issue, durability should also be assessed, especially in regions where extreme environmental conditions are present. In Chapter 4 the FRP resistance to corrosion has been investigated. Another important issue that affects the durability of these types of retrofits is the fact that they may be subjected to widely varying temperatures (such as $100{ }^{\circ} \mathrm{F}$ to $-40{ }^{\circ} \mathrm{F}$ ). Therefore, the freeze-thaw effect is a crucial factor that must be studied when evaluating this technology.

In addition, because of the different thermal expansion of concrete $\left(\alpha=10 \times 10^{-6} /{ }^{\circ} \mathrm{C}\right)$ and FRP ( $\alpha$ is almost zero) there is a strong possibility of connection failure between the concrete surface and the wrap at extremely low temperatures. Therefore, the low temperature effect has also been investigated as part of this research. 


\section{Brief introduction the freeze-thaw effect}

Pure water freezes at $0{ }^{\circ} \mathrm{C}$ and its volume increases by approximately $9 \%$ when it is converted into ice. If water is present in confined spaces, freezing will generate pressure. The freezing/thawing deterioration in concrete occurs when water in the pores turns into ice and the surrounding solid is therefore under tensile stress. If the induced stress is lower than the strength of the concrete, only this solid mass will have an elastic behavior. Therefore, this increase in volume will be completely released when the ice melts. However, if the induced stress is higher than the strength of the concrete, irreversible changes will occur and part of the volume increase will be irrecoverable. With the increase of the number of freezing and thawing cycles, the irreversible changes will cause damage to the solid such as cracking. Further freezing will then cause therefore increasing the damage to the solid in the form of more cracks.

One method commonly used to improve the freezing/thawing durability of concrete consists of entraining of air in it that is because the hydraulic pressure caused by water turning into ice is released through air bubbles. Also air bubbles can provide sites for ice to safely grow without expansive pressure. Another method consists of using High Performance Concrete (HPC). However, these are short-term solutions and do not successfully prevention damage in concrete in regions of severe weather conditions.

It is important to point out that if concrete were never to be saturated; there would be no danger of damage by freezing and thawing cycles. In reality, though, concrete structures cannot be protected from water such as those produced by rainfall. FRP composite wraps provide an excellent protection against water penetration if they are properly installed. Therefore, FRP composites cannot only provide more strength and 
more ductility, but they can also protect concrete structures, therefore improving their durability.

\section{$\underline{\text { Literature review }}$}

To date, most of the research work on FRP wrapped structural components has focused on strength and ductility. Little research has been to address durability issues due to extreme temperature effects. Some of the related research is discussed below.

The behavior of composite wraps under extreme temperatures is investigated in the work by Karbhari and Eckel [22]. In their research, they tested a series of FRP specimens (6"x12") at low temperature to assess the performance of three types composite, glass, carbon and aramid in cold regions climate. Their results showed that the carbon fiber reinforced plastics (CFRP) performed best in terms of structural behavior among the three.

Soudki and Green [23] have implemented an experimental study to evaluate the freeze-thaw effect of CFRP wrapped concrete specimens (6"x12") subjected to 50 freezethaw cycles. The results showed that the decreasing of strength for CFRP wrapped specimens is much smaller than for unwrapped specimens. Also their results indicate that wrapped specimens subjected to the freeze-thaw cycles appeared to have a more catastrophic failure when compared to the one kept at room temperature.

Toutanji and Balaguru [24] have performed an experimental study on the durability of concrete columns (6"x12") wrapped by two types of FRP sheets - glass and carbon (GFRP and CFRP). These specimens were separated into three groups according to different environmental conditions: (1) room temperature; (2) 300 wet-dry salt water 
cycles, and (3) 300 freeze-thaw cycles. The results from these tests were compared and it was found that CFRP experienced no strength and ductility reduction for wet-dry exposure, whereas GFRP experienced strength and ductility reduction. Both CFRP and GFRP experienced significant reductions in strength and ductility due to temperature cycles.

Liao et al. [25] have studied the long-term behavior of bar specimens (5"x0.5" 0.25 ") in terms of fatigue, freeze-thaw and salt spraying. The specimens wrapped with GFRP/vinyl ester or GFRP/polyester were separate into two groups - one set of specimens was sealed with an epoxy sealant on the edges and the other was not sealed on the edges. All the results compared to unconditioned specimens showed that for both groups there was a reduction in flexural strength/modulus and toughness, while the dynamic modulus remained almost unchanged. However, the reduction in the sealed specimens was lesser than in the unsealed ones. Besides, it was found that GFRP/vinyl ester specimens were more durable than the GFRP/polyester specimens.

\section{Experimental procedure}

The effect of freeze-thaw cycling on TYFO-S (GFRP) wraps used for repairing or strengthening columns has been investigated. This has been accomplished by testing a number of concrete specimens wrapped with GFRP.

\section{Material properties}

The TYFO-S wraps used in the experiment are composed of glass fibers mixed with aramid fibers, and mixed with epoxy during application. A thorough description of this type of material has been given in chapter 2 . 


\section{Specimen preparation}

The following specimens have been tested: thirty 6 " in diameter by 12 " in length circular cylinders and seventeen 3 " $\mathrm{x} 4$ "x15" small beams. As mentioned in chapter 2 , the specimens were divided into two groups before wrapping, the specimens in one group were air-dried and the specimens in the other group were wet cured after 14 days.

The epoxy used in the experiments consisted of resin and hardener mixed at a ratio of 2:1. A mechanical mixer was used to thoroughly mix the components to form the epoxy system. The concrete cylinders were cleaned and surface dry at the time of application of the wraps. The GFRP wraps were soaked into the epoxy system tank for total impregnation. A thin layer of epoxy was applied to each concrete cylinder. A GFRP sheet was then applied on its surface. To avoid the development of voids between the sheet and the concrete surface, hand pressures was applied at each layer. In all cases (1 layer to 3 layers), the overlap length of the outside layer was approximately 3 in $(80 \mathrm{~mm})$ [26] to ensure the development of full composite strength.

Group 1: The control specimens were uncovered samples, which were not subjected to any extreme environmental condition. Group 2: Air-dry cured specimens were wrapped either with one to three layers of GFRP or with epoxy alone. Group 3: Wetcured specimens were wrapped either with one and two layers of GFRP or with epoxy alone.

\section{Specimen model}

Water cannot generally penetrate real bridge columns through their ends. Since other researchers have only performed experiments on cylinders with free ends, tests on specimens with covered ends have been conducted in the present work. In these 
experiments, this impermeability has been simulated by covering the ends of the cylinder specimens with epoxy. This also simulates the cases in which the beam-column regions (caps) are wrapped with FRP.

\section{Test procedures}

To study the influence of the different coefficients of thermal expansion of the constituent materials, the specimens were subjected to 50 "Low to Normal" temperature cycles. More specifically, the specimens were kept at $32{ }^{\circ} \mathrm{F}$ for 8 hours during the night and at room temperature for 16 hours during the daytime (Figures 5-1 and 5-2). After 50 cycles, the specimens were instrumented with strain gages and axial compression tests were conducted to determine the stress-strain relation.

For the freeze-thaw tests, the procedure given in reference [27] was modified to conform to the specifications in ASTM C666 [28]. The specimens were placed in a freezer room at Purdue University overnight in which the temperature was decreased gradually to $\mathrm{OF}(-18 \mathrm{C})$ for 16 hours. They were removed the next morning and thawed in a water bath at room temperature for 8 hours. After 50 freeze thaw cycles, all specimens were instrumented with strain gages and axial compression tests were conducted.

All specimens were brought to room temperature before being tested. The uniaxial compression tests were conducted until failure, using the hydraulic testing machine. Axial and circumferential strain gages at the center points were installed in all specimens. All strain gages were mounted using standard procedures [29]. The specimens with GFRP wraps were capped using a sulfur mix on their two ends to provide smooth and horizontal surfaces. The strains and the corresponding axial load were recorded during the tests by means of an automatic data acquisition system. 
The seventeen 3"x4"x15" small beams shown in Figure 5-3 were tested for 300 freeze-thaw cycle tests at the Freeze-Thaw Concrete laboratory at INDOT (Indiana Department of Transportation). Those specimens were also divided into two groups, free ends and covered ends and follow the specifications given in ASTM C666 [28].

\section{$\underline{\text { Results }}$}

Table 5-1 gives the results for all 3"x4"x15" small beams subjected for 300 freezethaw cycles after 10 days curing. These small beams were mixed by hands and the compaction was not good. Their surface contained numerous pores, so the qualities for those specimens were poor. The main goal of this test was to show that even poor quality beams (damaged structures), recover their strength when wrapped with FRP. From this test, it can be shown that FRP can potentially be used to successfully repair severely damaged structures. Figure 5-3 illustrates the processes involved in the freeze-thaw testing.

For the 6"x12" cylinders, the results from the test have been plotted into charts. All the charts show the variation of axial stress with axial strain, on the right side, and of axial stress with radial strain, on the left side. The stresses are given in lbs per square inches (psi) and the strains are given in inch per inch (in/in).

Figures 5-4 to 5-7 show the stress-strain behavior during the compression tests. All these figures correspond to low temperature-room temperature cycles, for the four cases tested: epoxy covered and one to three GFRP layers. In these figures, RT means room temperature and LT means low temperature. As it can be seen from these figures, in all cases the thermal changes did not affect much the overall behavior of these systems, i.e. 
the difference is of the order of $5 \%$. In fact, it can be seen that the stresses and the ductility are slightly higher at low temperature than those in the system cured at room temperature. Therefore it can be concluded that concrete gained strength at low temperatures.

Figures 5-8 to 5-11 illustrates the effect of freeze-thaw cycles on the epoxy covered specimen and on the specimen wrapped with one to three layers of FRP, respectively. FT is used in these figures to indicate freeze-thaw. As it can be seen from these figures, freeze-thaw cycles have almost no effects on the ultimate stress, but it clearly reduces ductility of the specimens.

Figures 5-12 and 5-13 show the effects of thermal change on the columns when they are wrapped during their curing time. The data shows a slight reduction in stress when compared to the specimens wrapped after curing.

Figure 5-14 depicts the stress-strain behavior for all the wrapped specimens under freeze-thaw conditions and Figures 5-15 to 5-17 show the failure modes for all tested specimens. For the cases of one to three layers, the failure modes were such that failure occurred within the central region of the height of the column. However, for the one layer specimen, one failure occurred at the top region.

From Figures 5-1 to 5-14, it has been observed that the axial strain is approximately the same as the radial strain. The stress-strain relationship show that there is almost no change in stiffness when applying the GFRP wraps. This is excellent benefit when compared to steel jackets. Also, the stress-strain relations can be approximated by means of a bi-linear curve for the confined concrete cylinders. It can also be inferred that the wrapped specimens have more energy absorption capacity before failure; however, the 
failure for one to three layers was sudden without much warning. Even though some noises were heard approximately at the time when the stress-strain curve reached reach another slope, but the specimens were still able to carry more load. Therefore, a drawback of the wrapping technique is the difficulty in predicting when a wrapped specimen is about to fail. The failure mechanism in all cases consisted of the breakage of the composite wraps, and crushing of the concrete inside. However the composite jackets kept the concrete in the specimens from spalling (see Figures 5-15 to 5-17).

\section{$\underline{\text { Conclusions }}$}

Durability tests have been conducted in order to investigate the potential of using FRP composites as a material for rehabilitation or for strengthening of structural members under severe environmental conditions. The influence of the thermal cycles and freeze-thaw exposures on GFRP-wrapped concrete specimens has been thoroughly evaluated. The following conclusions can be drawn from the results of these tests.

1. The long-term durability characteristics of GFRP composites as repair materials are one of the main reason why it can be successfully used as a retrofit.

2. FRP wraps can successfully be used to:

(a). Restore at least the initial strength of the structure (ductility), and to

(b). Protect concrete and steel reinforcement from severe environmental conditions such as corrosion and freeze-thaw (durability).

3. Exposure to low temperature cycles can slightly improve the strength and ductility for fresh concrete. However, since this is a small improvement it should not be considered in design. 
4. Since the two ends of the specimens tests were protected by epoxy, therefore preventing water penetration, it was expected that exposure to freeze-thaw cycles would have no effect. Even though this is true for strength, degradation of the ductility has been observed.

5. The failure of the wrapped specimens was sudden without much warning. 
Table 5-1. Results from freeze and thaw cycles on seventeen 3"x4"x15" small beam specimens.

Small Beam--
Freeze Thaw
\begin{tabular}{||c|c||c|c|c|c|c||}
\hline \\
\hline & Total No. Of Specimen & Very Good & Good & Not good & Bad & Very bad \\
\hline A-1L & 2 & 1 & 1 & & & \\
\hline A-2L & 2 & 2 & & & & \\
\hline W-1L & 2 & 2 & & & & \\
\hline W-2L & 1 & & & 1 & & \\
\hline A-E & 2 & & 2 & & & \\
\hline W-E & 3 & 1 & 1 & 1 & & \\
\hline A & 3 & & 1 & 1 & & 1 \\
\hline W & 2 & & & & & 2 \\
\hline
\end{tabular}



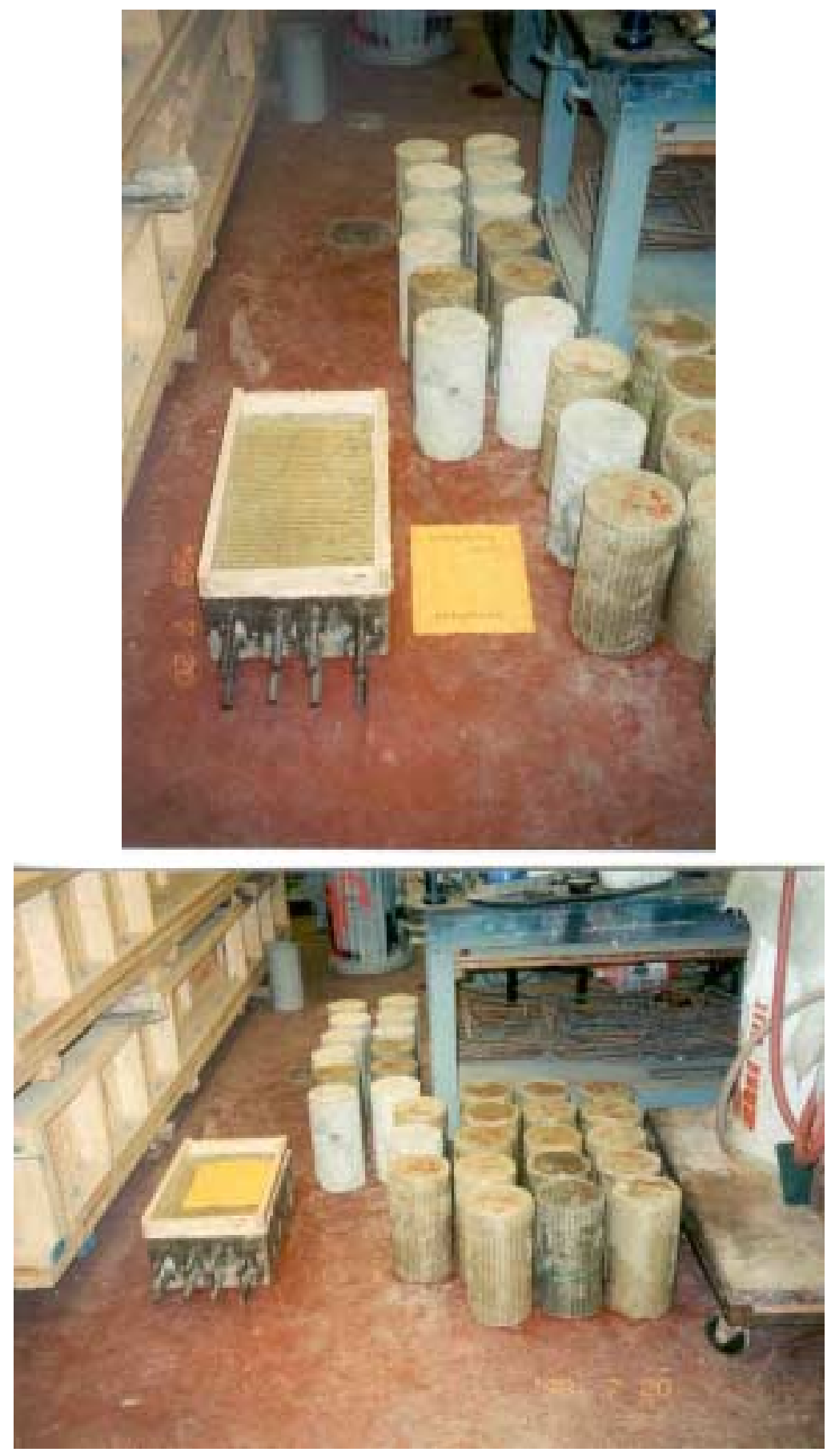

Figure 5-1 Low to room temperature cycle tests. 

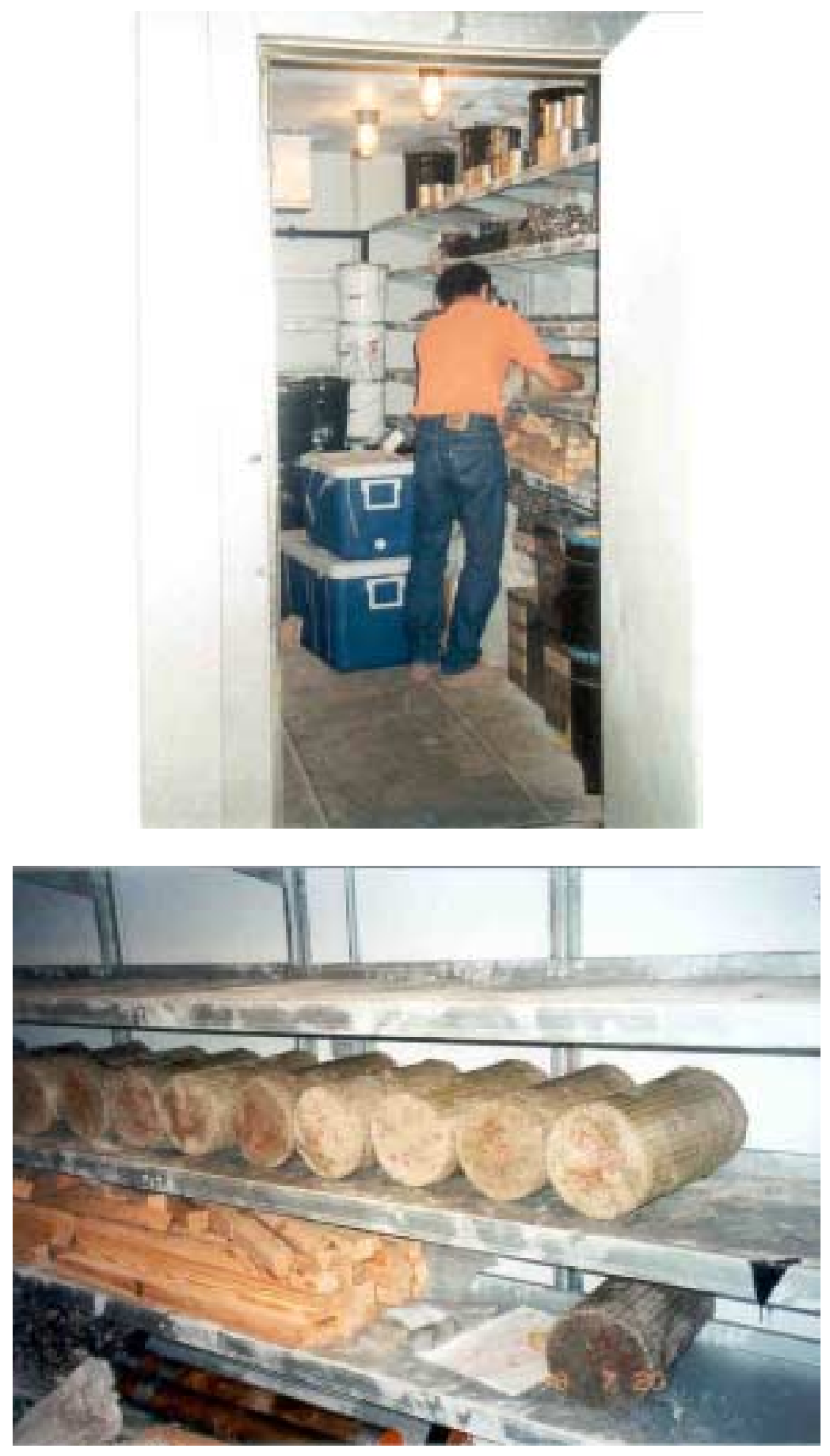

Figure 5-2 Low to room temperature cycle tests. 

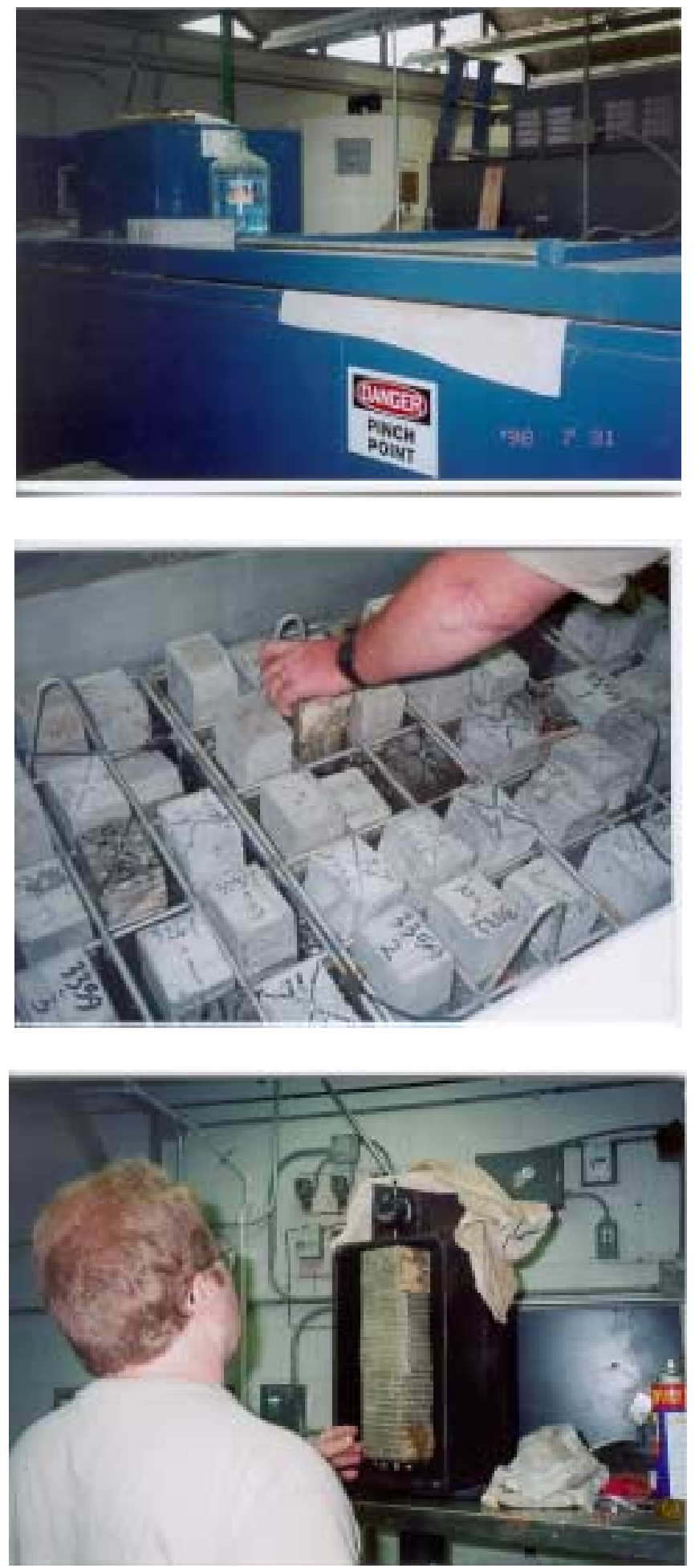

Fig 5-3 Freeze-thaw tests at Freeze-Thaw Concrete Laboratory at INDOT. 


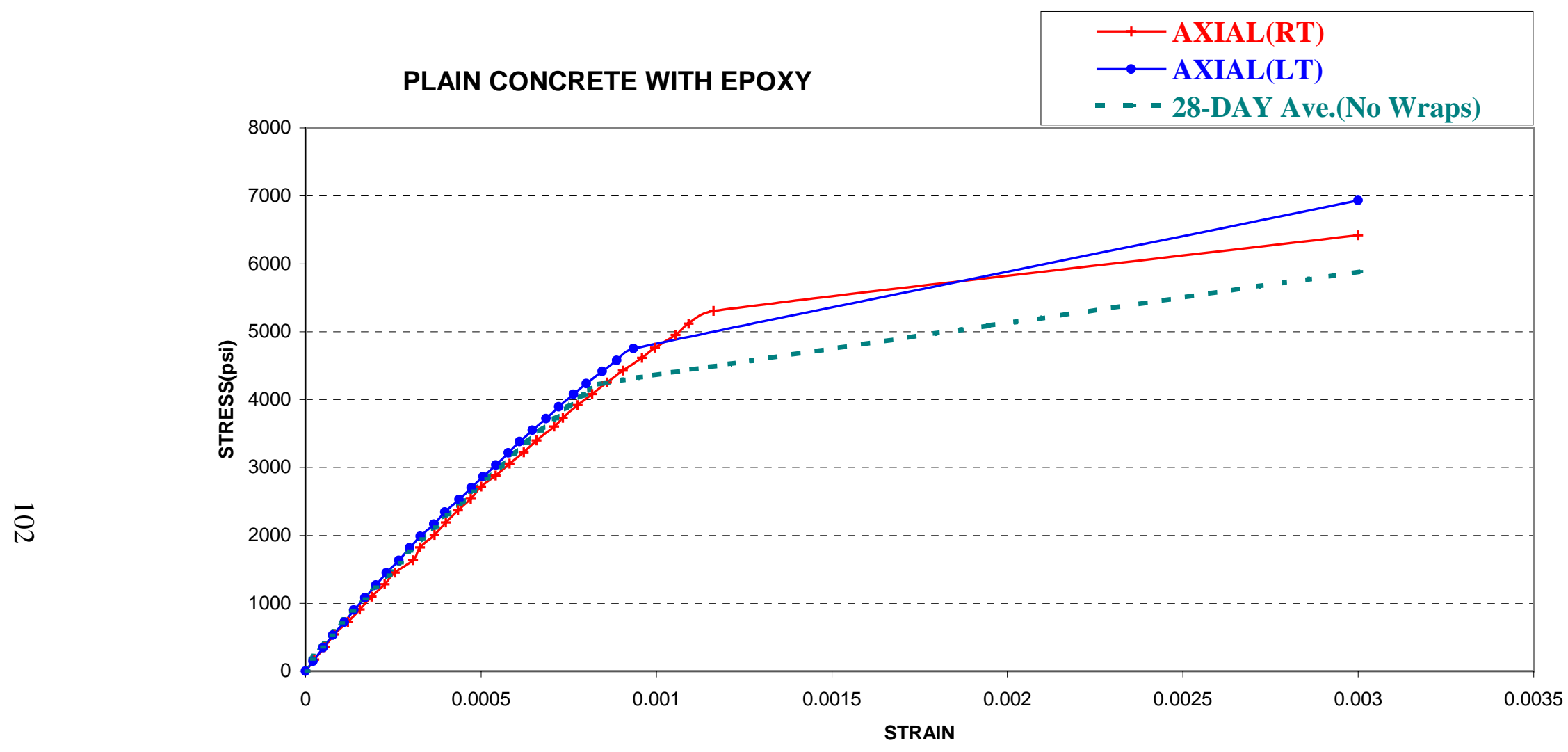

Figure 5-4 Stress-strain relationships for plain concrete with low temperature cycles. 


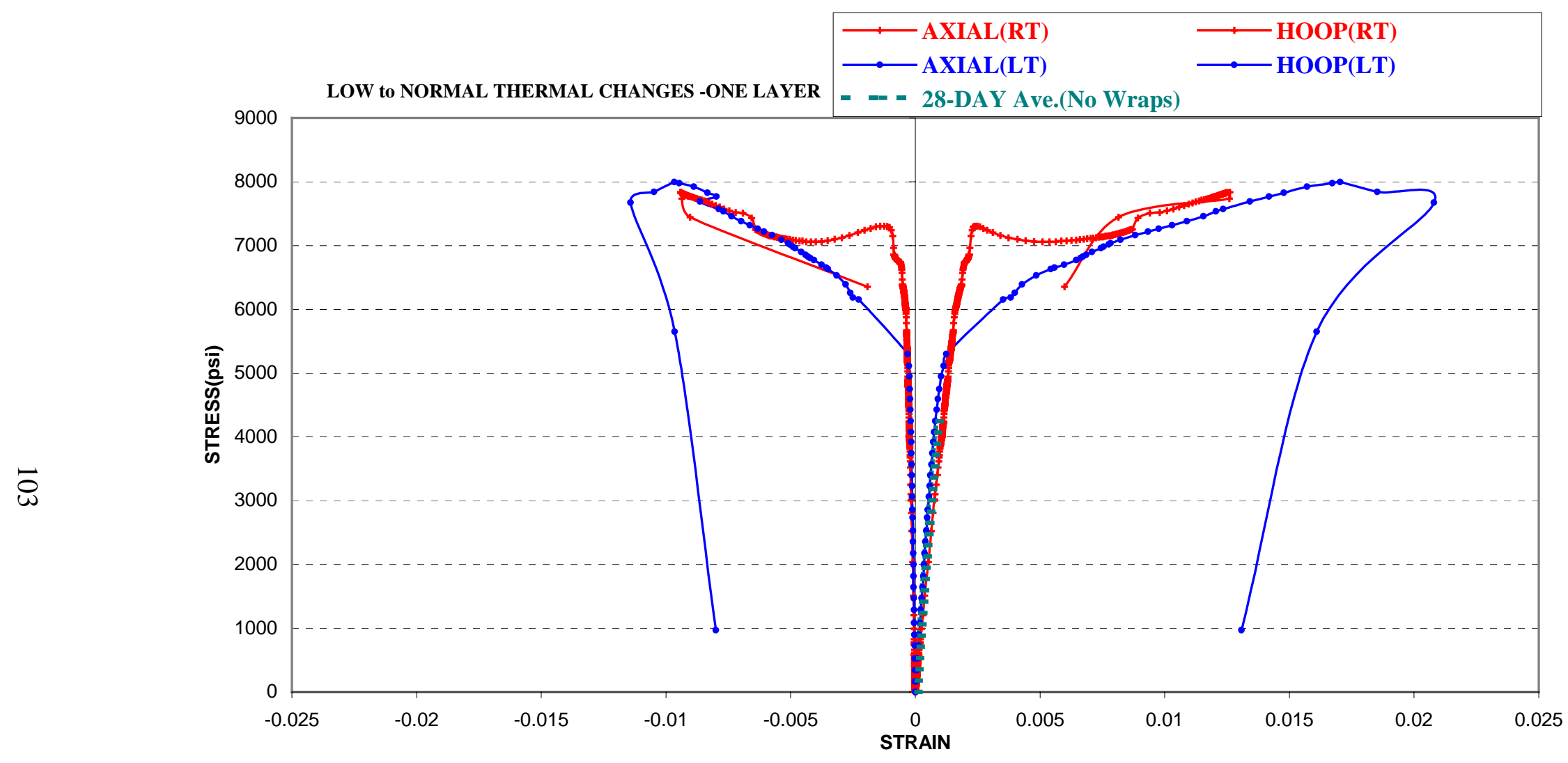

Figure 5-5 Stress-strain relationships for one layer with low temperature cycles. 


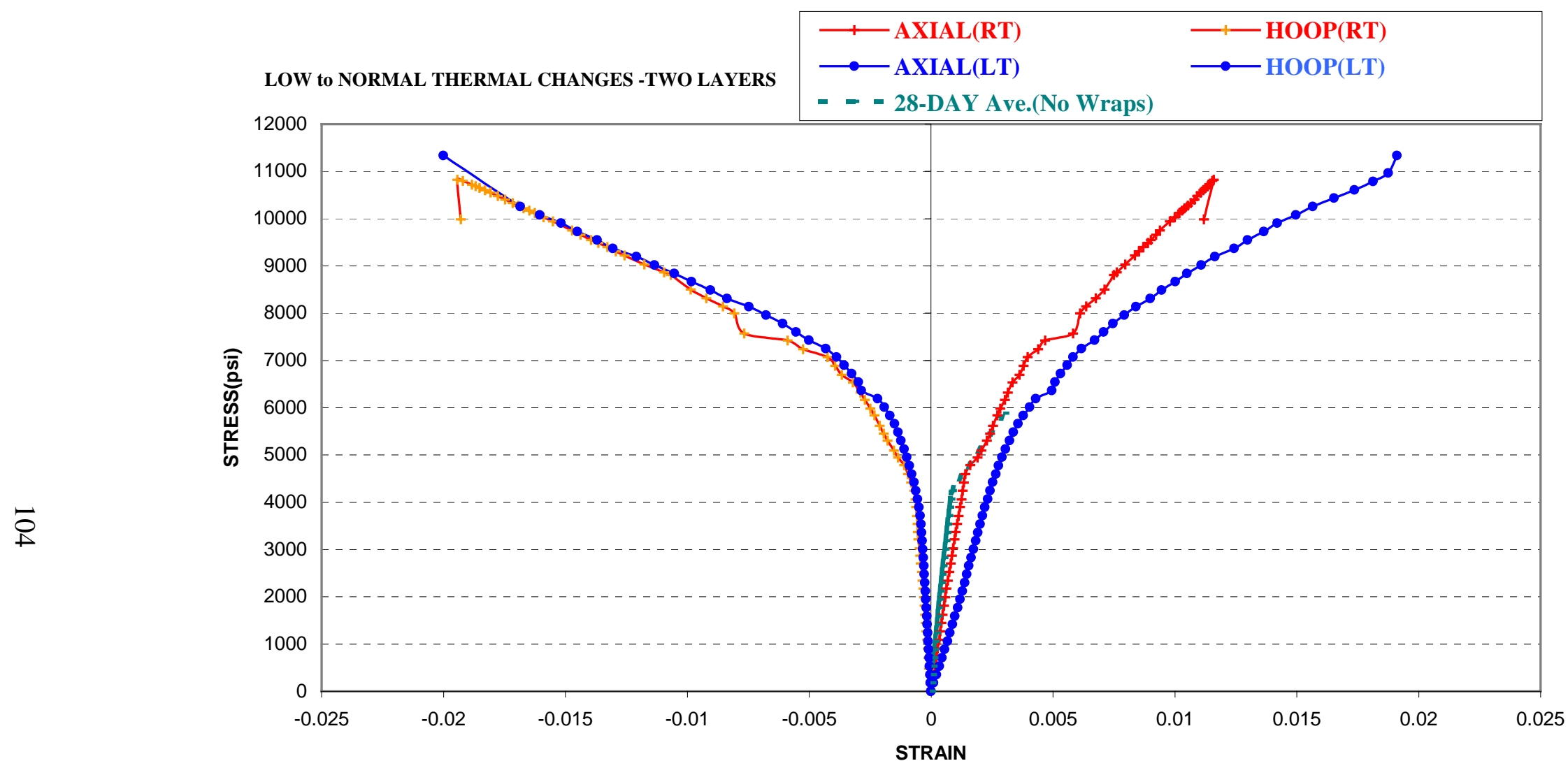

Figure 5-6 Stress-strain relationships for two layers with low temperature cycles. 


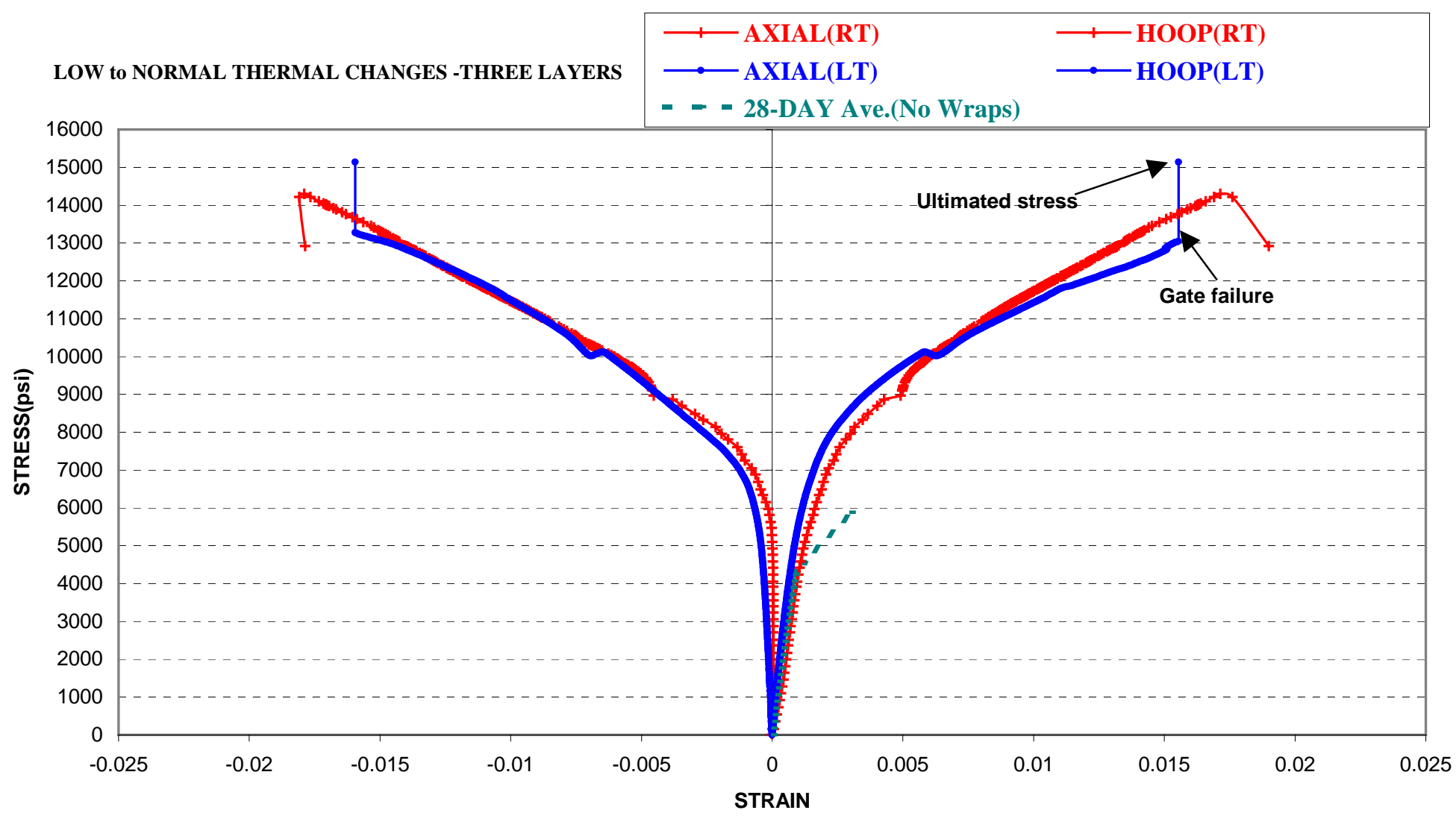

Figure 5-7 Stress-strain relationships for two layers with low temperature cycles. 


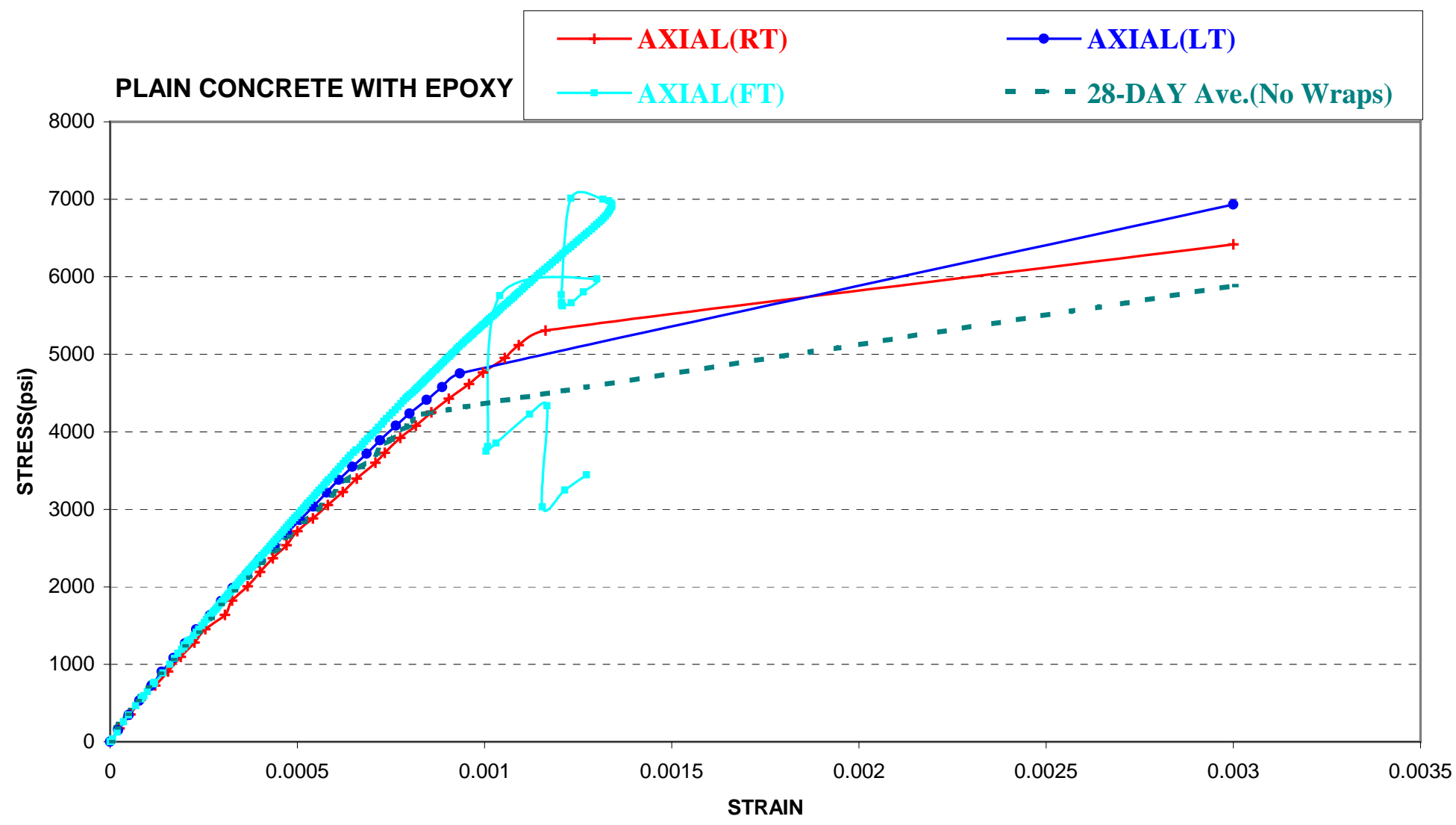

Figure 5-8 Stress-strain relationships for epoxy cover specimens with different temperature cycles. 


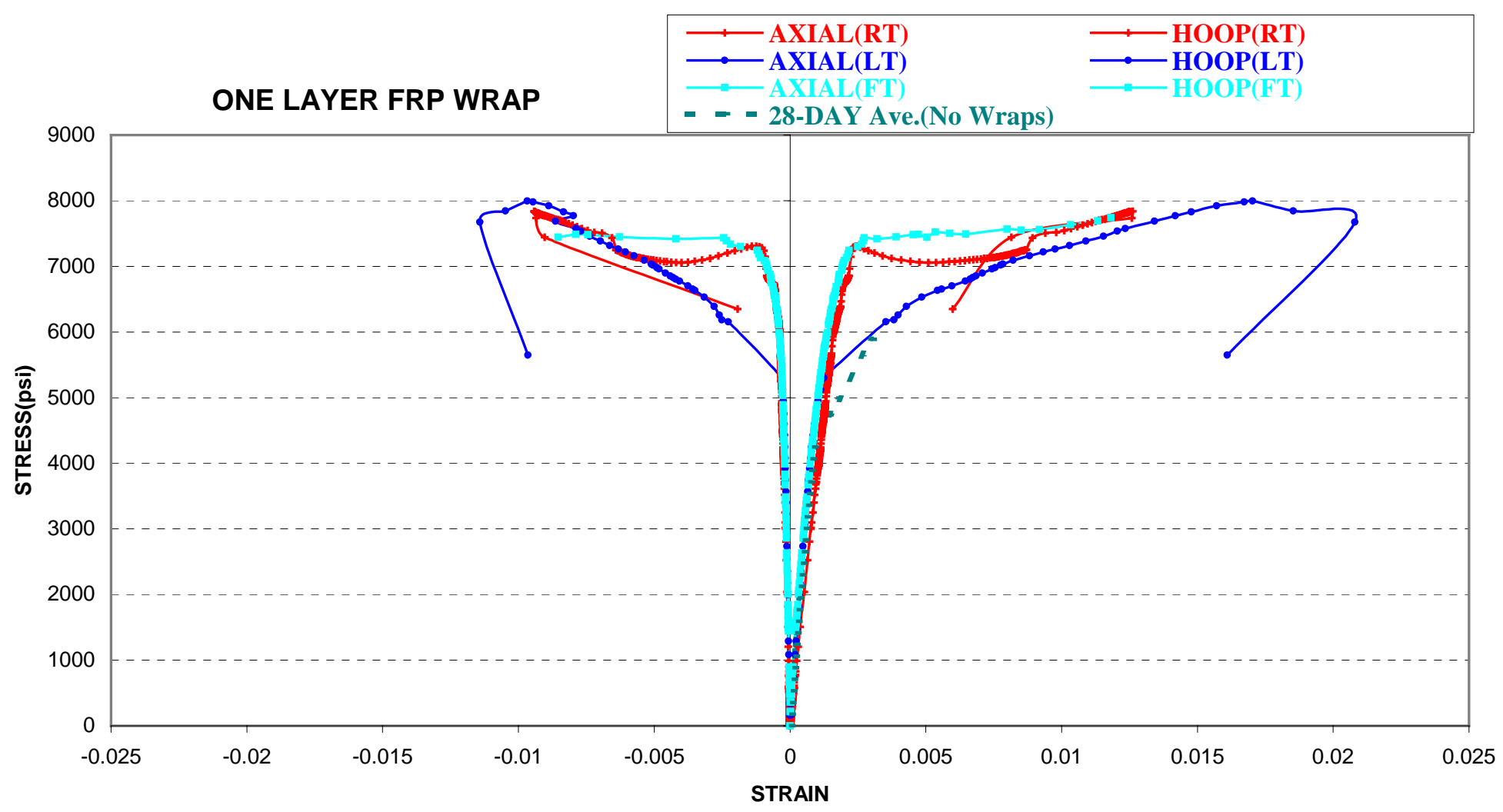

Figure 5-9 Stress-strain relationships for one-layer specimens with different temperature cycles. 


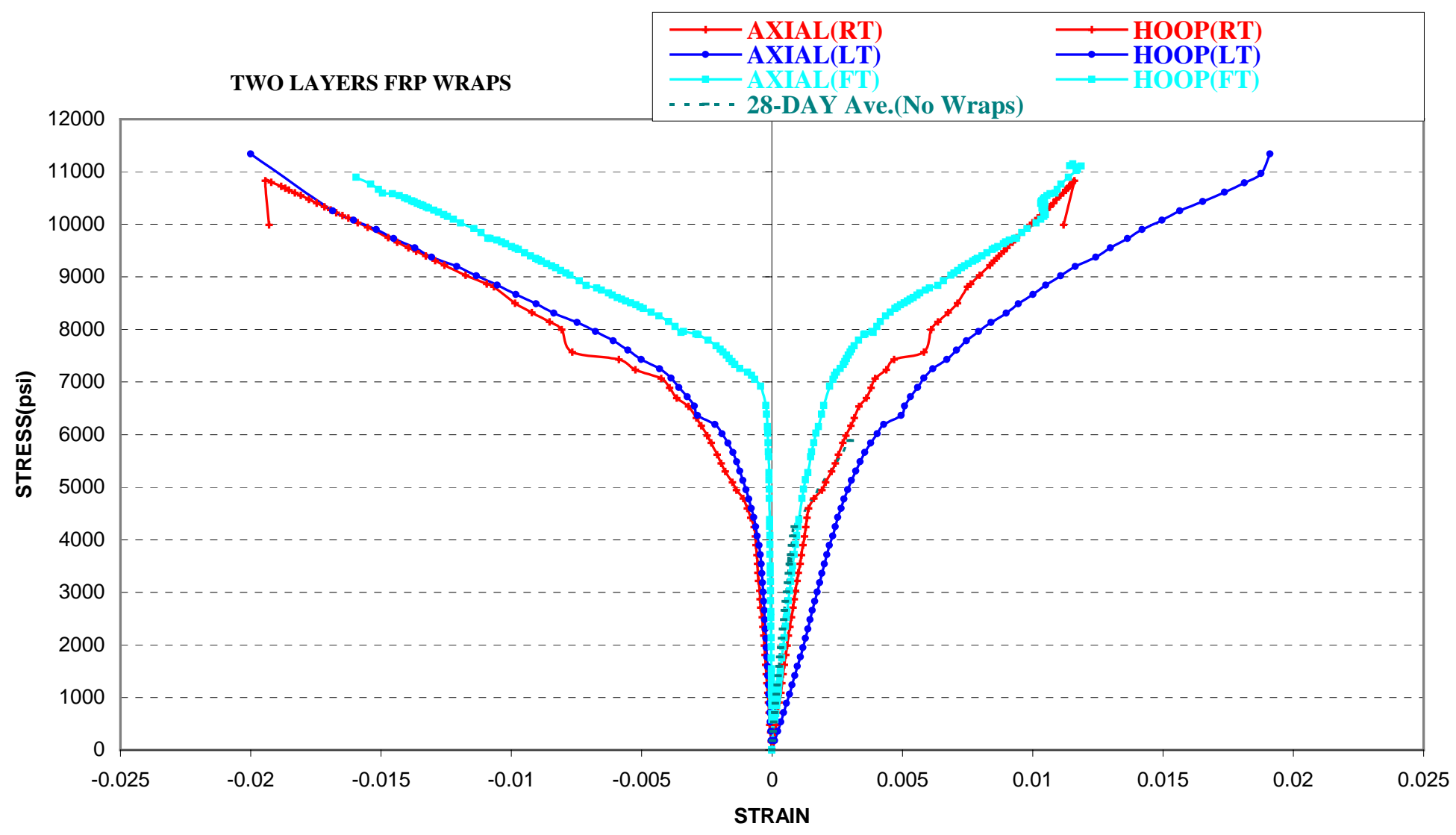

Figure 5-10 Stress-strain relationships for two-layer specimens with different temperature cycles. 


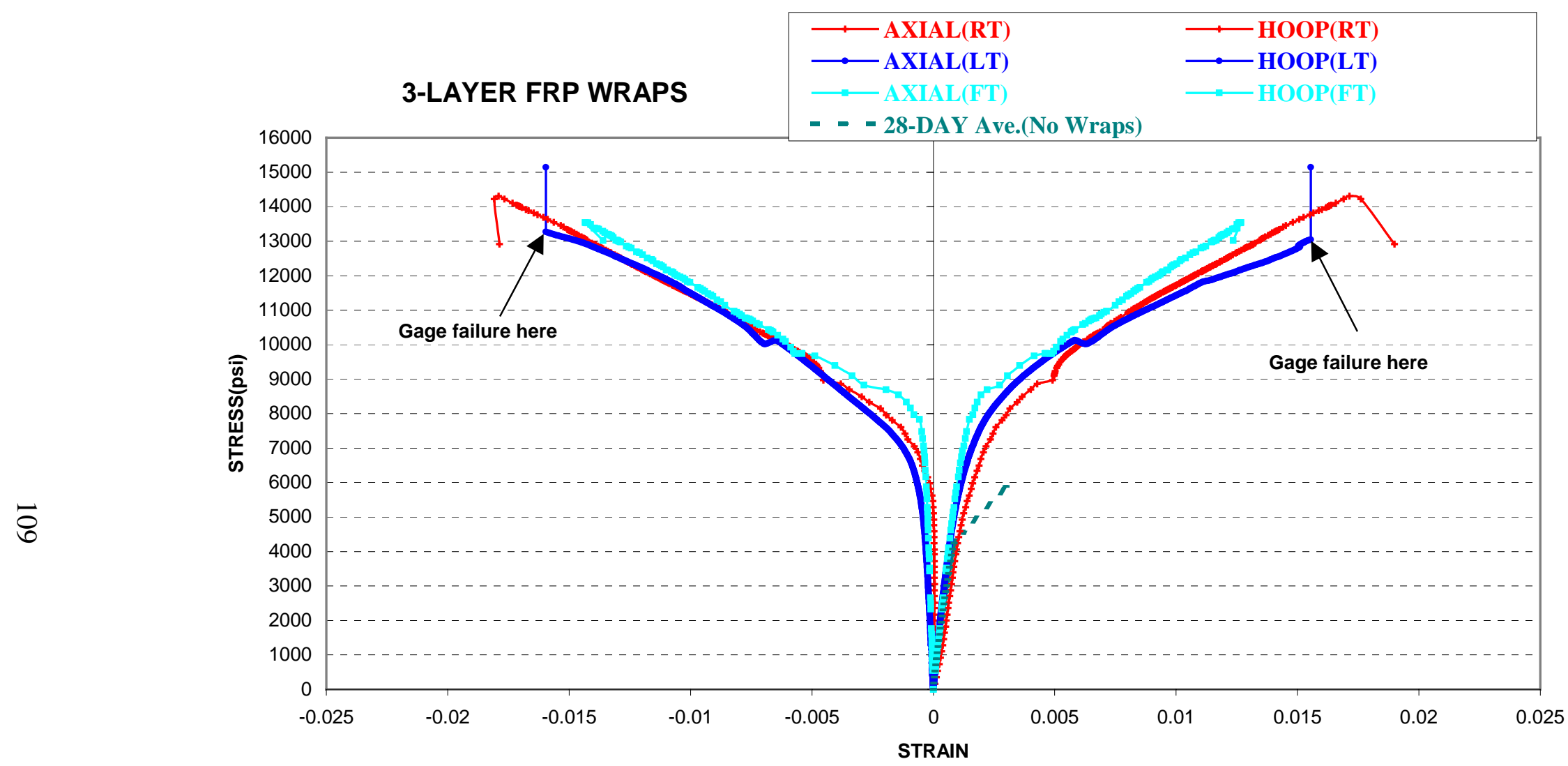

Figure 5-11 Stress-strain relationships for three-layer specimens with different temperature cycles. 


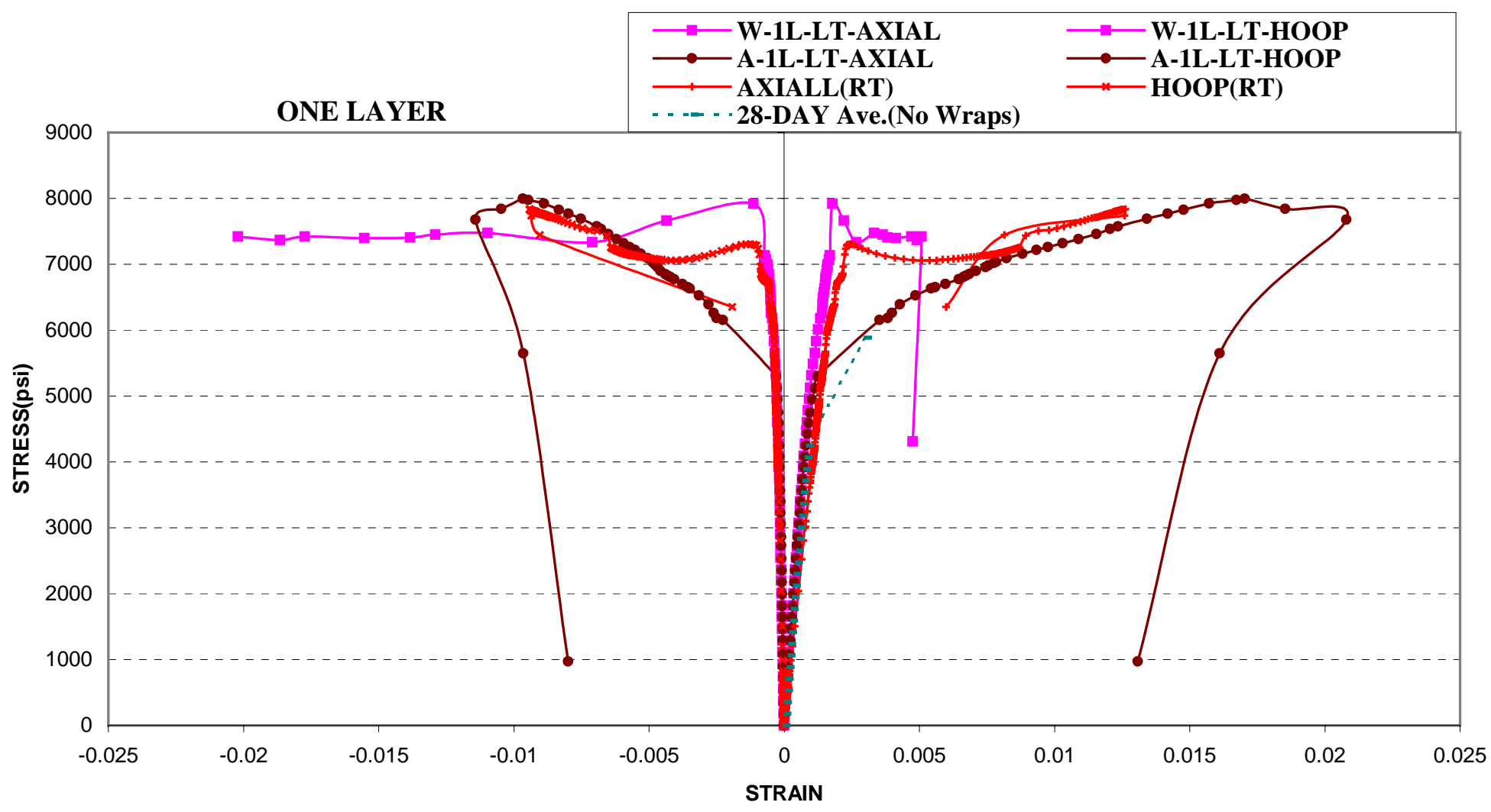

Figure 5-12 Stress-strain relationships for one-layer specimens wrapped with different conditions. 


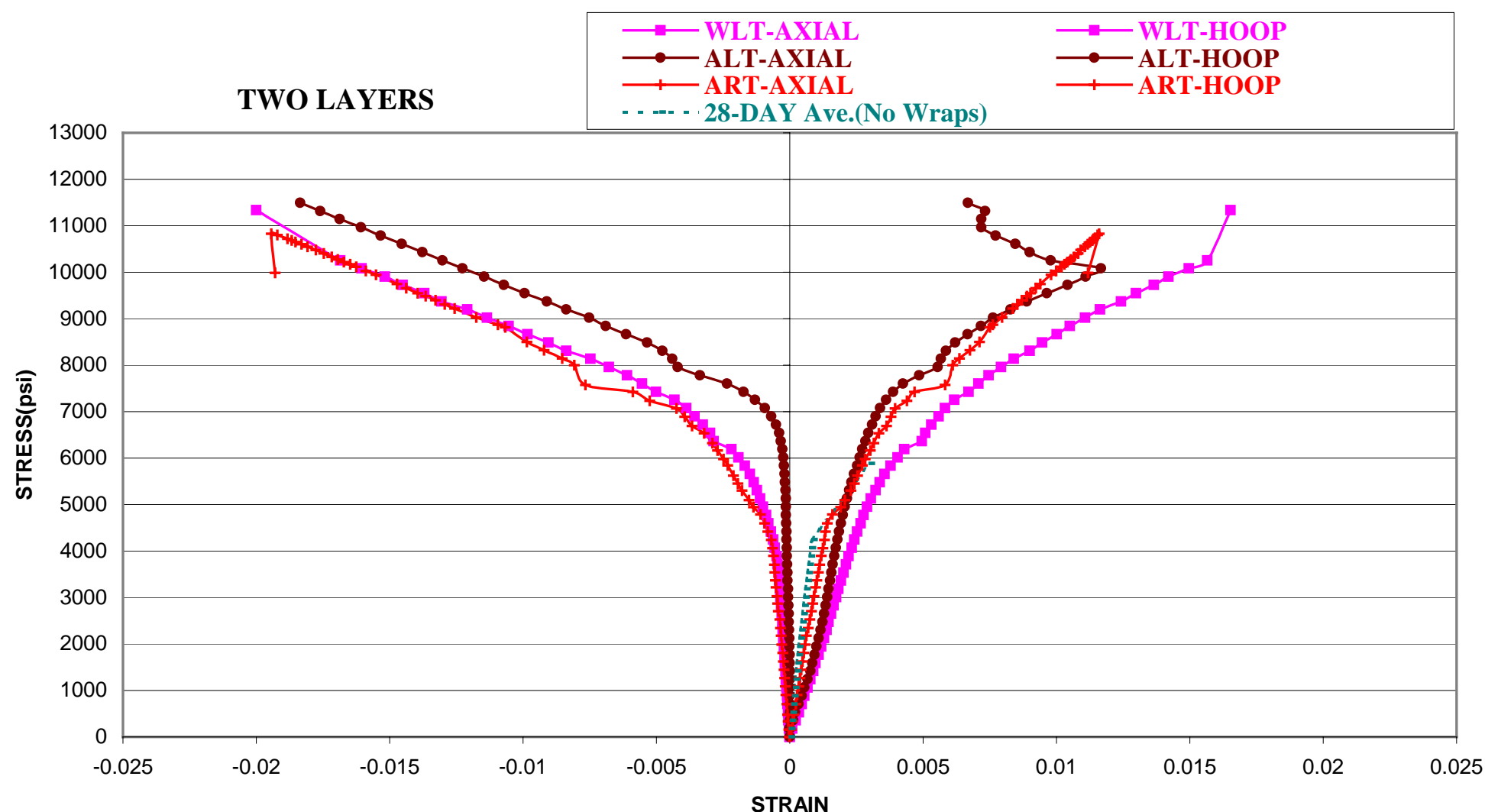

Figure 5-13 Stress-strain relationships for two-layer specimens wrapped with different conditions. 


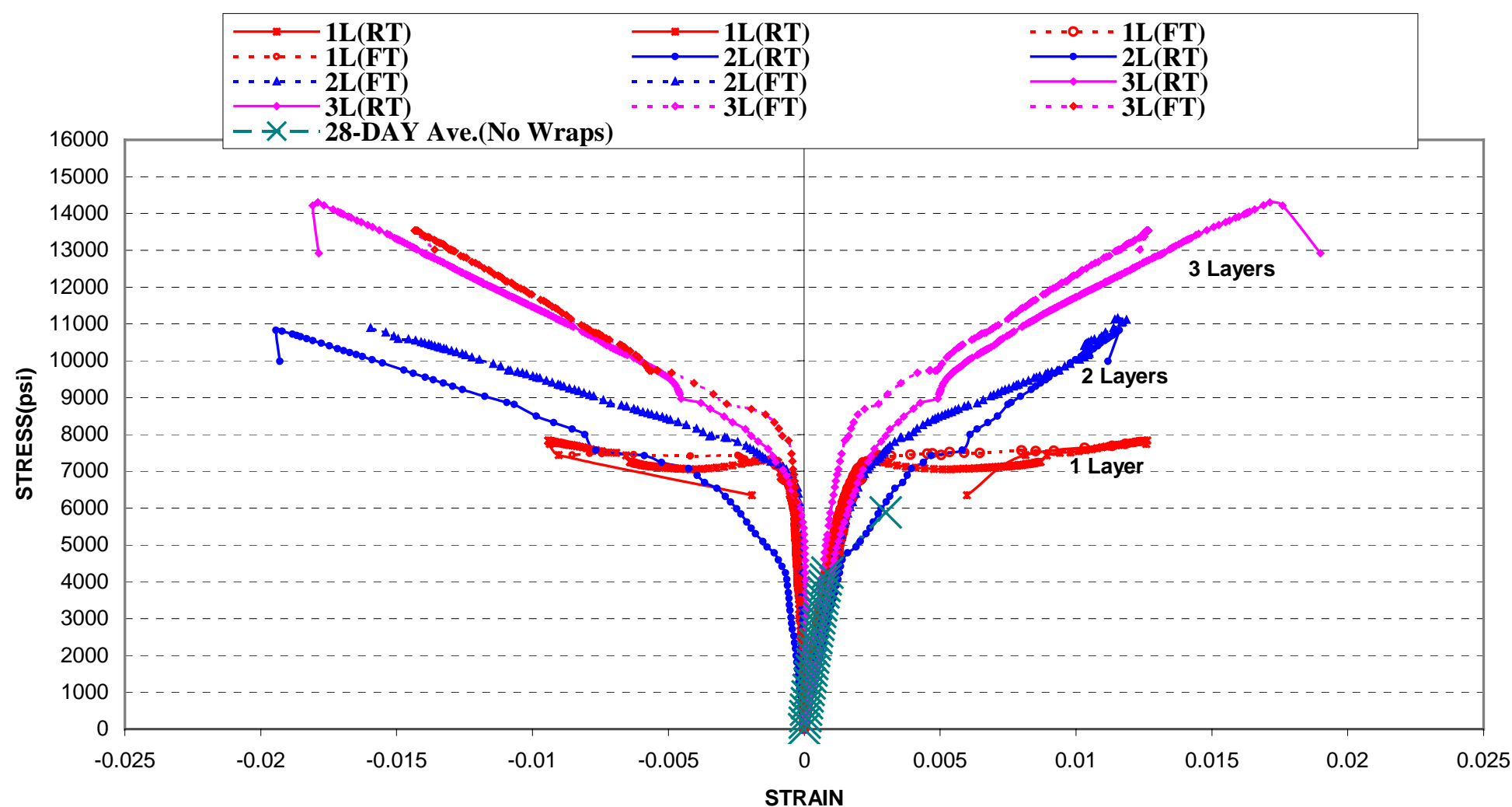

Figure 5-14 Stress-strain relationship for one to three layers. 

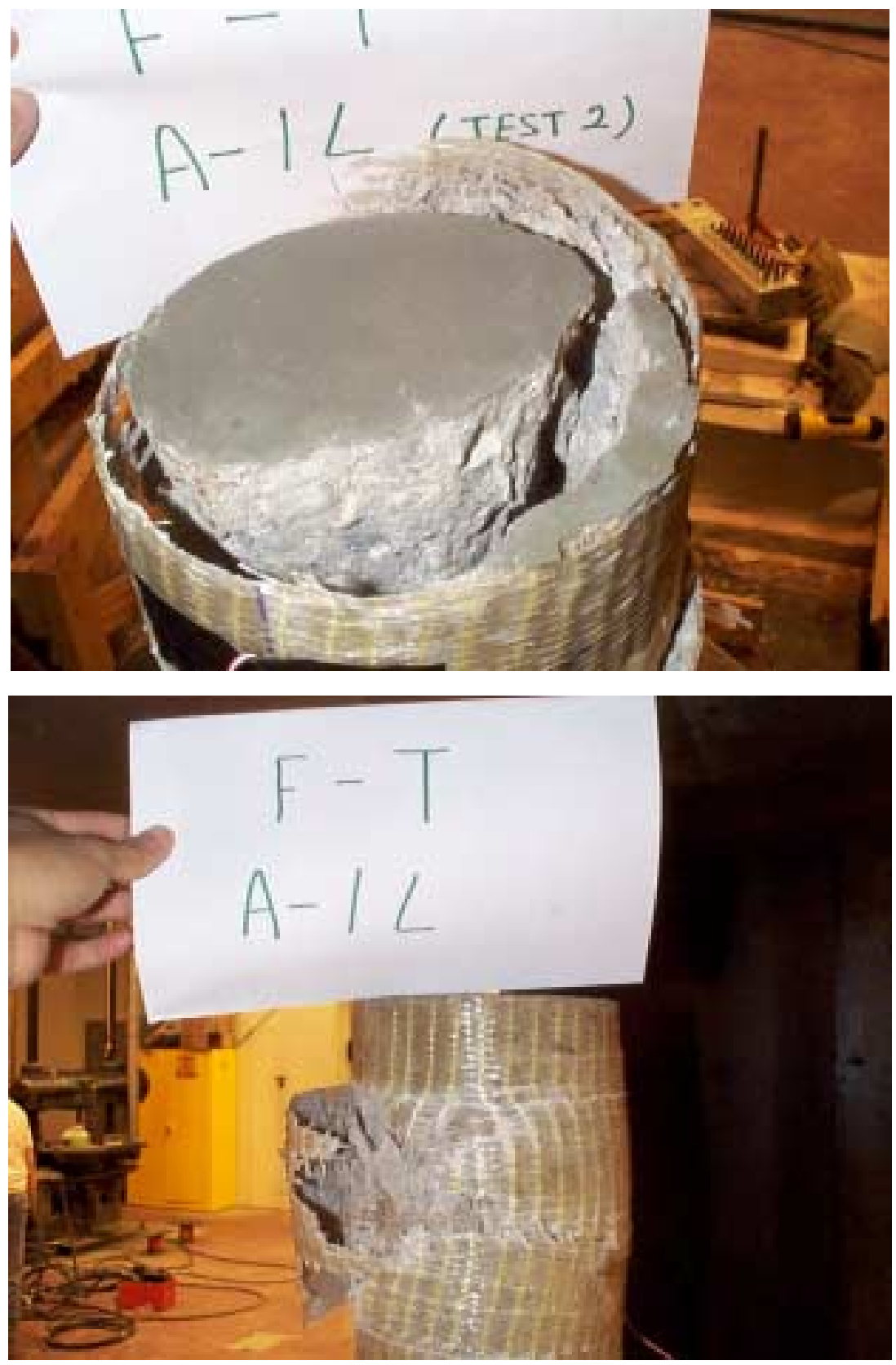

Figure 5-15. One-layer FRP wraps. 

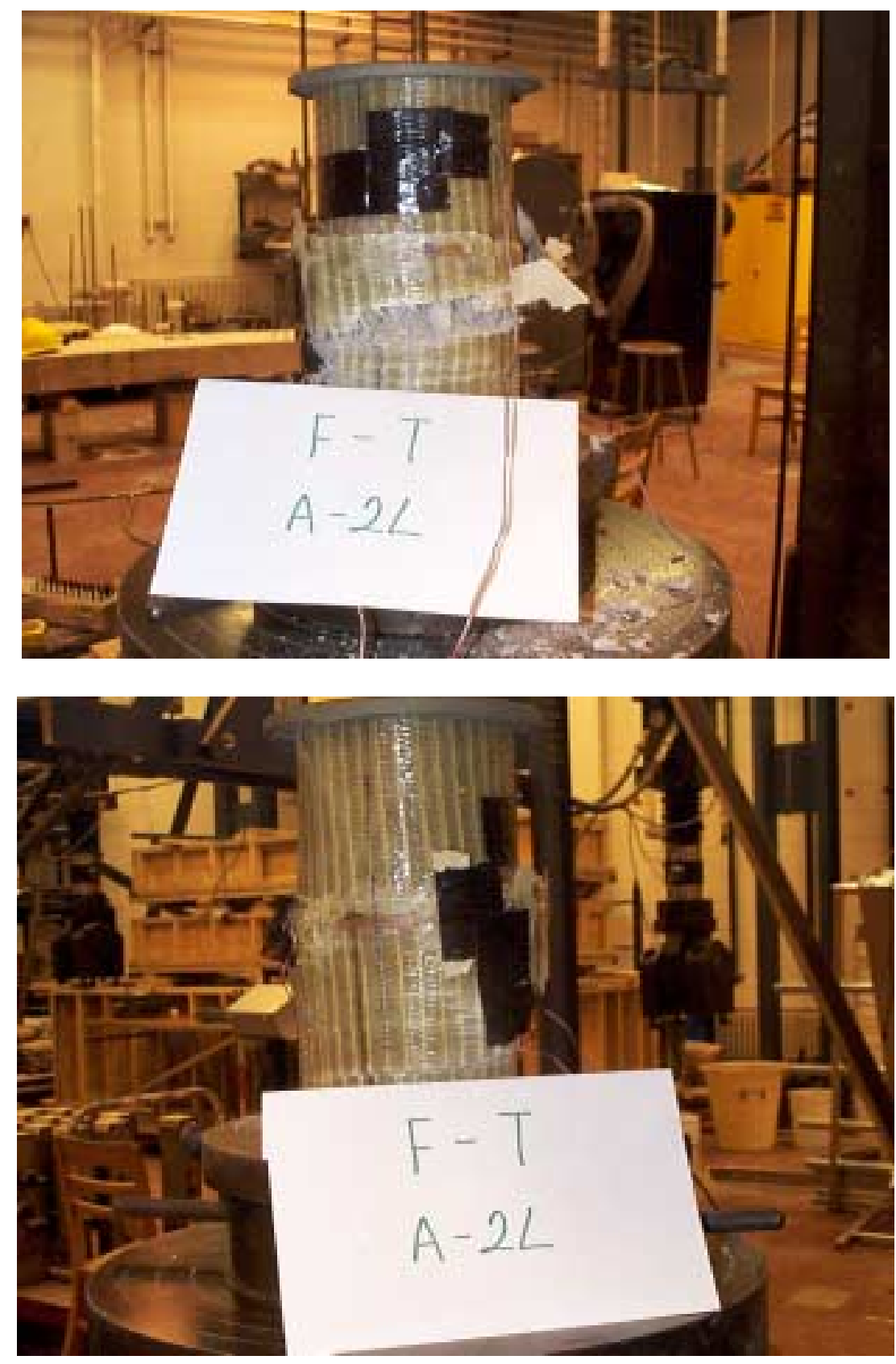

Figure 5-16. Two-layer FRP wraps. 

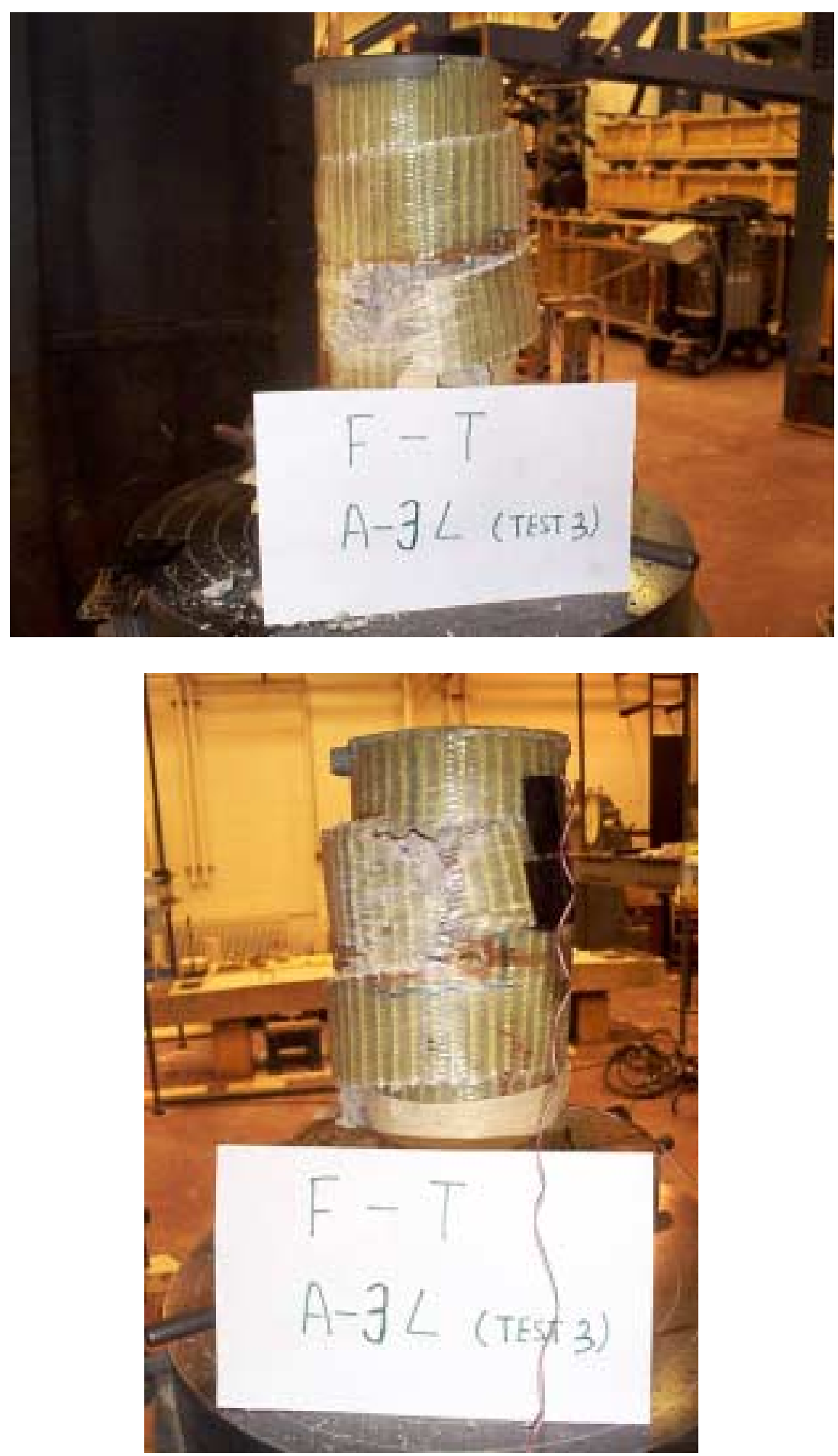

Figure 5-17. Two-layer FRP wraps. 


\section{CHAPTER 6 Summary, Conclusions, and Recommendations}

\section{Summary}

The primary objective of this study was to evaluate the performance of FRP wraps in Indiana in terms of their resistance to corrosion and freeze-thaw effect, and of strength gain. This has been achieved through a series of laboratory tests and field evaluations. The laboratory experiments involved exposure tests of concrete specimens to salty water cycles for both unwrapped and wrapped FRP specimens over a period of 56 weeks. They also involved exposure tests of concrete specimens to freeze-thaw cycles for both unwrapped and wrapped FRP specimens. The field evaluation consisted of three major steps: a survey of the use of FRP by INDOT and other DOTs, field monitoring including temperature variations and strain measurements, and visual inspection of two bridges in Indiana, whose columns were wrapped with FRP.

- Both unwrapped and wrapped specimens were subjected to fifty "Low to Normal" temperature cycles $\left(0{ }^{\circ} \mathrm{F}\right.$ for 8 hours during the night and at room temperature for 16 hours during the daytime) in order to study the influence of the different coefficients of thermal expansion of the constituent materials. After 50 cycles, the specimens were instrumented with strain gages and axial compression tests were conducted to determine the stress-strain behavior.

- For the freeze-thaw tests, the procedure provided in the specification ASTM C666 was modified. The specimens were placed in a freezer room at Purdue University overnight in which the temperature was decreased gradually to $0{ }^{\circ} \mathrm{F}\left(-18{ }^{\circ} \mathrm{C}\right)$ for 16 hours. They were removed the next morning and thawed in a water bath at room temperature for 8 hours. After 50 freeze thaw cycles, all specimens were instrumented in the same way as the "Low to Normal" temperature cycles specimens. 
- To evaluate the corrosion prevention capacity of FRP applications, three methods have been used to measure the specimens subjected to exposure cycles. They are the half-cell potential method (ASTM C876-91), the corrosion current method (ASTM G109-92) and the corrosion resistance method (modified ASTM G109-92). The specimens were subjected to weekly acceleration cycles, that is one week they were exposed to salty water and one week of halogen light.

- The thirty-nine respondents of the survey of state DOTs show that FRP applications are used for corrosion protection, structural update/strengthening, and seismic retrofitting. All DOTs responding the survey indicated that FRP wraps have been performed satisfactorily to date, except in one case in Houston, Texas, due to improper installation.

- The environmental effects on the long-term performance of the FRP composites wrapped columns in Indiana have been monitored and evaluated. The parameters measured were temperature variations and strains throughout the columns.

- Visual inspections of the FRP wrapped columns of two bridges, one located in Gary, Indiana and the other in Fort Wayne, Indiana have been performed periodically. It has been observed that due to auto accidents, one of the FRP wrapped columns has experienced some damage to the FRP wraps themselves.

\section{Conclusions}

- From the laboratory tests, the different coefficients of thermal expansion of the constituent materials have not had any effect.

- In terms of short-term performance, it has been found that freeze-thaw cycles have little effect on the overall behavior of columns wrapped with FRP. 
- To date, it has been found that the FRP materials provide an excellent protection against aggressive environmental conditions even for a single layer. In addition, it has been found that epoxy alone also provides good corrosion protection. Therefore, it is recommended that in some areas epoxy should be applied for further corrosion protection.

- No severe temperature variation has been observed after the FRP wraps were applied.

\section{Implementation}

Ductility and durability are two main reasons why FRP composite jackets are installed on reinforced concrete structural components. These types of retrofit are used either to strengthen the structure or at least restore its initial strength (ductility), or to protect the structure from aggressive environmental conditions, such as freeze-thaw cycles, and prevent the exposure of the reinforcing steel to deicing salts, i.e., sodium chloride solutions (durability).

Although FRP wraps perform well in new structures, its most promising application is for deteriorated structures. This is because they are easy to install, have superior strength and durability characteristics, and incur in low maintenance costs. The present study has addressed the performance of these retrofits, in terms of their durability, in undamaged bridge columns. Based on the findings of this study, a number of items have been identified and are recommended for implementation. These items are described in detail next.

\section{Corrosion protection}

The results and conclusions from the laboratory corrosion tests performed on FRP wraps were limited to their short-term performance. So far, it has been observed that none 
of the tested specimens have experienced any active corrosion. However, exposure testing of the remaining specimens is strongly recommended in order to assess their long-

term performance. A by-product of such a study would be the development of a methodology for the detection of further corrosion in damaged columns retrofitted with FRP wraps. In other words, such a methodology would provide INDOT with a cheap, simple, and efficient way of detecting corrosion in FRP wrapped structural components.

\section{Freeze-thaw effect}

The results and conclusions from the freeze-thaw laboratory tests of FRP wrapped concrete specimens were also limited to their short-term behavior. Since the 6" X 12 " specimens could not be fit in the freeze-thaw machine at INDOT, we recommend that 4" $\mathrm{X} 8$ " specimens be tested in this facility, and also that the 6" X 12 " cylinders be further studied. This should provide insight on the long-term behavior of this type of retrofit under freeze-thaw conditions. Furthermore, these tests can also include damaged specimens repaired with FRP, as discussed further later on in this report.

\section{Field inspection}

It is recommended that the field performance of bridge columns wrapped with FRP be further monitored and inspected. In the current field application, damage to the FRP wraps themselves due to auto collisions has already been observed. Since the glass fiber is sensitive to water (moisture), once the epoxy cover is damaged, the glass fiber might absorb water causing volume expansion and consequently further damage other fibers. The future performance of these columns with damaged GFRPs cannot be predicted with the present study, and continued field inspections and monitoring are, thus, necessary. 
Furthermore, easy and quick repair methods should also be developed, implemented, and tested.

\section{Laboratory tests for damaged columns}

The present work has been limited to the performance of new columns wrapped with FRP. However, this technology has the greatest potential for repairing damaged structural components. This would be a natural extension of the present study. Two possible avenues to proceed with this work include laboratory testing and field monitoring. Damaged RC specimens wrapped with FRP wraps could be monitored in the laboratory. The experimental studies would consist of installing FRP on chosen damaged specimens and subjecting them to freeze-thaw cycles and to aggressive sodium chloride solutions. Specific measurements would be taken to monitor the specimens' freeze-thaw behavior, corrosion behavior, and moisture content. The results from such a study would respond the following questions:

(1) Does this type of retrofit prevent further corrosion in deteriorated columns?

(2) How well does this type of repair perform?

In the field, the creation of an application would help further validate the use of this technology for repairing deteriorated structural components. Such a study would help answer a number of questions, such as:

(1) What level of deterioration is permitted for the use of this technology?

(2) How many layers of FRP are necessary to restore the original level of strength of the component and to provide the desired protection? 
FRP confined concrete model due to environmental effects

The results of corrosion and freeze-thaw performance have been conducted in the lab, so far many researchers have been done different FRP confined concrete models; however, no one introduces the models with the environmental effects. It is recommended that developing this model in addition to combine other regular confined model. We can use the comprehensive FRP confined models to develop the design equations.

\section{$\underline{\text { Additional Research }}$}

As mentioned previously, the present study has been limited to new reinforced concrete columns retrofitted with FRP wraps. It focused on their performance in terms of durability. However, we expect that this material can have a significant economic impact if it is fully understood and tested. Additional related research topics in this area are discussed next.

\section{FRP tubes}

Some research has been done in the use of FRP tubes filled with concrete as structural components. The benefit of this type of technology is twofold: the FRP tubes serve both as formwork and reinforcement. In addition, it provides a convenient set up, it saves construction time, and reduces the total costs. First, a complete literature review on the use of FRP tubes filled with concrete as structural components (columns or beams) is recommended. Second, we recommend that an application of tube filled bridge columns be installed at a location chosen by INDOT. Their strength, ductility, long-term behavior, and cost would be studied and compared to those associated with traditional bridge column systems. 


\section{Extension to other structural components}

Other structural components such as beams, decks, etc. can also be retrofitted or repaired using this technology. A thorough comparison between their performance and the performance of traditionally built structural components is needed. Such a study would investigate and compare their bond strength, fatigue ability, ductility, long-term and corrosion behavior, and cost.

FRP as a retrofit for seismic applications

According to the United States Geological Survey, an earthquake of significant intensity is likely to strike somewhere in the New Madrid fault line in the next century. Portions of Indiana are within the New Madrid Seismic Zone and have the potential to be negatively affected by such an event. In order to prepare for such a catastrophic event, Indiana's highway bridges in this region should be retrofitted to withstand these effects. FRP has been successfully used in the West Coast for this type of application. A thorough literature review on this subject is highly recommended. From this review, existing techniques appropriate to Indiana's bridges would be studied for possible implementation. Furthermore, new techniques may also be developed as part of this work for the specific types of structural components used in Indiana's highway bridges.

A user-friendly software tool for the design of structural components wrapped with FRP

The implementation of the knowledge acquired from the present work and future related research in a user-friendly software tool is highly recommended. The goal of such a software tool would be to automate the design of FRP wrapped structural components. An easy-to-use graphical user interface based on modern software development technology would be created to guide the practicing engineer through the design process 
involved in these applications. Such a tool would help train new engineers, who have not been traditionally exposed to this type of design. Therefore, it would also have an economic impact to INDOT, since the time consumed in training new staff would be significantly shortened. 


\section{Reference:}

1. Lan, Yi-Ming, Sotelino, Elisa D., and Chen, W. F., State-of-the-art review of highway bridge columns retrofitted with FRP jackets, Department Report, CE-STR98-5, School of Civil Engineering, Purdue University, May 1998.

2. Lisa M. Samples, and Julio A. Ramirez, Methods of corrosion protection and durability of concrete bridge decks reinforced with epoxy-coated bars, Phase I, Draft Final Report, November 1998.

3. Plecnik, J. M., and Ahmad, S. H., Transfer of composites technology to design and construction of bridges, Final Report prepares for the U.S. Department of Transportation, Federal Highway Administration, September. 1989.

4. Microsoft Access Handbook.

5. Civil Engineering, ASCE, July 1997.

6. ACI (1996), State-of-the-art report on fiber reinforced plastic reinforcement for concrete structures, ACI 440R-96, Reported by ACI committee 440 .

7. Sun, C T. "Lecture on composite materials", in class notes, AA\&E, Purdue University, 1998.

8. Civil Engineering, ASCE, June 1998.

9. Cercone, Larry, and Korff James, Putting the wraps on quakes, Civil Engineering, July 1997.

10. ASTM. Standard Practice for Making and Curing Concrete Test Specimens in the Laboratory. (ASTM Designation: C192-95), 1995.

11. Hexcel Fyfe, Co, Installation procedures.

12. Hexcel Fyfe, Co. (1997), Commercial Advertisement. 
13. A. M. Neville, "Properties of Concrete", Fourth Edition.

14. Guangling Song and Ahmad Shayan, "Corrosion of Steel in Concrete: Cause, Detection and prediction. State-of-the art-review", 1998.

15. Arnon Bentur, Sidney Diamond, and Neal S. Berke, "Steel Corrosion in Concrete: Fundamentals and Civil Engineering Practice”.

16. H. Woods, "Durability of Concrete Construction." ACI and The Iowa State University Press, 1968.

17. ASTM, "Standard Test Method for Half-Cell Potentials of Uncoated Reinforcing Steel in Concrete.” (ASTM Designation: C876-91), 1993.

18. ASTM, "Standard Test Method for Determining the Effects of Chemical Admixtures on the Corrosion of Embedded Steel Reinforcement in Concrete Exposed to Chloride Environments." (ASTM Designation: G109-92), 1992.

19. P.R. Vassie, "A Survey of Site Tests for the Assessment of Corrosion in Reinforced Concrete, TRRL laboratory Report 953, 1989.

20. Langford and Broomfield, "Monitoring the Corrosion of Reinforcing Steel", Construction Repair, 1(2): pp.32, 1987

21. Broomfield et al, "Corrosion Rate Measurement and life prediction for reinforced concrete structures, In: proceedings of structural Faults and Repair-93", Vol.2: pp.155, 1993.

22. Karbhari and Eckel, "Effect of Cold Regions Climate on Composite Jacketd Concrete Columns”, Journal of Cold Rgions Engineering, Vol. 8, No. 3, September, 1994. 
23. Soudki and Green, "Performance of CFRP Retrofitted Concrete Columns at Low Temperatures", Advanced Composite Materials in Bridges and Structures, October 1996.

24. Toutanji and Balaguru, "Durability Characteristics of Concrete Columns Wrapped with FRP Tow Sheets”, Journal of Materials in Civil Engineering, February 1996.

25. Liao et al, "Long-term Durability of Composites in Secondary Infrastructure Applications", $28^{\text {th }}$ International SAMPE Technical Conference, November 4-7, 1996.

26. M. Demers and K. W. Neale, "Strengthening of Concrete Columns with Unidirectional Composite Sheets," Developments in Short and Medium Span Bridge Engineering '94, 1994, pp.895-905.

27. Khaled A. Soudki, and M. F. Green, "Freeze-Thaw Response of CFRP Wrapped Concrete," Concrete International, August 1997.

28. ASTM, "Standard Test Method for Resistance of Concrete to Rapid Freezing and Thawing." (ASTM Designation: C666-92), 1992.

29. Micro-measurement, "The strain gages installation." Handbook.

30. Aboutaha, R S. Engelhardt, M D. Jirsa, J O. Kreger, M E. "Seismic strengthening of R/C columns using steel jackets", Structural Engineering in Natural Hazards Mitigation Proc Symp Struct Eng Nat Hazard Mitigation. Publ by ASCE, New York, NY, USA. 1993, P 301-306.

31. Chai, Y H. Priestley, M J N. Seible, F. “Analytical model for steel-jacketed RC circular bridge columns", Journal of Structural Engineering-ASCE. V 120 n 8 Aug 1994, P 2358-2375. 
32. Chai, Y H. "Analysis of the seismic characteristics of steel-jacketed circular bridge columns", Earthquake Engineering \& Structural Dynamics. V 25 n 2 Feb 1996, P $149-161$.

33. Saadatmanesh, H. Ehsani, M R. Li, M W. "Strength and ductility of concrete columns externally reinforced with fiber composite straps", ACI Structural Journal. V 91 n 4 Jul-Aug 1994, P 434-447.

34. Saadatmanesh, H. Ehsani, M R. Jin, Limin. "Seismic strengthening of circular bridge pier models with fiber composites", ACI Structural Journal. V 93 n 6 Nov-Dec 1996, P 639-647.

35. Saadatmanesh, H. Ehsani, M R. Jin, L. "Seismic retrofitting of rectangular bridge columns with composite straps”, Earthquake Spectra. V 13 n 2 May 1997, P 281-304.

36. Picher, F., Rochette, P., and Labossiere, P. "Confinement of concrete cylinders with CFRP”, Proc., First Int. Conf. on Composite Infrastructures, Tucson, Ariz., P 829841.

37. Mirmiran, Amir. Shahawy, Mohsen. "Behavior of concrete columns confined by fiber composites", Journal of Structural Engineering-ASCE. V 123 n 5 May 1997, P 583590.

38. Mirmiran, Amir. Shahawy, Mohsen. "New concrete-filled hollow FRP composite column Composites Part B:Engineering", V 27 n 3-4 1996, P 263-268.

39. kanatharana, J and Lu, L. W., "Strength and Ductility of Concrete Columns Reinforced by FRP Tubes”, ICCI98, Arizona, P.370-384, 1998.

40. Kono, S., Inazumi, M. and Kaku, T., "Strength and Ductility of Concrete Columns Reinforced by FRP Tubes", ICCI98, Arizona, P.343-355, 1998. 
41. Seible, F. Davol, A. Burgueno, R. Nuismer, R J. Abdallah, M G. "Structural behavior of concrete filled carbon fiber composite tubular columns", Technology Transfer in a Global Community International SAMPE Technical Conference. V 281996. SAMPE, Covina, CA, USA, P 1258-1269.

42. Attard, M M. Setunge, S. "Stress-strain relationship of confined and unconfined concrete”, ACI Materials Journal. V 93 n 5 Sep-Oct 1996, P 432-442.

43. Spoelstra, Marijn R. and Monti, Giorgio. "FRP-confined concrete model Journal of Composites for Construction”, V 3 n 3 1999, P 143-150.

44. Hoshikuma, J. Kawashima, K. Nagaya, K. Taylor, A W. "Stress-strain model for confined reinforced concrete in bridge piers", Journal of Structural EngineeringASCE. V 123 n 5 May 1997, P 624-633.

45. Pantazopoulou, S J. Mills, R H. "Microstructural aspects of the mechanical response of plain concrete”, ACI Materials Journal. V 92 n 6 Nov-Dec 1995, P 605-616.

46. Mander, J. B., Priestley, M. J. N., and Park, R. "Theoretical stress-strain model for confined concrete”, J. Struct. Engrg., ASCE, 114(8), 1998, P 1804-1826. 
APPENDIX A 


\section{California}

\begin{tabular}{|c|c|c|c|c|c|}
\hline Project & Location & Consultant & No. of Elements \& Type & Type of Application & Installation \\
\hline $\begin{array}{l}\text { Caltrans } \\
\text { I-5 \& Hwy2 }\end{array}$ & $\begin{array}{l}\text { SB I-5 to EB Hwy2 } \\
\text { NB I-5 TO Griffith Park }\end{array}$ & Caltrans & $\begin{array}{l}12 \text { Columns (6' dia.) } \\
3 \text { Columns (4' dia.) }\end{array}$ & $\begin{array}{l}\text { Seismic } \\
\text { Seismic }\end{array}$ & $\begin{array}{l}\text { Sep. } 1991 \\
\text { Oct. } 1991\end{array}$ \\
\hline Los Angeles & $\begin{array}{l}\text { NB I-5 TO WB Hwy2 } \\
\text { Bents } 11 \& 12 \text { repaired }\end{array}$ & Caltrans & & Seismic & $\begin{array}{l}\text { Feb. } 1992 \\
\text { Aug. } 1995\end{array}$ \\
\hline Caltrans Hwy & 101 North, Santa Barbara & Caltrans & 2 Columns (5' dia.) & Seismic & Jul. 1992 \\
\hline Fashion Square & Sherman Oaks, CA & City of LA & \begin{tabular}{|l} 
Two 24"x24"x8' \\
Rectangular Columns
\end{tabular} & Seismic & Nov. 1994 \\
\hline Broxton Parking Structure & Los Angeles, CA & City of LA & Four Columns & Seismic Upgrade & Jun. 1997 \\
\hline
\end{tabular}

\section{Connecticut}

\begin{tabular}{|c|c|c|c|c|c|}
\hline Project & Location & Consultant & No. of Elements \& Type & Type of Application & Installation \\
\hline Big Foot Overpass & East Hartford, CT & CTDOT & 4 Concrete Columns & Non-seismic Repair & Dec. 1997 \\
\hline \multicolumn{6}{|l|}{ Georgia } \\
\hline Project & Location & Consultant & No. of Elements \& Type & Type of Application & Installation \\
\hline Georgia Pier Cap & Dalton, GA & GA DOT & $\begin{array}{l}2 \text { Pier Caps } \\
\text { (SCH-41 carbon) }\end{array}$ & Seismic Strengthening & Apr. 1997 \\
\hline
\end{tabular}

Illinois
\begin{tabular}{|l|l|l|l|l|l|}
\hline Project & Location & Consultant & No. of Elements \& Type & Type of Application & Installation \\
\hline Rte. 116 over Folky Slough & lllinois DOT & ILDOT & Strengthening & Sep. 1997 \\
\hline Archer Ave. Rte. 171 & Willow Springs, IL & ILDOT & $\begin{array}{l}\text { 20.3 Sq. Meters } \\
\text { Concrete Columns }\end{array}$ & Non-seismic Repair & Oct. 1997 \\
\hline Rte. 64 West of Rte. 59 & Dupage Co., IL & ILDOT & Non-seismic Repair & Nov. 1997 \\
\hline Polar Street & East St. Louis, Illinois & $\begin{array}{l}\text { Illinois DOT, } \\
\text { University of Illinois }\end{array}$ & 1 Column (4' dia.) & $\begin{array}{l}\text { Flexural test of } \\
\text { actual bridge column }\end{array}$ & \begin{tabular}{l} 
Sep. 1994 \\
\hline
\end{tabular}
\end{tabular}




Indiana
\begin{tabular}{|l|l|l|l|l|}
\hline Project & Location & Consultant & No. of Elements \& Type & Type of Application \\
\hline I-69 Overpass & Fort Wayne, IN & INDOT & Strallation \\
\hline U.S. 14 Bridge Column & Gary & INDOT & & $\begin{array}{l}\text { Strengthening } \\
\text { Corrosion Protection }\end{array}$ \\
\hline
\end{tabular}

Kansas
\begin{tabular}{|l|l|l|l|l|l|}
\hline Project & Location & Consultant & No. of Elements \& Type & Type of Application & Installation \\
\hline I-70 Topeka Ave. & Topeka, Kansas & Kansas DOT & Columns & $\begin{array}{l}\text { Non-seismic Corrosion } \\
\text { Repair }\end{array}$ & Oct. 1995 \\
\hline I-5 Overpass column & Kansas City, Kansas & Kansas DOT & 1 Column (20' tall) & Impact Repair & Jan. 1997 \\
\hline
\end{tabular}

Missouri

\begin{tabular}{|l|l|l|l|l|l|}
\hline Project & Location & Consultant & No. of Elements \& Type & Type of Application & Installation \\
\hline Lindberg Ave. Traffic Light & St. Louis, MO & MODOT & $\begin{array}{l}\text { Light Pole } \\
\text { Foundation Conical Shape }\end{array}$ & Structural Repair & May. 1995 \\
\hline
\end{tabular}

Nevada

\begin{tabular}{|l|l|l|l|l|}
\hline Project & Location & Consultant & No. of Elements \& Type & Type of Application \\
\hline Sparks & I-80 at Nugget Hotel & Nevada DOT & $\begin{array}{l}\text { 96 Columns (3' dia.) } \\
\text { Plastic Hinge Zone }\end{array}$ & Seismic \\
\hline
\end{tabular}

\section{New Hampshire}

\begin{tabular}{|l|l|l|l|l|}
\hline Project & Location & Consultant & No. of Elements \& Type & Type of Application \\
\hline Pembrook & Concord, NH & New Hampshire DOT & 8 Columns & Structural Repair \\
\hline
\end{tabular}

\section{New Jersey}

\begin{tabular}{|l|l|l|l|l|}
\hline Project & Location & Consultant & No. of Elements \& Type & Type of Application \\
\hline
\end{tabular}




\begin{tabular}{|c|c|c|}
\hline Timber Creek Overpass & Bellmawr, NJ & $\begin{array}{l}\text { New Jersey } \\
\text { Tumpike Authority }\end{array}$ \\
\hline
\end{tabular}

\section{New York}

\begin{tabular}{|l|l|l|l|l|l|}
\hline Project & Location & Consultant & No. of Elements \& Type & Type of Application & Installation \\
\hline Railroad Bridge & I-90 City of Buffalo Exit 52 & $\begin{array}{l}\text { New York } \\
\text { Thruway Authority }\end{array}$ & 2 Columns (3.5" dia.) & Corrosion Repair & Oct. 1994 \\
\hline City of New York & FDR Drive near Manhattan Bridge & City of New York & 2 Columns(2' x 4') & Corrosion Repair & May. 1994 \\
\hline
\end{tabular}

\section{Ohio}

\begin{tabular}{|l|l|l|l|l|l|}
\hline Project & Location & Consultant & No. of Elements \& Type & Type of Application & Installation \\
\hline Akron Sewer Rehabilitation & Akron, $\mathrm{OH}$ & City of Akron, $\mathrm{OH}$ & Masonry Pier & Non-seismic Repair & Nov . 1997 \\
\cline { 2 - 4 }
\end{tabular}

\section{Pennsylvania}

\begin{tabular}{|l|l|l|l|l|}
\hline Project & Location & Consultant & No. of Elements \& Type & Type of Application \\
\hline $\begin{array}{l}\text { Pennsylvania Lakawanna } \\
\text { County }\end{array}$ & Scranton I-84 over Routing Brook & Penn DOT & 6 Columns (5' dia.) & $\begin{array}{l}\text { Seismic Repair } \\
\text { Corrosion Control }\end{array}$ \\
\hline I-276 over Old York Rd. & Philadelphia, PA & $\begin{array}{l}\text { Pennsylvania } \\
\text { Turnpike }\end{array}$ & One Rectangular Co;. & Impact Repair \\
\hline
\end{tabular}

\section{South Carolina}

\begin{tabular}{|c|c|c|c|c|c|}
\hline Project & Location & Consultant & No. of Elements \& Type & Type of Application & Installation \\
\hline I-85 Bus Overpass & Spartanburg, SC & South Carolina DOT & Exterior Abeam of Deck & $\begin{array}{l}\text { Impact } \\
\text { Repair / Strengthening }\end{array}$ & Nov. 1996 \\
\hline Cainhoy Road & North Charleston, SC & South Carolina DOT & $\begin{array}{l}100 \text { Wood Piers / Slab } \\
\text { (SCH-41 carbon) }\end{array}$ & $\begin{array}{l}\text { Strengthening } \\
\text { for AASHTO Upgrade }\end{array}$ & Dec. 1996 \\
\hline
\end{tabular}

\section{Tennessee}

\begin{tabular}{|c|c|c|c|c|c|}
\hline Project & Location & Consultant & No. of Elements \& Type & Type of Application & Installation \\
\hline I-40 Harpeath River & Cheatham County, Tennessee & TNDOT & 4 Concrete Columns & Non-seismic Repair & Oct. 1997 \\
\hline
\end{tabular}




\section{Texas}

\begin{tabular}{|l|l|l|l|l|}
\hline Project & Location & Consultant & No. of Elements \& Type & Type of Application \\
\hline I-635 Dallas \& Marsh Lane & Dallas, Texas & Texas DOT & $\begin{array}{l}\text { 30" dia. Circular Column } \\
\text { Repair }\end{array}$ & Impact Repair \\
\hline I-37 \& New Braunfels & San Antonio, Texas & Texas DOT & $\begin{array}{l}\text { One column } \\
\text { (30" dia.) 9 tall }\end{array}$ & Provide Ductility \\
\hline I-10 \& San Jacinto River & Houston, TX & 5 Columns & Jan. 1995 \\
\hline US Highway 69 & Beaumont, TX & Texas DOT & T Columns & Provide Ductility \\
\hline I-635 Marsh & Dallas, Texas & Texas DOT & Jul. 1996 \\
\hline I-37 & San Antonio, Texas & TXDOT & Columns & Column Wrap \\
\hline Beaumont 69 & Beaumont, TX & $\begin{array}{l}\text { TXDOT, } \\
\text { David Hemsmeyer }\end{array}$ & Columns & Apr. 1995 \\
\hline
\end{tabular}

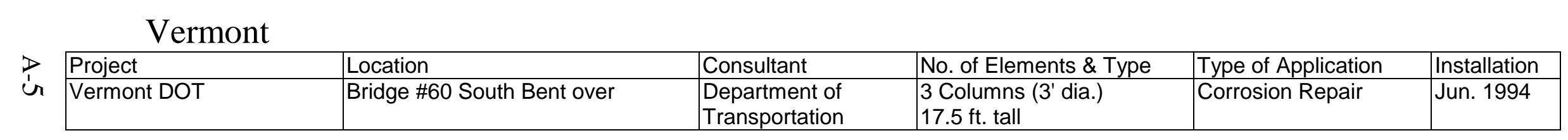

Virginia
\begin{tabular}{|l|l|l|l|l|l|}
\hline Project & Location & Consultant & No. of Elements \& Type & Type of Application & Installation \\
\hline $\begin{array}{l}\text { Off Route } 250 \text { N.E. } \\
\text { between Gayton \& } 621\end{array}$ & Richmond, VA & VADOT & 1 Concrete Column & Structural Repair & Oct. 1997 \\
\hline $\begin{array}{l}\text { Rte. 29 Bridge over } \\
\text { Rapidan River }\end{array}$ & Ruckersville, VA & Virginia DOT & 15 Columns & Flood Repair \\
\hline
\end{tabular}

\section{Washington}

\begin{tabular}{|l|l|l|l|l|}
\hline Project & Location & Consultant & No. of Elements \& Type & Type of Application \\
\hline Mannette Bridge & Kitsap County, Washington & Wash. State DOT & $\begin{array}{l}\text { 2'-6"x6' Pier Caps } \\
\text { Four 23' long } \\
\text { Four 27'-10" long }\end{array}$ & Seismic \\
\hline
\end{tabular}




\section{Wisconsin}

\begin{tabular}{|c|c|c|c|c|c|}
\hline Project & Location & Consultant & No. of Elements \& Type & Type of Application & Installation \\
\hline Wisconsin & I-90 at Church St. Madison & Wisc. DOT/Dane Co. & 6 Columns (2.5' dia.) & Repair & Oct. 1993 \\
\hline Wisconsin & I-94 at Rte $12 / 18$ Madison & Wisconsin DOT & 2 Columns (2.5' dia.) & Repair & Jul. 1993 \\
\hline Wisconsin DOT & I-90OVER Route $14 \mathrm{E}$ at Janesville & $\begin{array}{l}\text { Wisconsin DOT } \\
\text { Engineering }\end{array}$ & $\begin{array}{l}10 \text { Columns (30" dia.) } \\
15 \mathrm{ft} \text { tall }\end{array}$ & Corrosion Repair & Aug. 1994 \\
\hline
\end{tabular}


APPENDIX B

B-1 
A CD-ROM will be delivered with the report. In this CD-ROM, it will provide all information from the field or in the laboratory tests. 
APPENDIX C

C-1 
This survey is multiple choices. Please mark with an X or circle the answer. Have you ever heard about FRP (Fiber Reinforced Plastics) applications?

(A) Yes. Where?

When?

(B) No.

The survey begins. Thank you. ()

Q1. Is FRP used at all in your state?

(A) Yes. Skip to No.1a next page (page 2), please.

(B) No. Complete the following.

What repair techniques do you most commonly use?

Have you ever considered using FRP materials?
(A) Yes.
(B) No. Why not?

Are there any future applications for FRP planned?

(A) No. Why? If you have ever considered this technology.

(B) Yes.

Where?

When? (MM/Year)

What types?

\& What types of FRP?
(A) Seismic Strengthening
(A) Carbon FRP(CFRP)
(B) Strengthening/Upgrade
(B) Glass FRP(GFRP)
(C) Corrosion Protection
(C) Aramid FRP(AFRP)
(D) Others
(D) Others

What types of Epoxy?

Go to P7. (last page), please. 
1a. What reasons did you determine to use FRP for existing/new structures?

1b. To what structures is FRP applied?
(A) New structures
(B) Old structures
(C) Others

1c. What were the reasons for rehabilitation?
(A) Corrosion
(B) Over-Loading
(C) Shear
(D) Strengthening/upgrade
(E) Others

1d. Could any original pictures of the damage be provided?
(A) Yes. See attached then go to 1e.
(B) No. Go to $1 \mathrm{e}$.

1e. What types of rehabilitation method were used?
(A) Seismic Strengthening
(B) Strengthening/Upgrade
(C) Impact Repair
(D) Corrosion Repair
(E) Corrosion Protection
(F) Crack Repair
(G) Shear Strengthening
(H) Others

1f. What types of structures were FRP applied to?
(A) Bridges
(B) Buildings
(C) Others

Go to next page, please. 
$1 \mathrm{~g}$. What types of structural elements were?
(A) Columns
(B) Beams
(C) Slabs
(D) Others

1h. What methods of wrapping/patching were used?
(A) Robot wrapping
(B) Hand/Manual wrapping
(C) Hand/Manual patching
(D) Others

1i. If the type of structural (in question $1 \mathrm{~g}$.) was a beam, do you have any special method to wrap it (install it)?
(A) The same as column wraps.
(B) Different one (please specify):

Q2. Could you provide any pictures before/after rehabilitation?
(A) Yes. See attached then go to Q3.
(B) No. Go to Q3.

Q3. Please provide the location and date of completion of rehabilitation?

Location 1:

$\begin{array}{ll}\text { Begin: } & \text { Day } \_ \text {, Month } \_, 19 \_ \\ \text {Complete: } & \text { Day } \_ \text {_ Month } \_, 19 \_\end{array}$

If more than two locations, please fill out each.

Location 2:

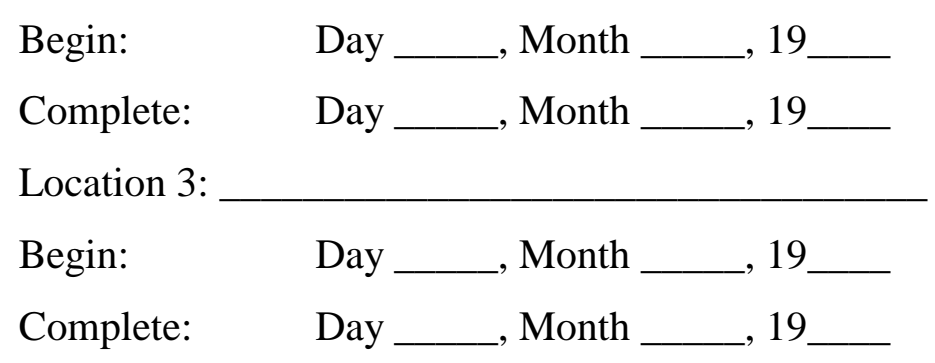

\section{Go to next page, please.}


Q4. How often do you check the performance of FRP applications?
(A) Once a year
(B) Twice a year
(C) Never
(D) Others

4a. How do you check the performance?

Q5. Are any pre-treatment processes used before wrapping/patching is applied?

(A) No, go to Q6.

(B) Yes,

5a. Describe the pre-treatment process.

5b. Approximately, what is total cost for pre-treatments (clean the corroded steels, patching the surfaces etc.) before wrapping FRP materials?

For Cost $\$$

For Cost $\$$

For Cost $\$$

Q6. Approximately, what is the unit price (\$/per foot/per layer) for FRP applications (not including the pre-treatment)?

$\$$

6a. What type of Epoxy?

Q7. Approximately, what is the total cost for FRP applications?

$\begin{array}{ll}\text { Material (FRP): } & \$ \\ \text { Epoxy: } & \$ \\ \text { Installation: } & \$ \\ \text { Total: } & \$\end{array}$

Go to next page, please. 
Q8. What type of FRP was used?
(A) CFRP (Carbon Fiber Reinforced Plastic)
(B) GFRP (Glass Fiber Reinforced Plastic)
(C) AFRP (Armid Fiber Reinforced Plastic)
(D) Others

8a. If the answer in Q8 is more than two, please explain why?

8b. Please describe briefly why using CFRP instead of using GFRP (more economic) if you choose CFRP?

Q9. What number of layers is used?
(A) One layer
(B) Two layers
(C) Three layers
(D) Varied layers
(E) Others

9a. If varied layers are used for one element, please explain.

9b. Please provide the contractor information.

9c. It would be useful if you could provide the design layout. If it is convenient, please indicate your willingness to do so.

(A) Yes. See attached then go to Q10.

(B) No. It is not possible, go to Q10.

\section{Go to next page, please.}


Q10. Please describe briefly or attached some relevant materials for design criteria of FRP application.

Q11. Why was FRP used instead of other methods (i.e., reinforced concrete repair/patching or steel jackets or etc.)?

Q12. What repair techniques did you most commonly use before?

Q13. Are there any future applications for FRP planned?

(A) No. Could you give reasons why?

(B) Yes.

Where? (1)

When?

Where? (2)

When?

- What types?

\& What types of FRP?
(A) Seismic Strengthening
(A) CFRP
(B) Strengthening/Upgrade
(B) GFRP
(C) Corrosion Protection
(C) AFRP
(D) Shear Strengthening
(D) Others
(E) Fire Protection
(F) Others

- Contractor name if known?

\section{Go to next page, please.}


If you would, please provide a way for me to contact you in the future.

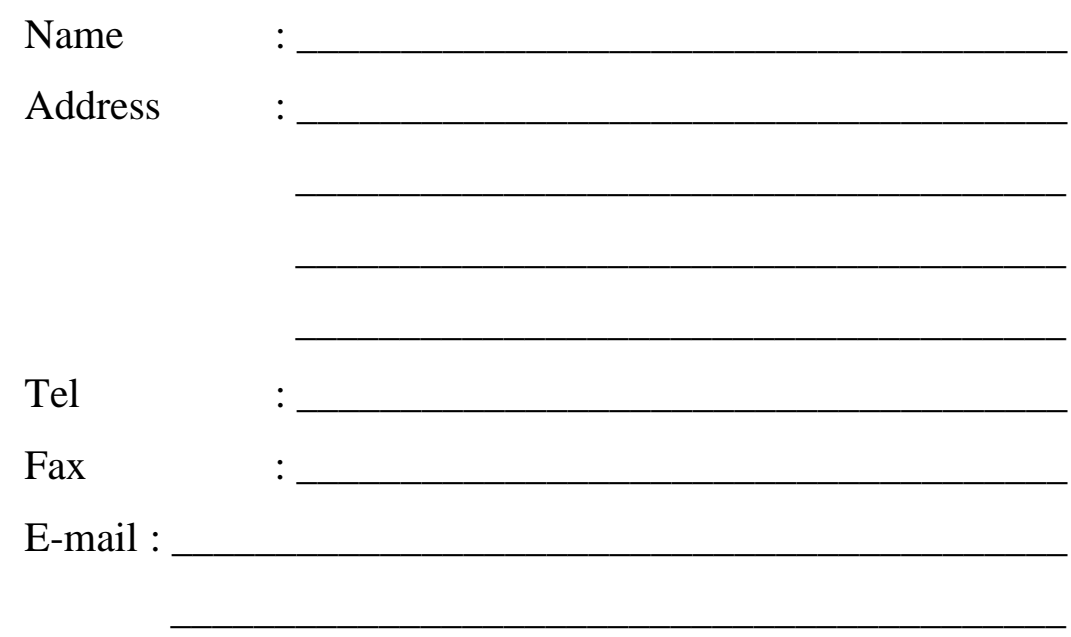

Would you like to have a copy of survey report?

(A) Yes.

(B) No, not this time.

Any comments about this survey?

Thank you, Sincerely.

\section{Ming-Hung Teng}

Graduate Research Assistant 


\section{APPENDIX D}

D-1 


\section{Field Inspection of Concrete Bridge Columns Wrapped by FRP in}

\section{Gary, Indiana}

\section{$\underline{\text { Introduction }}$}

FRP (Fiber Reinforced Plastics) have been widely used in civil infrastructures. They are mainly used for seismic retrofit, rehabilitation, strengthening, crack repair, and corrosion control/repair etc. They have been shown to be more effective, time efficient and durable than conventional methods. In Indiana, they have been used for corrosion protection purposes only. Two bridges in Gary and Fort Wayne, IN were rehabilitated using FRP wraps. The bridges in those two locations were seriously damaged due to severe environmental conditions and the use of de-icing salt causing corrosion. The field inspection method presented in this paper aims to assess the condition of concrete bridge columns wrapped by FRP in Gary, Indiana.

\section{$\underline{\text { Brief Description }}$}

The bridge is shown in Figure D-1 and is located on U.S. route 12, the second bridge east of the Gary Airport. There are five piers of bents under this bridge. The east of second bent is the only columns that were rehabilitated using FRP wraps in 1995, except their footing. The bent included seven $3 \times 2.5 \times 14 \mathrm{ft}^{\wedge} 3$ long columns with the $2 \mathrm{ft}$ height $\mathrm{X}$ $47 \mathrm{ft}$ length footing. And the column caps (or beams) are about $3 \mathrm{ftx} 47 \mathrm{ft}$. The bridge was subjected to heavy traffic and heavy deicing salt, so it suffered the serious corrosion problems. As a result, the whole bent (7 columns) was rehabilitated and was wrapped by 3 layers FRP to improve the durability.

\section{Field Inspection Procedures}

Field inspection included the following two procedures: 
1. Identification of all columns: The wrapped columns were numbered one to seven. Number one was the northernmost column, and number seven was the southernmost one (from Figures D-2 to D-4).

2. Close visual inspection: Visual inspection was used to detect any cracks and delaminated or spalled areas. Pictures were taken of these.

\section{$\underline{\text { Results }}$}

During the field inspection, the condition of all the wrapped columns was satisfactory. There were no cracked or spalled areas on the surfaces, however, after comparison with the columns of the bridge in Fort Wayne, which were wrapped by the same material; some defects were found as list below:

1. There are void spaces between the layers of FRP wraps, especially in columns two, six and seven (Figure D-5).

2. On some column surfaces, it was apparent that smoothing operation, necessary before wrapping, was not performed well (Figure D-6). This might cause stress concentrations in this area.

3. On the other bents, columns without being wrapped show some cracks and spalling areas (Figures D-7 and D-8).

4. The column footings, below the wrapped column, also contained some cracks and spalling areas on their surfaces (Figure D-9).

\section{Summary}

A field inspection of the bridge piers wrapped by FRP in Indiana has been carried out.

To conclude, due to the demand for renewed civil infrastructure, FRP has become a worldwide trend and has successfully rehabilitated bridge structures in Gary and 
elsewhere. On the basis of this report and other research, it can be concluded that FRP have worked satisfactorily in Indiana. However, studies of FRP application for rehabilitation, strengthening and protection should be ongoing and continued monitoring of wrapped columns is still necessary.

\section{$\underline{\text { Recommendations }}$}

Some recommendations are given below:

1. Some areas like column footings should have Epoxy applied for further corrosion protection even if they do not require wraps.

2. Columns in Figure D-4 had corrosion problems should be repaired either by FRP (even 1 layer) or Epoxy.

3. The surfaces of the wrapping structures should be well prepared using a grinder to establish a smooth dust-free surface, free of undulations, in order to give complete contact between the concrete and the column wrap. They shall be free from fins or sharp edges that will cause stress concentrations and damage the fiber.

4. The contact surfaces of the column shall be completely dry when the composite is applied.

5. More research is needed to identify the long-term performance or durability issues of FRP wraps systems.

6. To effectively assess the long-term performance of FRP wraps system, close inspection of bridge structures in the field should be continued.

7. FRP is also a good temporary solution if budget constraints prevent complete renovation of the structure. For example, if we only wrapped the damaged columns 
instead, the cost would be only around $20 \%$ of total cost (included clean the corroded steel rebars and patch the fresh concrete. Please see page 17 for details.) 

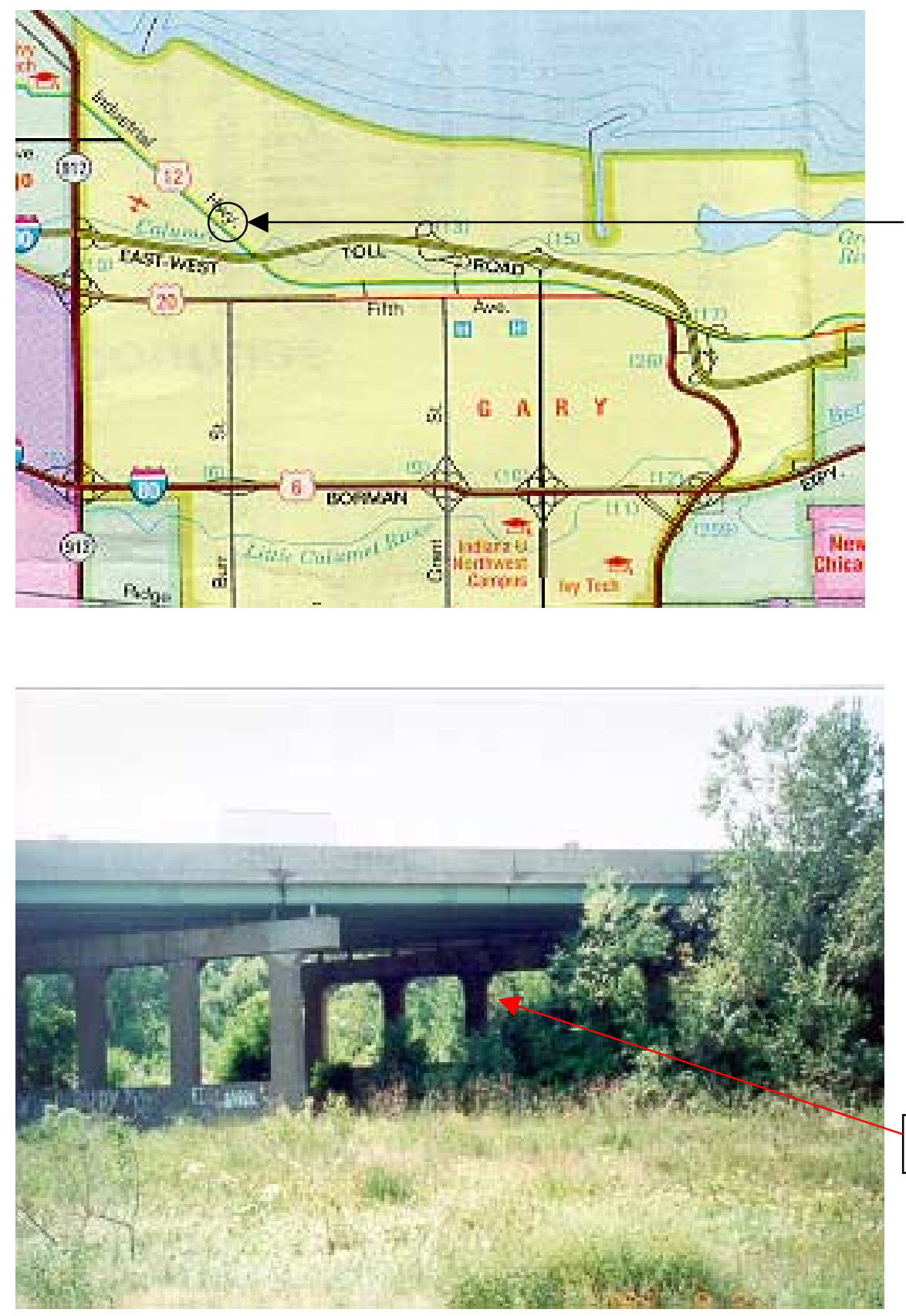

The Wrapped Columns

Figure D-1 Location of the bridge and side view of the bridge 

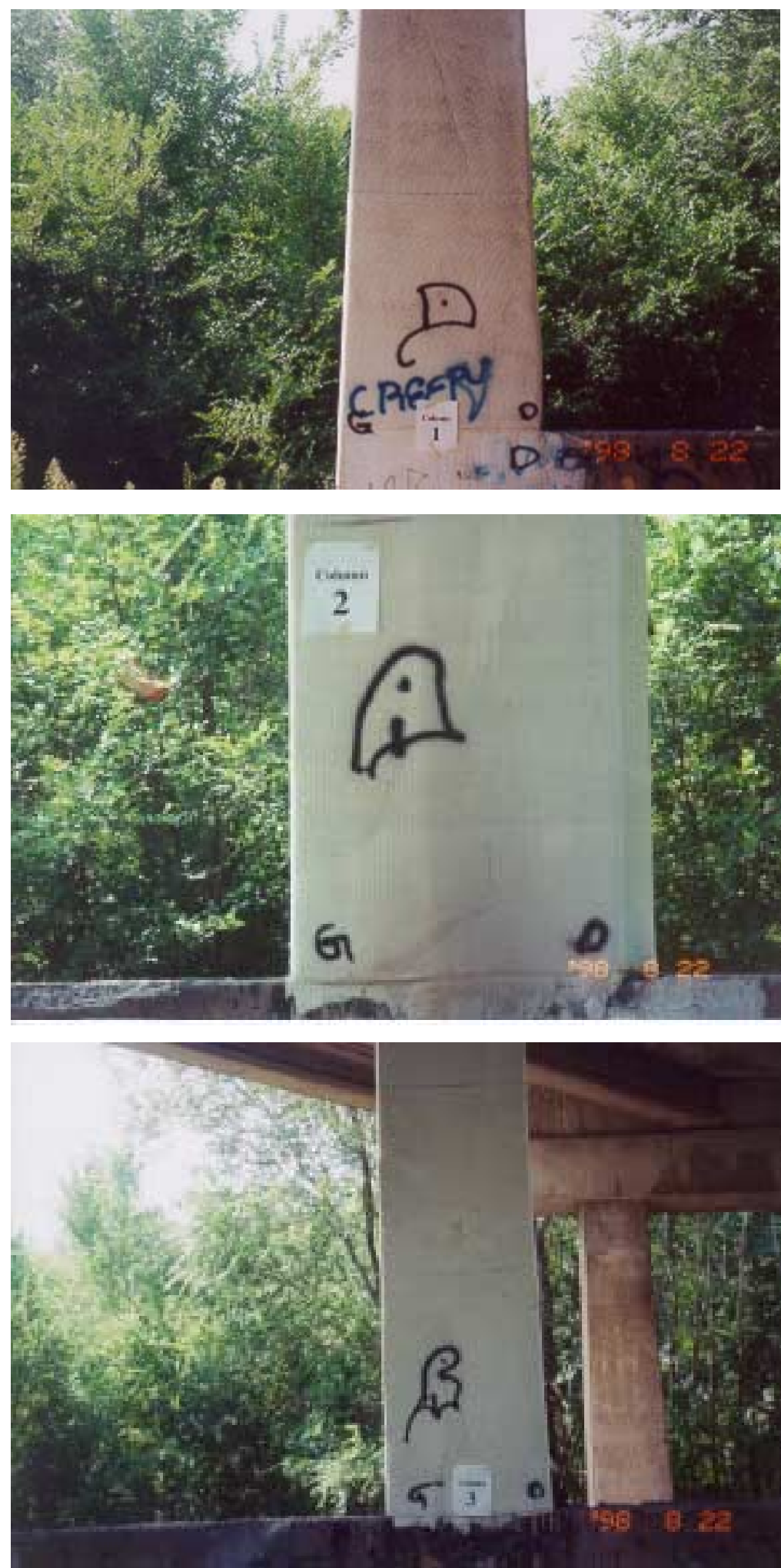

Figure D-2 Number of column from 1 to 3 

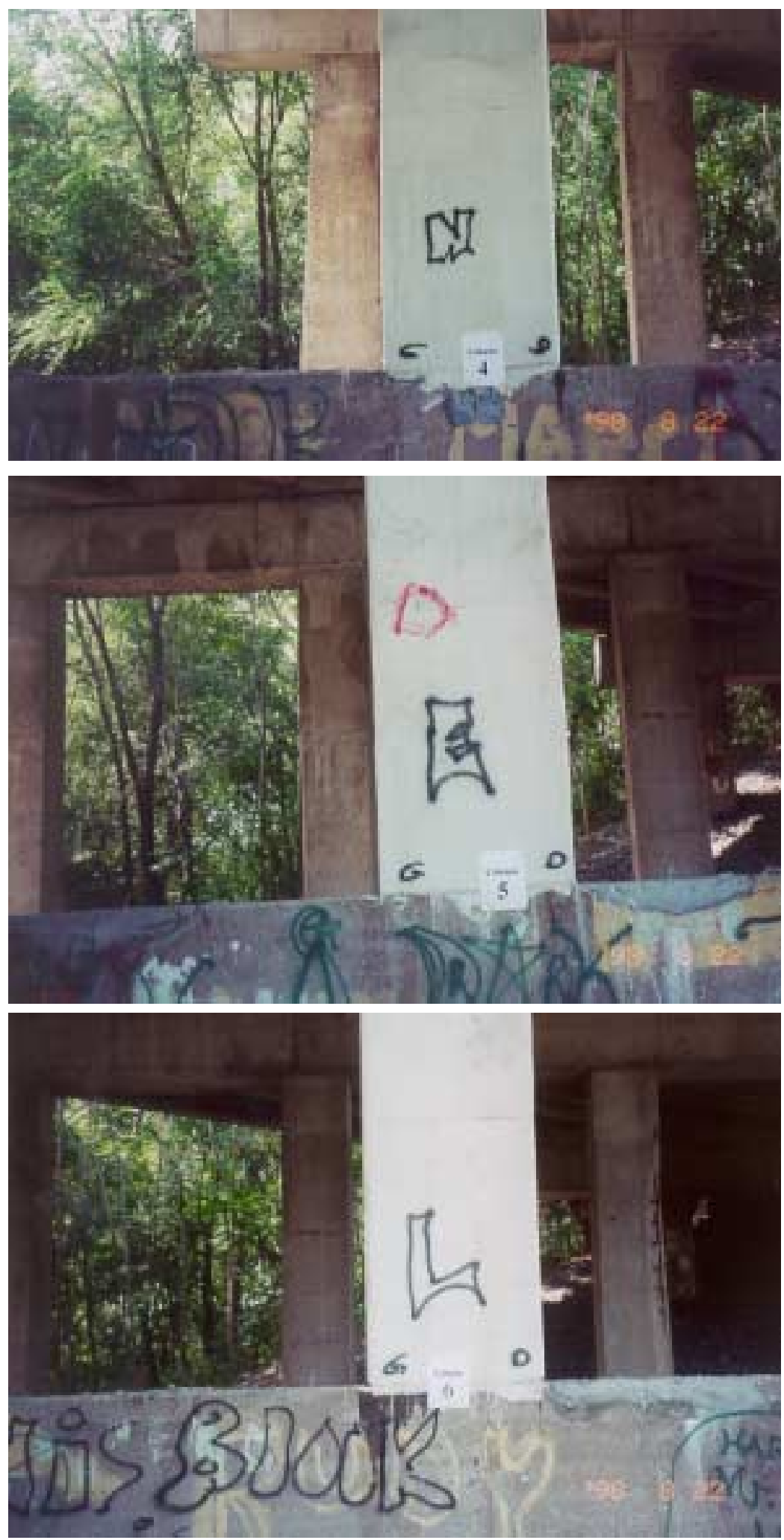

Figure D-3 Number of column from 4 to 6. 


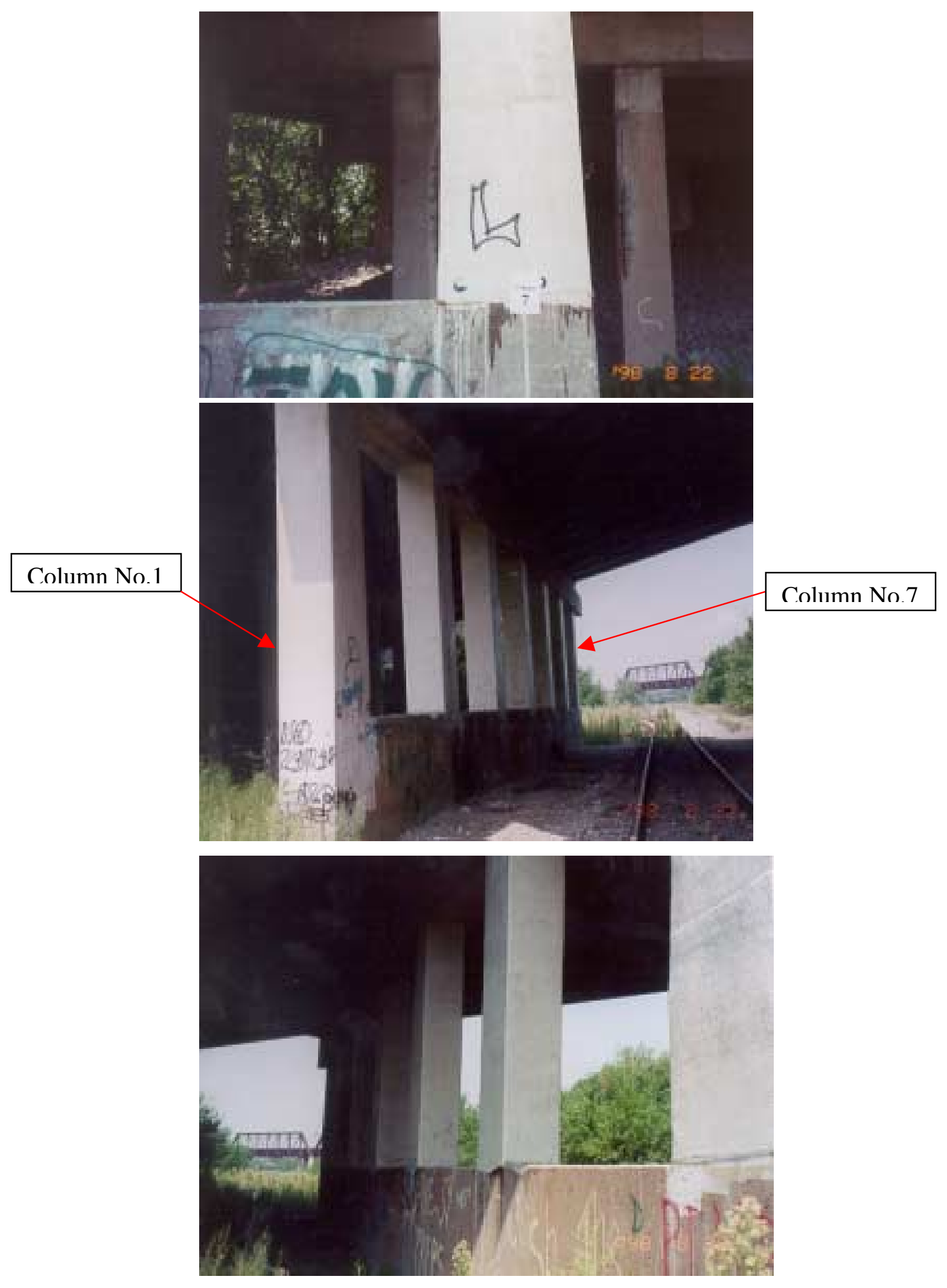

Figure D-4 Number 7 and total view of columns 

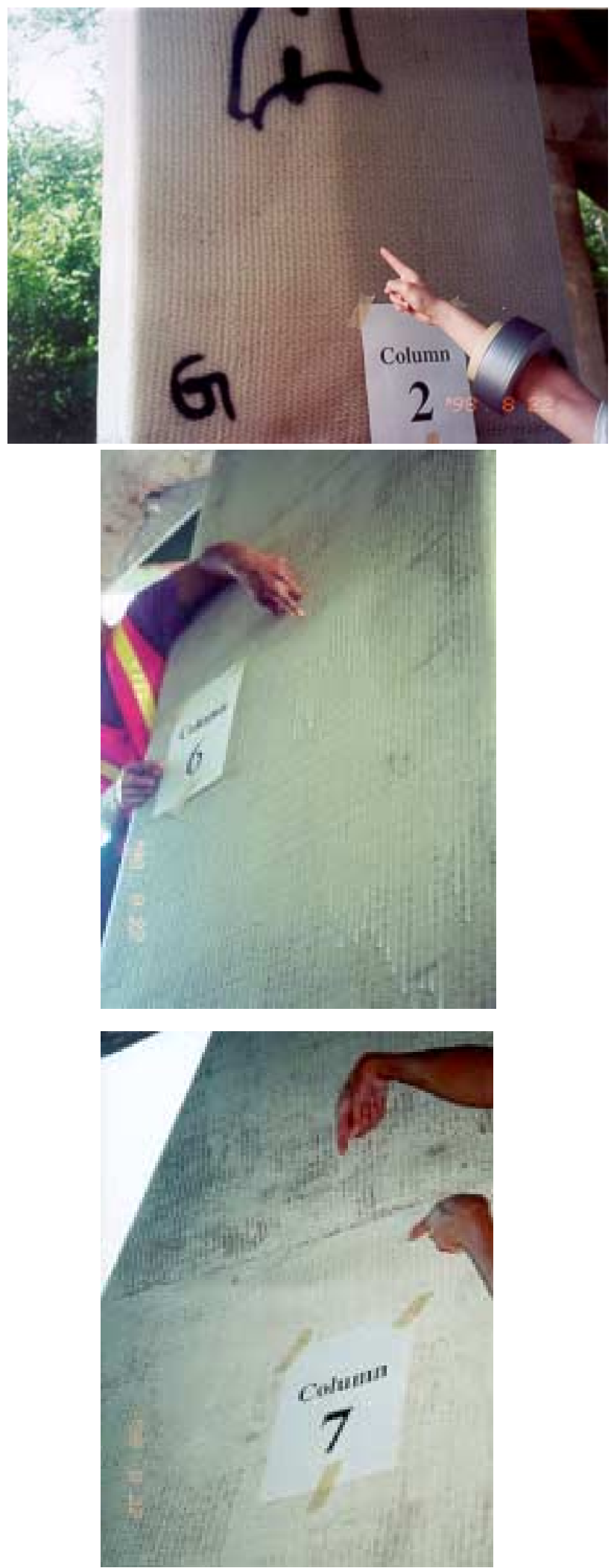

Figure D-5 Some void spaces between the layers 

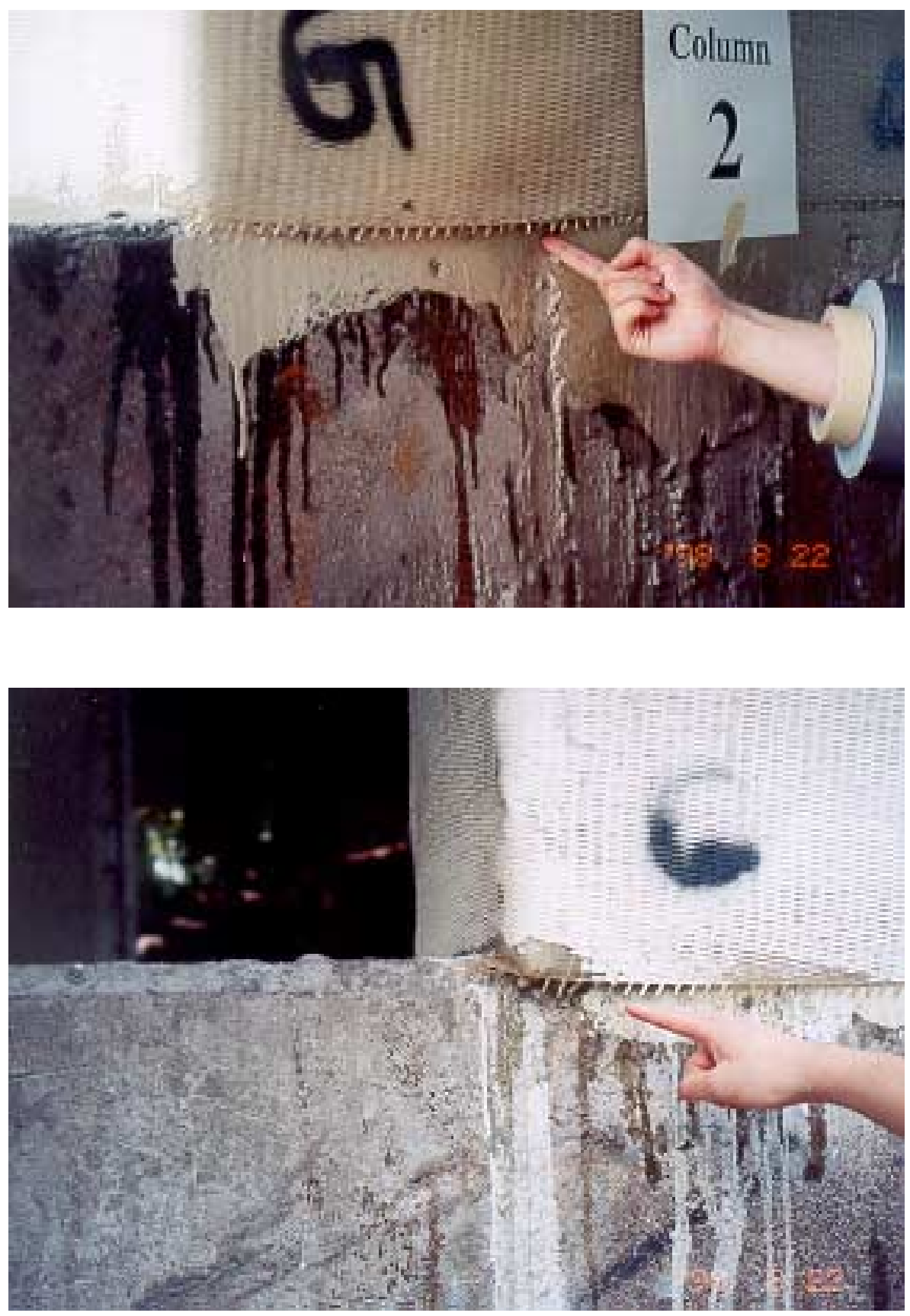

Figure D-6 Stress concentration areas 

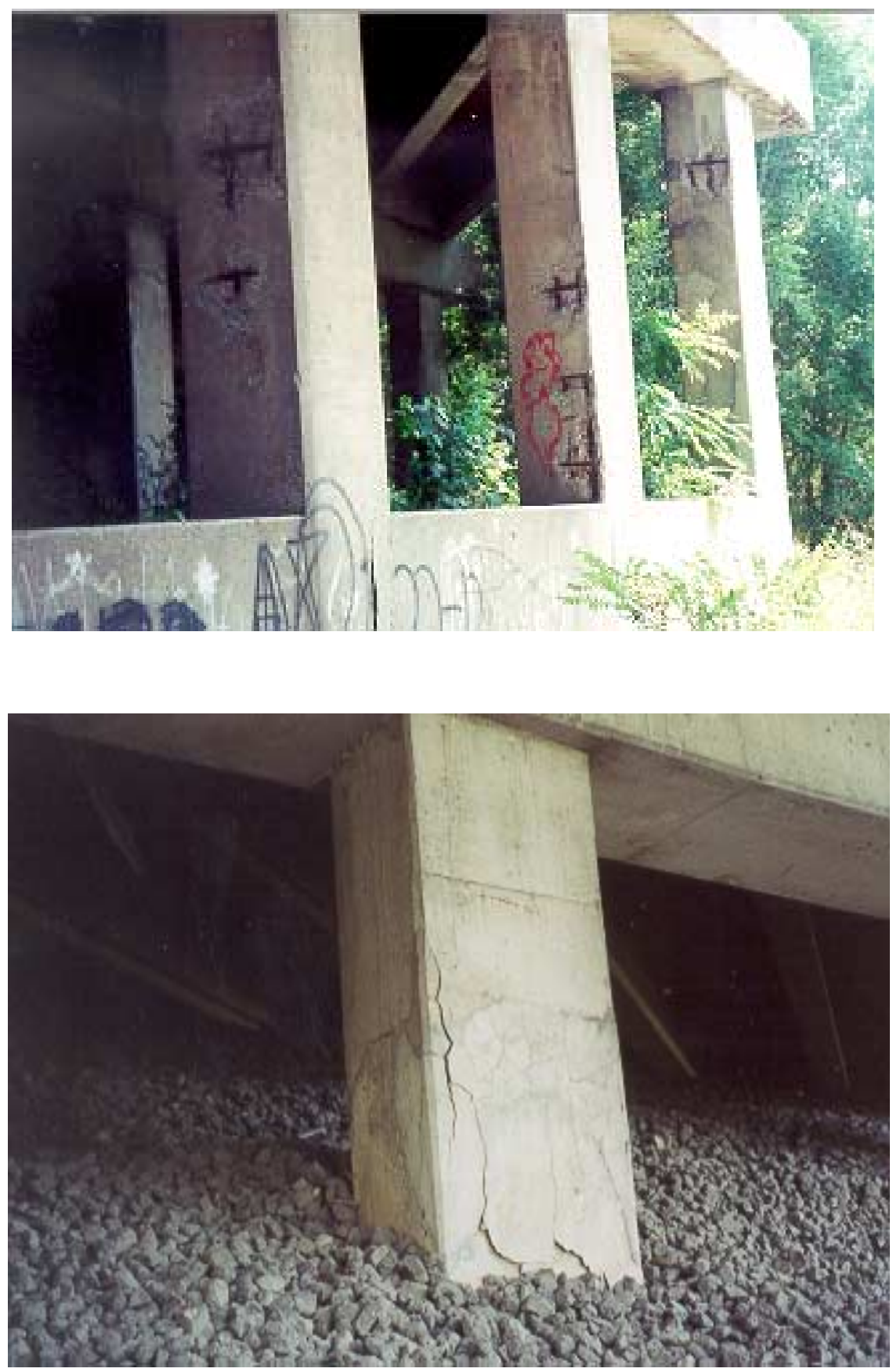

Figure D-7 Corrosion, spalling and cracks on some columns 

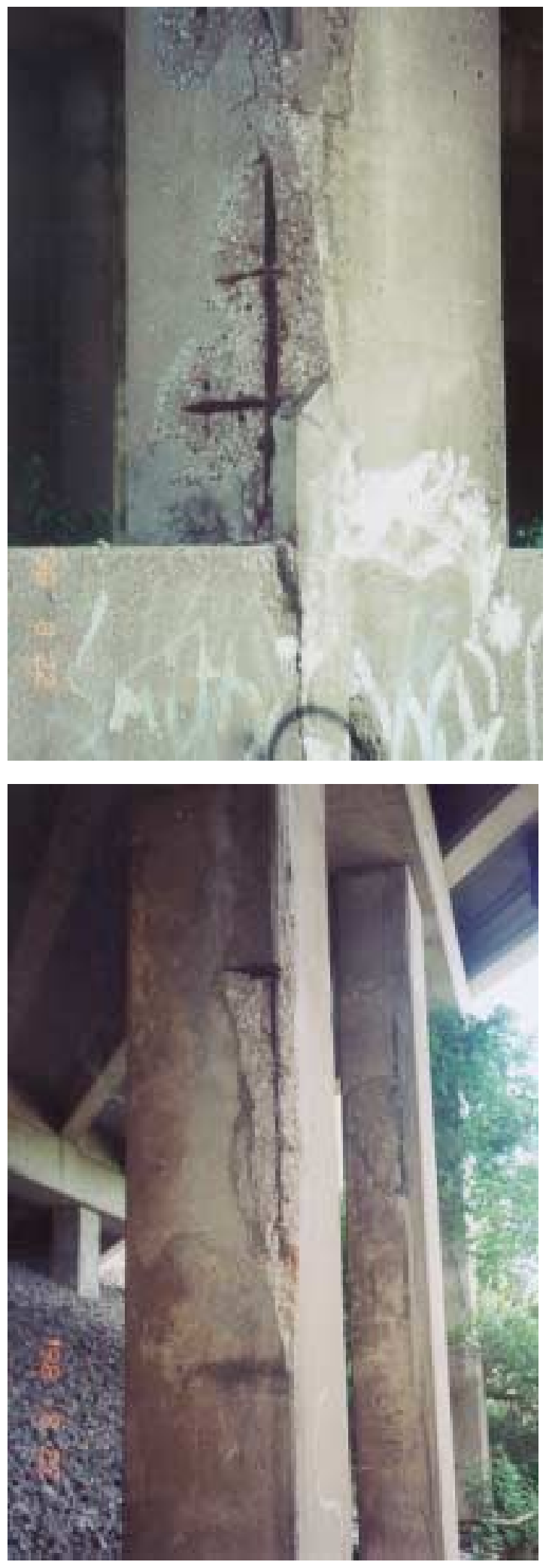

Figure D-8 Corrosion, spalling and cracks on some columns 

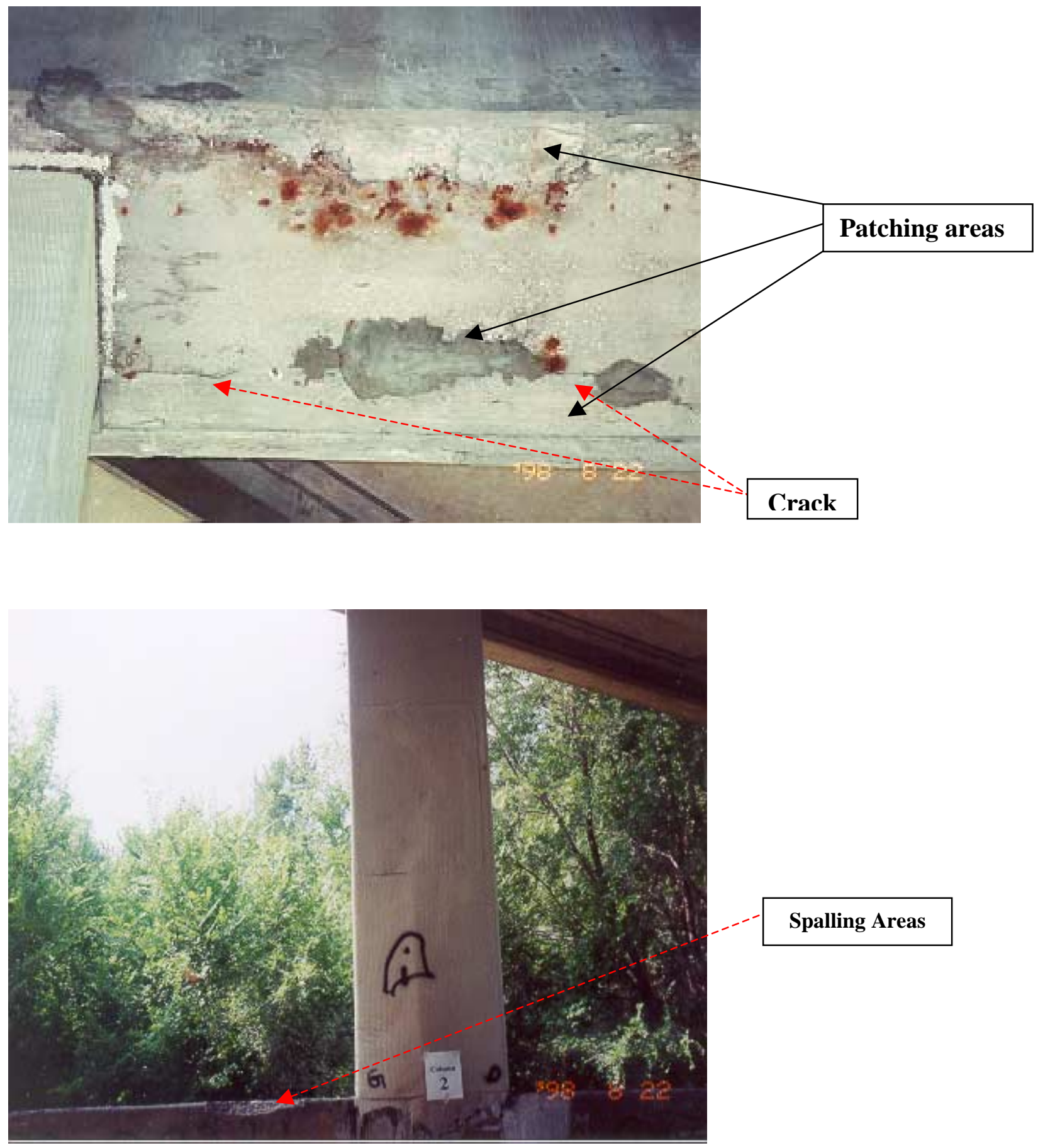

Figure D-9 Cracks and spalling besides the wrapped column. 